\title{
Studying the healing and long-term outcomes of two partial thickness wound models using different wound dressings
}

\author{
Matilda Karlsson
}





\title{
Studying the healing and long-term outcomes of two partial thickness wound models using different wound dressings
}

\author{
Matilda Karlsson
}

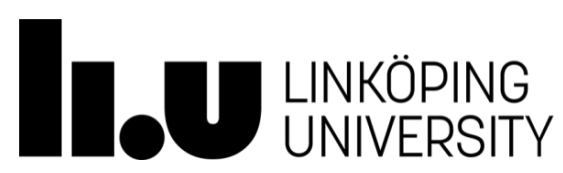

Department of Hand Surgery, Plastic Surgery and Burns, and Department of Clinical and Experimental Medicine, Faculty of Medicine and Health Sciences,

Linköping University, Linköping, Sweden 
(C) Matilda Karlsson, 2019

The published articles have been reprinted with the permission of the copyright holder.

Printed in Sweden by LIU-Tryck, Linköping, Sweden

ISBN: 978-91-7519-008-2

ISSN: 0345-0082 
Till mina barn Selma och Matheo

You should know anything in this book might be wrong 


\section{Principal Supervisor}

Folke Sjöberg, MD, PhD, Professor

Department of Hand Surgery, Plastic Surgery and Burns, and Department of Clinical and Experimental Medicine,

Faculty of Medicine and Health Sciences,

Linköping University, Linköping, Sweden

\section{Assistant supervisors}

Moustafa Elmasry, MD, PhD, Associate professor

Department of Hand Surgery, Plastic Surgery and Burns, and

Department of Clinical and Experimental Medicine,

Faculty of Medicine and Health Sciences,

Linköping University, Linköping, Sweden

Pia Olofsson, MD, PhD

Department of Hand Surgery, Plastic Surgery and Burns, and Department of Clinical and Experimental Medicine,

Faculty of Medicine and Health Sciences,

Linköping University, Linköping, Sweden

\section{Opponent}

Christina Lindholm, RN, PhD, Professor emeritus

Sophiahemmet University, Stockholm, Sweden

\section{Committee board}

Carina Bååth, RN, PhD, Associate Professor

Department of Health Sciences

Faculty of Health, Sciences and Technology, Karlstad University, Sweden 
Gunilla Sydsjö, psychotherapist, Adjunct professor Department of Clinical and Experimental Medicine Division of Children's and Women's Health Faculty of Health Sciences

Linköping University, Sweden

\section{Substitute}

Anna-Christina Ek, RN, PhD; Professor emeritus

Department of Medical and Health Sciences

Divison of Nursing

Faculty of Health Sciences

Linköping University, Sweden 


\section{TABLE OF CONTENTS}

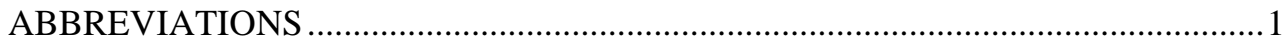

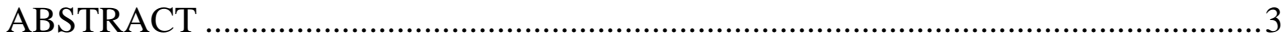

SVENSK SAMMANFATTNING .....................................................................

LIST OF ORIGINAL PAPERS ....................................................................

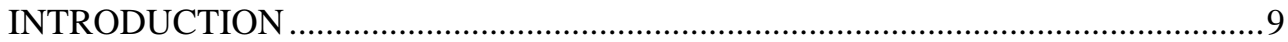

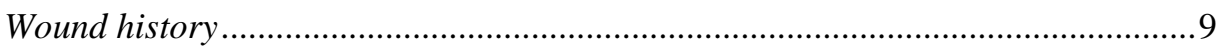

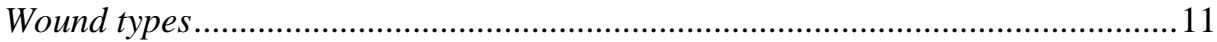

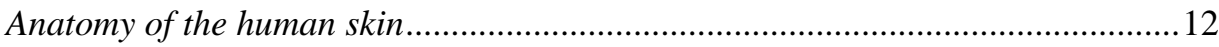

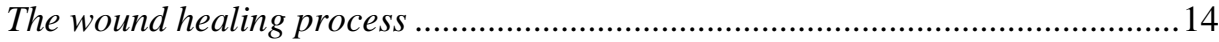

Description of the wound models of this thesis ................................................... 17

Factors that delay wound healing and influence scar outcome ...........................22

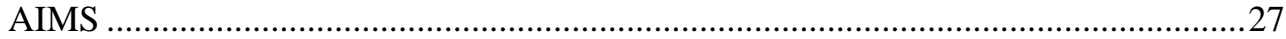

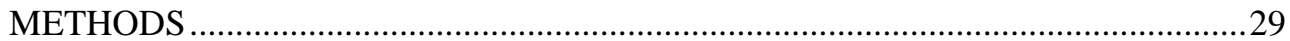

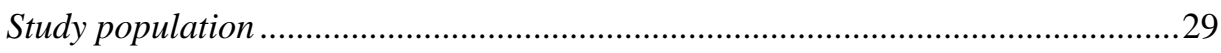

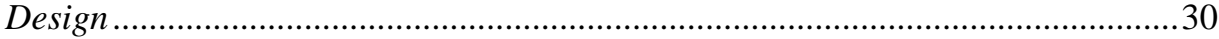

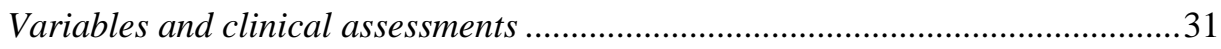

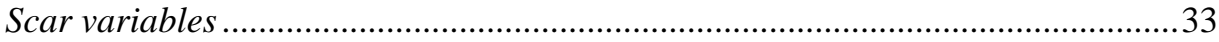

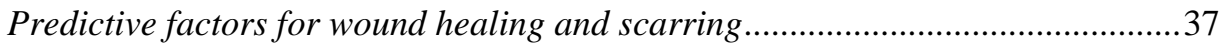

Dressing materials evaluated in this thesis ....................................................... 41

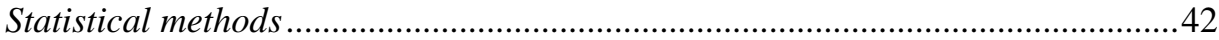

Ethical considerations .................................................................................44

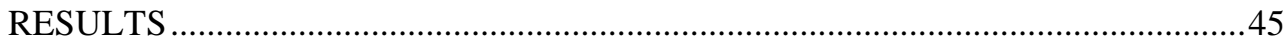

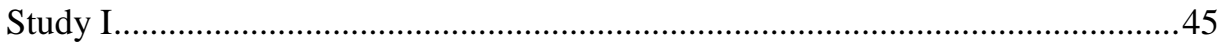

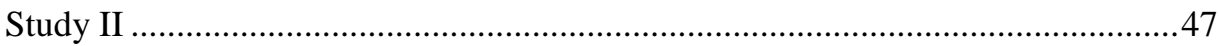




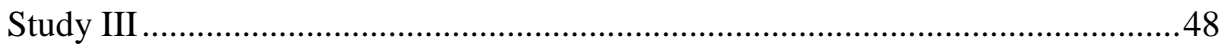

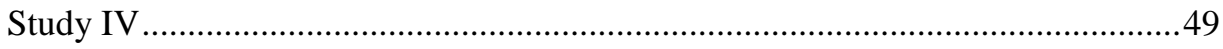

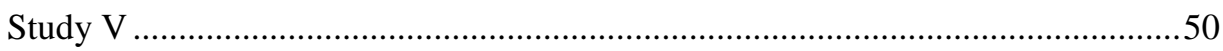

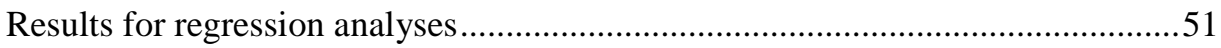

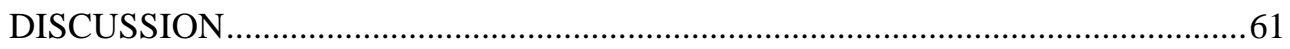

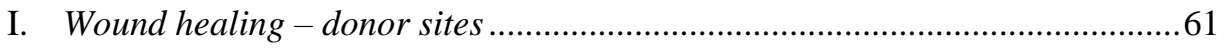

I. Wound healing - partial thickness burns.........................................................66

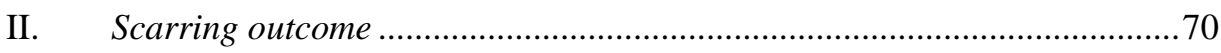

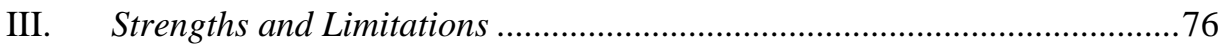

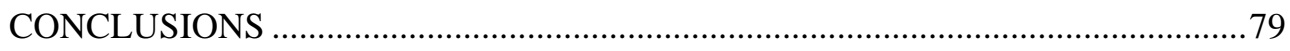

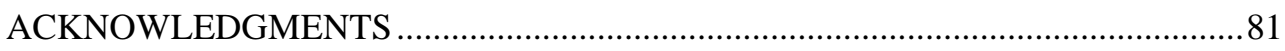

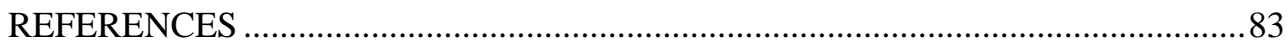

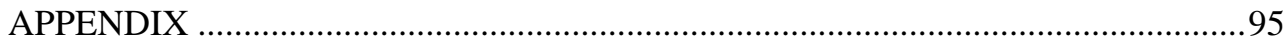





\section{ABBREVIATIONS}

\begin{tabular}{|c|c|}
\hline BMI & Body Mass Index \\
\hline BUD & Burn Unit Database \\
\hline $\mathrm{CE}$ & Conformité Européenne \\
\hline $\mathrm{CI}$ & Confidence Interval \\
\hline CONSORT & Consolidated Standards of Reporting Trials \\
\hline CRF & Case Report Form \\
\hline CRP & C-Reactive Protein \\
\hline DAMPs & Damage-Associated Molecular Patterns \\
\hline DDB & Deep Dermal Burn \\
\hline ECM & Extra Cellular Matrix \\
\hline EGF & Epidermal Growth Factor \\
\hline FGF & Fibroblast Growth Factor \\
\hline HTS & Hypertrophic Scarring \\
\hline IGF-1 & Insulin-like Growth Factor 1 \\
\hline IL-1 & Interleukin-1 \\
\hline ITT & Intention To Treat \\
\hline LOS & Length Of (hospital) Stay \\
\hline MMP & Matrix Metalloproteinase \\
\hline NPWT & Negative Pressure Wound Therapy \\
\hline OR & Odds Ratio \\
\hline PDGF & Platelet Derived Growth Factor \\
\hline POSAS & Patient and Observer Scar Assessment Scale \\
\hline PPPM & Parents' Postoperative Pain Measure \\
\hline PX & Porcine Xenograft \\
\hline $\mathrm{RCT}$ & Randomised Controlled Trial \\
\hline SOC & Standard Of Care \\
\hline STSG & Split Thickness Skin Graft \\
\hline TBSA & Total Body Surface Area \\
\hline TIMP & Tissue Inhibitor of Metalloproteinases \\
\hline TGF & Transforming Growth Factor \\
\hline TNF- $\alpha$ & Tumour Necrosis Factor alpha \\
\hline VEGF & Vascular Endothelial Growth Factor \\
\hline VIF & Variance Inflation Factor \\
\hline
\end{tabular}




\section{ABSTRACT}

Background: Safe and effective wound dressing treatments are important for proper wound healing. Such procedures therefore need to be evidence-based regarding the most important outcome measures such as healing time, less discomfort for the patient, duration of hospital care and, importantly, less scarring. As the relation between longer healing times and more severe scarring is known, it is important to find dressing treatments that reduces such complications by providing fast and proper wound healing. In this thesis, four established wound dressing treatments (hydrofibre covered with film; porcine xenografts and polyurethane foam, with and without silver), were evaluated for two types of acute, partial thickness wounds: split thickness skin graft (STSG) donor sites and partial thickness burn wounds in two randomised, controlled clinical trials (RCT) with longterm scar follow ups. The relations between factors thought to influence wound healing and scarring as sex, infection, wound extent and depth, healing time and skin grafting were also investigated in these two wound models.

Methods: Data from these trials were collected on sex, infection rates, wound depth and extent, need of skin grafting, healing times and scarring frequency together with demographic data. Scars were evaluated at 8 years in Study II and III and at 6 and 12 months after injury in Study V.

Results: Two dressing treatments; hydrofibre covered with film and porcine xenografts gave significantly faster healing of the STSG donor sites than the standard of care (SOC) dressing, the polyurethane foam. The hydrofibre was thereafter implemented as the new SOC at the department. The long-term scar follow up showed that the hydrofibre group was most satisfied with their donor site scar, providing further evidence for the implementation of this dressing strategy. From the observer's perspective no differences were found between these treatment groups. For partial thickness burns the treatment with a silvercontaining foam dressing showed significantly shorter healing time, whereas for the scars, no difference between dressing groups could be detected. A number of factors were identified that affected healing time: for donor sites only male sex was associated with shorter healing time. Sex was also the only factor that influenced donor site scarring, where female patients, both subjectively and objectively, were rated with higher scores (worse outcome). For partial thickness burns a larger extent of the burn wound, presence of deep dermal burns, and the need of 
skin grafting, all had a negative impact on both healing time and final scar. The final scar was also significantly affected by longer wound healing times and infection.

Conclusion: The results suggest that the use of hydrofibre dressings covered with film on donor sites resulted in positive short-term and long-term outcomes. Regarding partial thickness burns, silver foam dressing resulted in faster healing but as for the final scar, no difference could be seen. Several factors were associated with longer healing times and more severe scarring such as: female sex, larger burns, deep dermal burns, skin grafting, and infection. Longer healing times were related to more severe scarring. 


\section{SVENSK SAMMANFATTNING}

Bakgrund: Säkra och effektiva förbandsbehandlingar är av stor klinisk betydelse. Därför behövs evidensbaserade sårbehandlingar med fokus på de viktigaste utfallen som läkningstid, minskning av patientens lidande, vårdtid och mindre ärrbildning. Eftersom förhållandet mellan längre läkningstid och mer allvarlig ärrbildning är känt är det viktigt att hitta sårbehandlingar som minskar komplikationer, ger snabb läkning av såret och acceptabla ärr. I denna avhandling utvärderades etablerade sårbehandlingar (hydrofiber täckt med film, xenotransplantat från gris och polyurethanskumsförband, med och utan silver), för två typer av akuta delhudskador; tagställen för delhudstransplantatet och dermala brännskador, i två randomiserade kontrollerade kliniska studier. Förhållandet mellan påverkansfaktorer såsom kön, infektion, sårdjup, såromfattning, läkningstid och hudtransplantation och utfall för läknings- och ärresultat har också undersökts.

Metoder: Data för kön, infektionsfrekvens, sårdjup och omfattning, behov av hudtransplantat, läkningstid och ärrbildning från två randomiserade kontrollerade studier samlades in tillsammans med demografisk data. Ärren utvärderades efter 8 år i studie II och III samt vid 6 och 12 månader efter skada i studie V.

Resultat: Två sårbehandlingar; hydrofiber täckt med film och xenotransplantat från gris visade signifikant snabbare reepitalisering av tagställen än standardförbandet (polyuretanskum). Hydrofibern implementerades som den nya standardbehandlingen på kliniken. Den långsiktiga ärruppföljningen avslöjade att gruppen med hydrofiber var den mest nöjda med sina tagställes-ärr, vilket gav ytterligare styrka till genomförandet av behandlingen. Ur observatörsperspektivet hittades inga skillnader mellan dessa grupper. För dermala brännskador gav behandlingen med silverinnehållande skumförband signifikant bättre läkningsresultat, för ärrbildning upptäcktes inte någon skillnad mellan grupperna. Ett antal faktorer som påverkade läkningstider identifierades; för tagställen gav endast manligt kön kortare läkningstider. Kön var också den enda faktorn som påverkade tagställets ärrresultat där kvinnor, både subjektivt och objektivt, bedömdes med högre poäng (sämre utfall). För dermala brännskador var det faktorer såsom en större omfattning av brännskadorna, närvaron av djupa dermala brännskador och behovet av hudtransplantation som hade negativ påverkan på både läkningstider och slutliga ärr-resultat. Det slutliga ärrutfallet påverkades också signifikant av längre läkningstider och infektion. 
Konklusion: Data tyder på att användningen av hydrofiber täckt med film på tagställen gav positiva resultat både på kort- och lång sikt. När det gäller förband för dermala brännskador resulterade silverskumförband i snabbare läkning men vad gäller ärr kunde ingen skillnad hittas. Flera faktorer var relaterade till längre läkningstider och mer ärrbildning som kvinnligt kön, större omfattning av brännskador, djupa dermala brännskador, hudtransplantation och infektion. Längre läkningstider var relaterat till mer allvarlig ärrbildning. 


\section{LIST OF ORIGINAL PAPERS}

This thesis is based on the following studies, which will be referred to in the text by their roman numerals

I. Karlsson M, Lindgren M, Jarnhed-Andersson I, Tarpila E. Dressing the split-thickness skin graft donor site: a randomized clinical trial. Adv. Skin Wound Care. 2014 Jan; 27(1):20-5.

II. Karlsson M, Elmasry M, Steinvall I, Sjöberg F, Olofsson P, Thorfinn J. Scarring at donor sites after split-thickness skin graft: a prospective, longitudinal, randomized trial. Adv. Skin Wound Care. 2018 Apr; 31(4):183-188.

III. Karlsson M, Elmasry M, Steinvall I, Sjöberg F, Olofsson P, Scarring at donor sites after split-thickness skin graft: a prospective, longitudinal, randomized trial; the Observer view. [Submitted]

IV. Karlsson M, Elmasry M, Steinvall I, Sjöberg F, Olofsson P, Thorfinn J. Superiority of silver-foam over porcine xenograft dressings for treatment of scalds in children: A prospective randomised controlled trial. Burns. 2019 Sep;45(6):1401-1409

V. Karlsson M, Steinvall I, Sjöberg F, Olofsson P, Elmasry M. Burn scar outcome at 6 and 12 months after injury in children with partial thickness scalds: did the dressing treatment matter? [Submitted] 


\section{INTRODUCTION}

\section{Wound history}

As long as humans have existed, we have experienced and feared wounds. A wound, by its definition, is a disruption of the integrity of skin [1]. It is known to not only cause pain, but also threaten humans with infections, and in the worst cases sepsis, amputation, and death. It is then not surprising that the treatment of wounds is one of the first medical interventions that we know of that has been described in historical records.

The history of wound treatment dates back more than 5000 years. And as documentation of these early activities cannot be found, we have to rely on more recent publications.

By the year $2200 \mathrm{BC}$, the process of wound treatment was described in ancient Egypt. Procedures such as washing the injury, making dressings, and bandaging the wound are pictured in historical documents such as the Edwin Smith papyrus (dated at approximately $1700 \mathrm{BC}$ ) [2]. Modern treatment is based on the same basic ideas: cleaning and debridement of the wound, followed by the application of dressings; the only step excluded these days is the part where we make the dressing ourselves. In ancient times, dressings were not produced by multinational companies, but at home using nature's own materials such as mud, plants, herbs, or animal parts. Many of these "natural treatments" such as honey, plant cellulose, maggots, alginates, and animal skin are still in use and some of them more popular than ever [3-5]. Others that are often referred to historically, such as the application of fresh meat, milk, wine, and the licking of wounds by dogs, are less popular now.

More than 2000 years before bacteria were discovered; members of early civilisations such as Mesopotamia, Arabia, Egypt, and Greece described the connections between a clean environment and the proper healing of wounds. The first description of bacteria is thought to have taken place around 1676, by the Dutch textile merchant Antonie Van Leeuwenhoek, who observed them in water through a magnifying glass. Van Leeuwenhoek wrote a letter to the Royal Society of London describing his observation of thousands of living creatures in the water. He called them " animalcules"[6]. Today, knowledge of bacteria and how they spread and affect the healing process has evolved considerably, although 
many questions still remain. The medical breakthrough of the discovery of antibiotics by Alexander Fleming in 1929 and the introduction of penicillin in therapy in 1941 has had a significant impact on the course of infections. Today, few would doubt its favourable effects on infections, but unfortunately, widespread use has led to the development of antibiotic resistance, a problem that is anticipated to significantly affect health care outcome in times to come if a solution has not been reached. The role of antiseptic agents in wound care is therefore more important than ever $[7,8]$.

Antiseptics are agents that inhibit the growth and development of microorganisms, but unlike antibiotics, antiseptics are non-specific and are thought to be of a lower risk for the development of bacterial resistance. Antiseptic substances applied to wounds have a far longer history than that of antibiotics, but with the introduction of antibiotics, clinicians started to rely on them to prevent and treat infections [9].

One of the oldest antiseptics in wound care is probably honey [10]. Other antiseptics such as iodine and silver have been used for hundreds of years, and similarly to honey, they are still in use. Several Cochrane reports have been published in the last years regarding the use of topical antimicrobials (antibiotics and antiseptics) in acute wounds [10-12], surprisingly often with a focus on healing time rather than rate of infection. To summarise current knowledge (that is mostly based on scientific studies of lower quality and therefore provides low levels of evidence) it is suggested that topical antiseptics may result in shorter healing times than topical antibiotics. Evidence on whether antiseptic treatment is actually better than non-antiseptic techniques is still lacking [12].

The history of wound surgery, surprisingly, also dates back a long way in history. Covering wounds with skin grafts ${ }^{1}$ was first described thousands of years ago, but most advances have been achieved over the past 200 years, particularly since the 1940s.

In 1869, a Swiss surgeon, Jacques-Louis Reverdin, reported his technique of "epidermic grafting," which involved implanting "islands" of epidermis into the wound to serve as centres of re-epithelialisation and growth. The "islands" were harvested from the arm, by using a sharp lancet and the shaving of small pieces of the epidermis. The pieces were then applied in the first experiments on a granulation wound on the patient's thumb. The detached epidermis stayed vital on the ${ }^{1}$ Skin graft means that healthy skin is harvested and transplanted to the wound to cover 
thumb and was capable of adhering and proliferating, to create a new epithelium[13]. A couple of years later, Reverdin admitted that the graft had also contained the papillary layer of the dermis and so was not truly an "epidermis graft'[14]. Although Reverdin's pinch grafting was a significant step forward in skin grafting, it had several limitations. The grafts caused contractures that were no better than those formed around non-grafted wounds, which limited their usefulness, particularly around joints. The grafts also healed slowly, the new scar tissue was not resistant to physical stress, and the results were cosmetically unsatisfying [15].

In 1872, the French surgeon Louis Léopald Ollier introduced the next step in skin grafting by harvesting larger grafts that included both epidermis and part of the dermis. These grafts, called split-grafts or mid-thickness grafts had several benefits when compared with Reverdin's "pinch grafts" as they resulted in faster healing, less formation of scars, and less contraction $[14,15]$. Today split thickness skin grafting is one of the most commonly-used techniques to cover wounds [15].

So, the question that arises is, are we trapped in the past of wound care? The answer is no. As we improve our knowledge, and know more about the roles of different cells and factors that inhibit and promote the wound healing process, new treatments have been developed and are constantly emerging. Negative pressure wound therapy (NPWT), protease-inhibiting dressings, tissue-engineered products created through the culture of cells from humans and animals, are just a few of the more recent developments [5].

\section{Wound types}

A wound, as we described it initially in this chapter, is an injury to the skin, but depending on the underlying cause, we usually divide wounds into two different types; ulcers and vulnus. Ulcers are "hard to heal" wounds that develop because of underlying illnesses or when healing is delayed as the result of an underlying illness. Leg and decubitus ulcers (bed sores) are typical examples of "hard to heal wounds". Vulnus or "acute" wounds occur suddenly, spontaneously, or as a result of injury or operation. Examples of acute wounds are bites, bullet or stab wounds, burns, and wounds created during operation [16].

The focus of this thesis is on two kinds of acute wounds (split thickness skin graft (STSG) donor sites and partial thickness burns), how they usually heal, and how this process can be improved. 


\section{Anatomy of the human skin}

The skin is a complex organ that covers the entire surface of our bodies. It accounts for about $15 \%$ of the total body weight of an adult. It consists of three separate layers (Fig.1), the epidermis (upper layer), the dermis, and the hypodermis, which is also referred to as the subcutaneous fat or subcutis [17].

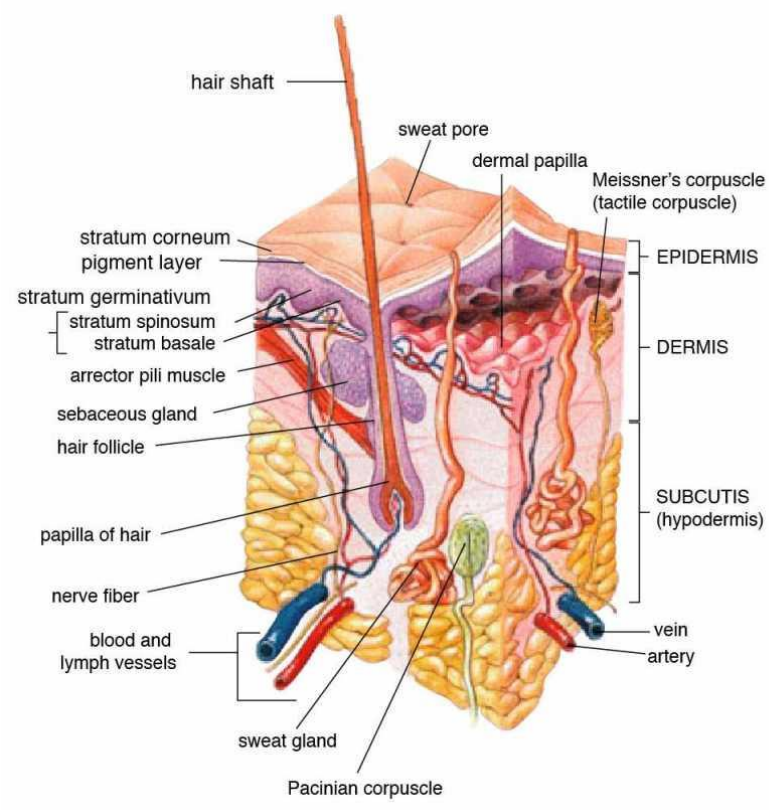

Figure 1. Anatomy of the human skin. Contributed by Wikimedia Commons, USGOV (Public Domain). StatPearls Publishing LLC; 2019 Jan. Copyright $\odot 2019$

The epidermis is the stratified epithelium that covers the outmost part of our bodies and it generally had a thickness of around $0.1 \mathrm{~mm}$, but it varies considerably between different locations on the body. The thinnest epidermis can be found on the eyelids and the thickest in the palms and soles. About $90 \%$ of all cells in the epidermis are keratinocytes, and the rest are melanocytes, Langerhans cells, and Merkel cells. The epidermis can be divided into four to five layers, depending on where it is sited on the body [17].

The layer closest to the dermis is called the Stratum Basale and it contains mainly keratinocytes, melanocytes, and stem cells. There are also Merkel cells, which are thought to work as mechanoreceptors [18]. The keratinocytes in this layer are classed as "young" because they have recently differentiated from stem cells, and 
they develop and mature as they migrate towards the surface of the skin. The melanocytes produce melanin, which is responsible for pigmentation. The next layer is called Stratum Spinosum, comprising most of the epidermis and contains several layers of cells that are connected by desmosomes, which allow cells to remain tightly bound to each other. In this layer, Langerhans cells can be found, which are immunologically active cells. The third layer is called Stratum Granulosum (not shown in Fig.1) and it contains several layers of cells that contain lipid-rich granules. In this layer, cells begin to "die" as they move away from the nutrients that are located in the deeper parts of the skin. The fourth layer is called Stratum Lucidum and can only be found in the thick skin of the soles and palms. The outmost part, the Stratum Corneum contains corneocytes, which are keratinocytes at their last stage, terminally differentiated. The corneocytes and lipid-rich matrix that surround these cells make this layer a protection against the external environment and regulate the permeability of the skin.

Epidermis renews itself within a month and heals, if damaged, from epidermal appendages such as hair follicles, sweat and sebaceous glands in the dermis, and from cut edges of skin, without scarring. The epidermis does not contain any blood vessels [17-19].

The second skin layer, the dermis, is located between the epidermis and the subcutaneous fat, and primarily consists of collagen (mainly type I and III) and fibres made of elastin that create a dense connective tissue that "protects" the body from strain. The collagen in the dermis is produced by fibroblasts, the most common cell type in connective tissue. The deeper-lying fibroblasts are responsible for maintaining the extra cellular matrix (ECM) in the dermis by producing not only collagen (type I, III, and IV) but also proteoglycans, fibronectin, laminins, glycosaminoglycans, metalloproteinases, and prostaglandins. The more superficially-located fibroblasts are responsible for re-epithelialisation during wound healing. This means that the fibroblasts are critical in the reconstruction and regeneration of skin tissue and re-epithelialisation after injuries [20].

The dermis is divided into two layers, the superficial thinner layer of which is called the papillary dermis, and the deeper thicker layer of which is called the reticular dermis. The papillary dermis is tightly connected to the epidermis through a basement membrane. Hemidesmosomes, a specialised form of protein, creates a strong junction between the two layers [21]. The dermis contains adipocytes, macrophages, touch receptors, and thermoreceptors that are responsible for heat sensation as well. In addition, hair follicles, sweat glands, sebaceous glands, apocrine glands, lymphatic vessels, nerves, and blood vessels are also present. Sweat and sebaceous glands, and hair follicles are actually epidermal appendages 
that extend down to the dermis and hypodermis (the subcutaneous fat) and contain epidermal skin cells. Sweat glands contribute to thermoregulation, and sebaceous glands to the lubrication of the epidermis. Blood vessels provide nourishment and waste removal for both dermal and epidermal cells in the dermis [22].

The hypodermis is the third and deepest layer of the skin and refers to the fatty tissue below the dermis. This tissue insulates the body from cold temperatures and provides shock absorption. Fat cells in the hypodermis also store nutrients and energy. The hypodermis is the thickest in the buttocks, palms of the hands, and soles of the feet. The hypodermis also contains some skin appendages like the hair follicles, sensory neurons, and blood vessels [23].

Children are thought to have a thinner epidermis than adults, fewer lipids, less melanin, and a flatter junction between the dermis and epidermis. They are also thought to have a higher water content and $\mathrm{pH}$ in the skin [24].

\section{The wound healing process}

The macroscopic process of wound healing has been "described" for more than 100 years and since then, there has been a constant development of new knowledge. Although considerable knowledge has evolved in this field during the last 20 years there are still large areas to be explored.

The normal process of wound healing may be described as four highly integrated and overlapping phases: the haemostasis and inflammation followed by proliferation, and then lastly the maturation phase $[25,26]$.

The haemostasis phase begins with the disruption of blood vessels, which exposes collagen in the dermis to platelets in the blood. Activated platelets stimulate the release of numerous growth factors, inflammatory markers, and cytokines, which end up in activated coagulation pathways and in the formation of the fibrin clot. The clot re-establishes haemostasis, provides a provisional extra ECM for cell migration, and releases several cytokines that are important for wound healing such as platelet-derived growth factor (PDGF), transforming growth factors (TGF), fibroblast growth factors (FGF), and epidermal growth factors (EGF). All these mediators, in their turn, attract and activate leukocytes (neutrophils), macrophages, and fibroblasts, which all together move the wound healing process to the next phase $[25,26]$ 
The inflammatory phase includes an important increase in vascular permeability that allows leukocytes and primarily neutrophils to migrate and phagocytose "any" bacteria. Enzymes are released that digest necrotic tissue. The neutrophils are thought to be recruited by Damage-associated molecular patterns (DAMPs), hydrogen peroxide $\left(\mathrm{H}_{2} \mathrm{O}_{2}\right)$, lipid mediators, and chemokines that have been released by injured cells. The rapid production of $\mathrm{H}_{2} \mathrm{O}_{2}$ in the wound is thought to minimise infections, activate keratinocyte regeneration, recruit neutrophils, and promote the formation of new vessels. Neutrophils, which are not normally found in uninjured skin, release toxic, antimicrobial granules that contain mainly proteases. Proteases are important enzymes that have antimicrobial activity, and are able to break down the basement membrane and the ECM, allowing further neutrophils to migrate to the injured area. One of the often-discussed proteases is matrix metalloproteinase (MMP). Some types of MMP are more present in the fluid of acute wounds and are therefore more likely to cause a perfect balance in collagen up and down regulation, while other MMPs are present in chronic, or slow healing wounds, and are likely to cause down regulation of collagen, which will result in a suboptimal environment for wound healing [25-27].

As mentioned earlier, a new family of wound dressings, protease-inhibiting dressings has been developed to overcome the issue of the "breaking down by MMPs". Specific tissue inhibitors of metalloproteinases (TIMPs) work as "controllers" of MMP in the wound healing process.

The early activity of neutrophils is critical to inhibit bacterial colonisation and wound infection. Further cleansing of the tissues is undertaken by monocytes when they infiltrate the area and become macrophages. Typically, the neutrophil population is replaced within a few days by macrophages, which facilitate normal wound healing, regulate fibroblast activity, and enable the deposition and remodeling of ECM and granulation tissue. This activity involves the secretion of numerous cytokines and growth factors, including PDGF, TGF- $\beta$, tumour-necrosis factor alfa (TNF- $\alpha$ ), and interleukins. Macrophages further stimulate inflammatory cytokines such as PDGF, TGF (alfa and beta), FGF, EGF, interleukin -1 (IL-1) and insulin-like growth factor 1 (IGF-1), which are all thought to be vitally important for the regeneration of injured tissue. Mast cells release vasoactive cytokines such as prostaglandins and histamine, which increase capillary permeability and promote local dilation to aid the migratory process. Through these mechanisms, the inflammatory phase creates a clean wound bed [25, 26].

The proliferative phase includes angiogenesis, the production of granulation tissue, the deposition of collagen, and re-epithelialisation of the wound. The crea- 
tion of new blood vessels (angiogenesis) is thought to start because of the hypoxic release of growth factors such as vascular endothelial growth factor (VEGF) and PDGF, both of which stimulate the endothelial cells located in the walls of blood vessels. Stimulated endothelial cells break down the ECM in the granulation tissue then proliferate and migrate out into the tissue, creating new capillaries. The release of FGF also triggers angiogenesis, which supplies the new wound with oxygen, glucose, and other factors necessary for proper healing. As blood flow returns to the area, oxygen saturation normalises and VEGF decreases to slow the process of angiogenesis. This autoregulatory mechanism plays a role in preventing excess production of collagen and reduces the risk of abnormal scar formation.

The formation of granulation tissue starts with fibroblasts migrating into the wound and producing additional ECM. Collagen levels rise steadily for several weeks before slowing down. The tensile strength of the wound correlates with the amount of collagen deposition during this period.

As long as the epidermal appendages are intact, re-epithelialisation of the wound can occur both from the wound edges and from the stimulated epidermal appendages that contain epidermal cells and stem cells. How the body stimulates epidermal cells to migrate and proliferate in the wound area is not fully understood, but one theory is that the absence of neighbor cells (the "free edge effect") may signal to the epidermal cells to migrate. Other factors that may be important, are the local release of growth factors and increased expression of growth-factor receptors. Partial thickness wounds (that stretch below the epidermal skin appendages into the reticular dermis, or when such appendages have been damaged) heal more slowly and the area of the wound needs to be replaced by granulation tissue $[25,26]$.

The maturation, or scarring, phase is the final stage of wound healing, which includes contraction, collagen cross-linking and remodeling. Contraction occurs in open wounds to reduce the surface area with the help of myofibroblasts, transformed fibroblasts, and their synthesis of alpha-smooth muscle actin. Myofibroblasts are thought to attach to collagen and pull the fibres to the edges of the wound. When the tissues are sufficiently restored, the myofibroblasts undergo apoptosis and the fibroblasts, macrophages and endothelial cells involved in healing now leave the tissues. Collagen is deposited and recreated during the scarring phase, most likely controlled by MMPs, which are secreted by macrophages, epidermal cells, endothelial cells, and fibroblasts. 
As the wound is closed, a down regulation of capillaries takes place, resulting in a pale scar. After the scar matures, fibroblasts decrease in number. Epidermal appendages, such as hair follicles and sebaceous glands, and the stem cells normally found in these appendages, are often absent in the scar. This results in a dermal layer that contains few cells. The scar also contains less elastin than normal skin, which contributes to the lack of elasticity seen in scar tissue. A mature cutaneous scar consists of a large amount of collagen, 80-90\% of which is type I collagen and the rest type III. The basement membrane of the epidermis that develops over scar tissue is flatter than normal because it does not contain the rete pegs that normally penetrate the dermis to keep the layers "connected". The maximum strength of the new tissue is about $70 \%-80 \%$ of undamaged tissue [28]. Regarding the "re-pigmentation" of the wound, there are two potential sources from which melanocytes can be recruited to repopulate scars. Melanocytes from the surrounding unwounded skin can migrate into the wound at the edges, and epidermal elements such as hair follicles and sebaceous glands in the wound bed can also provide a source of melanocytes [25, 26, 28].

\section{Description of the wound models of this thesis}

As described earlier in the Introduction section, the focus of this thesis is on two kinds of partial thickness acute wounds; donor sites after the harvest of split thickness skin grafts and partial thickness skin burns (sometimes referred to as second degree burns).

Donor sites are wounds that are created under sterile conditions during operation, when healthy skin is harvested to cover wounds that will not heal spontaneously in a reasonable time (within 14 to 21 days). Skin grafts can be harvested in different thicknesses (Fig. 2) [15]. In this thesis, we focus on donor sites created when the surgeon harvests split thickness skin grafts. In Study I, skin grafts are harvested from the thigh with the dermatome (skin harvesting "machine") set to 0.012 inches, which produces medium/intermediate thick grafts, and creates a wound approximately $0.2-0.3 \mathrm{~mm}$ deep This should leave the epidermal appendages (glands and follicles) of the dermis almost intact [29, 30]. The most commonly-used donor site is the thigh [30]. 


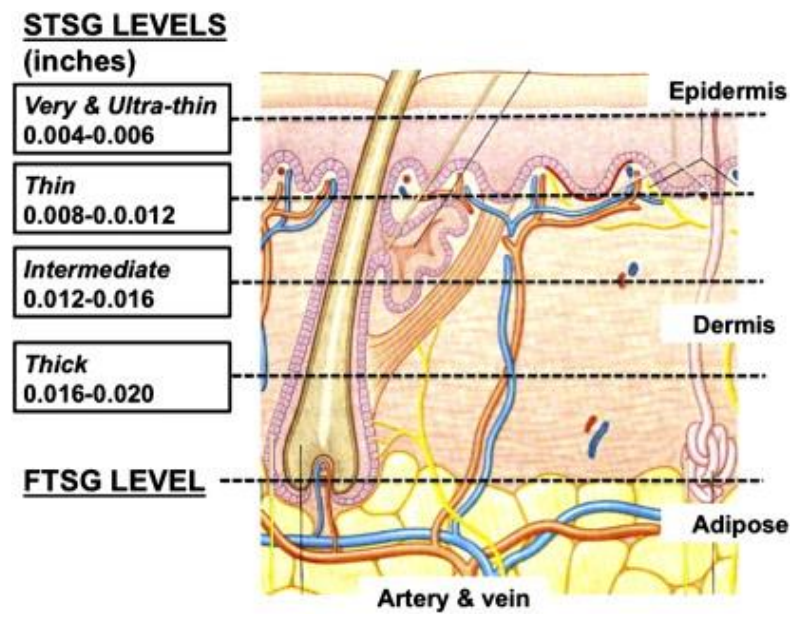

Figure 2. Illustration of skin layers and skin graft depths ${ }^{2}$

The depth of a burn is commonly classified as superficial, partial thickness, or full thickness. Superficial burns only affect the epidermis while partial thickness burns, affects different depths (layers) of the dermis. Full thickness burns affect all layers of skin (Fig. 3) [31].

Partial thickness burns are burns that extend through the epidermis and down into the dermis. One common cause of partial thickness burns is hot liquid. Partial thickness burns are often divided into two groups; superficial and deep partial thickness burn (sometimes a third group is mentioned, mid-dermal burns).

Superficial partial-thickness burns extend into the papillary, or superficial, layer of the dermis. Blisters, both intact and ruptured, are common and the wound is wet and pink/red. When pressure is applied to the reddened area, the area will blanch and rapid capillary refill is noted upon release of the pressure. These burns are painful because the nerve ends are exposed to air (Fig. 4).

Deep partial-thickness burns extend downward into the reticular layer of the dermis and are either mixed red or pale. Areas of redness will continue to blanch when pressure is applied, but capillary refill may be delayed when pressure is released. Blisters can be seen and the exposed surface of the wound is wet or moist, similar to superficial partial-thickness burns (Fig. 5). Oedema is marked,

\footnotetext{
${ }^{2}$ Reprinted from The Journal of Foot and Ankle Surgery, volume 49, issue 4, Christopher Bibbo. VERSAJET-Hydrosurgery Technique for the Preparation of Full Thickness Skin Grafts and the Creation of Retrograde Split Thickness Skin Grafts, issue 4 July-August 2010 pages 404-407, Copyright 2010, with permission from Elsevier.
} 
and sensation is altered in areas of a deep partial-thickness burn [31-33]. In this thesis the term deep dermal burns (DDB) will be used for burns of this depth.

Burns are not only assessed with regard to their depth, but also by their extent, to ensure appropriate, acute burn care. The extent of the burn is described by giving the percentage of burn covering the total body surface area (TBSA). A burn covering $1 \%$ of the TBSA is called a $1 \%$ TBSA burn. When calculating the percentage of burn, the observer most often use either the rule of nines [34] the rule of palm [35] or the Lund and Browder Chart [36]. The rule of nines estimation of body surface area burned is based on assigning percentages to different areas of the body. Areas are "divided into nines", where the entire head is estimated as $9 \%$, the entire trunk as $36 \%$ (and can be further divided into $18 \%$ for anterior trunk and $18 \%$ for the back). The rule of palm estimation is used by using the patient's palm including fingers, which is said to represent $1 \%$ of their body. Recent publications have shown that this might lead to an overestimation of the burned area, but it is still used clinically, particularly for minor burns. The gold standard for burns that we use in our burn centre is the Lund and Browder chart developed in 1944 - where unlike the rule of nines, the age of the patient is taken into consideration (the percentage of burned surface area for the head decreases and that for the legs increases as the child ages [37].

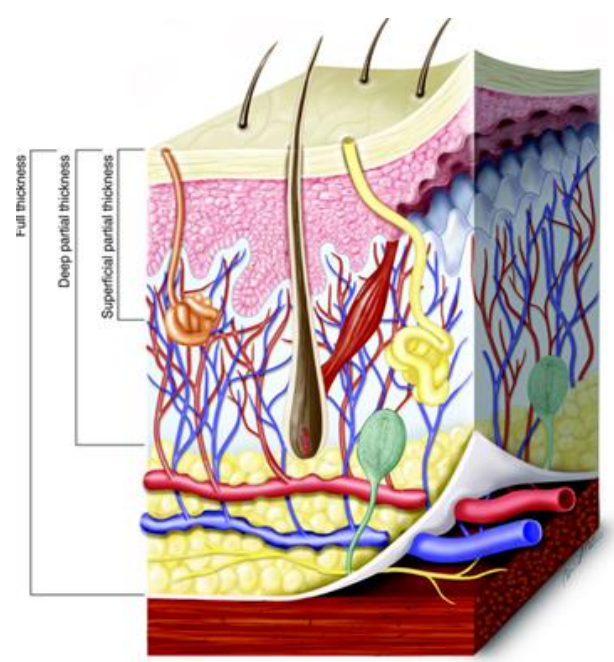

Figure 3. Anatomy and histology of the skin, showing the depths of burns ${ }^{3}$

\footnotetext{
${ }^{3}$ Reprinted 2019 from Shupp, Jeffrey W.; Nasabzadeh, Teresa J. A Review of the Local Pathophysiologic Bases of Burn Wound Progression.The Journal of Burn Care \& Research. 2010, Vol. 31, number 6, page 849-873, by permission of Oxford University Press
} 


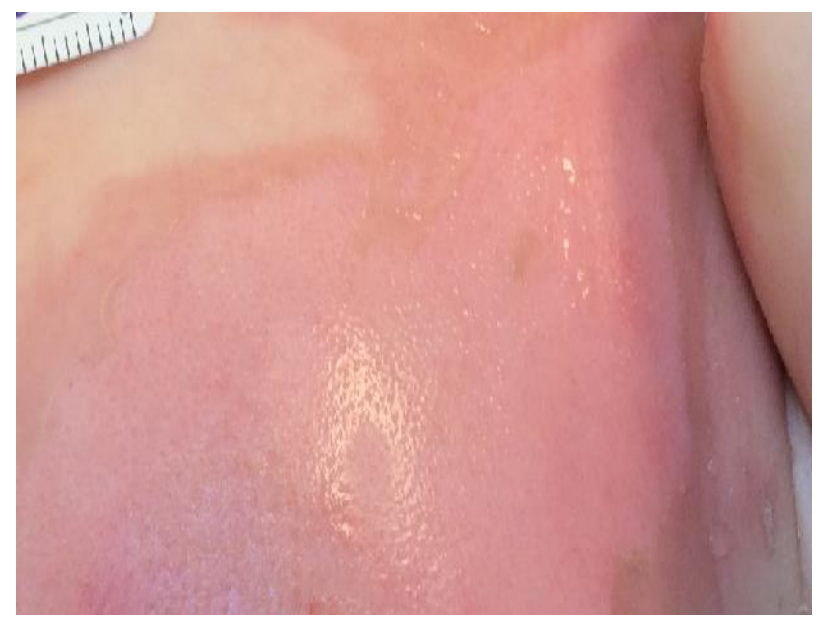

Figure 4. Superficial dermal burn located on the trunk of one of the children participating in Study IV (images used after written consent from guardians)

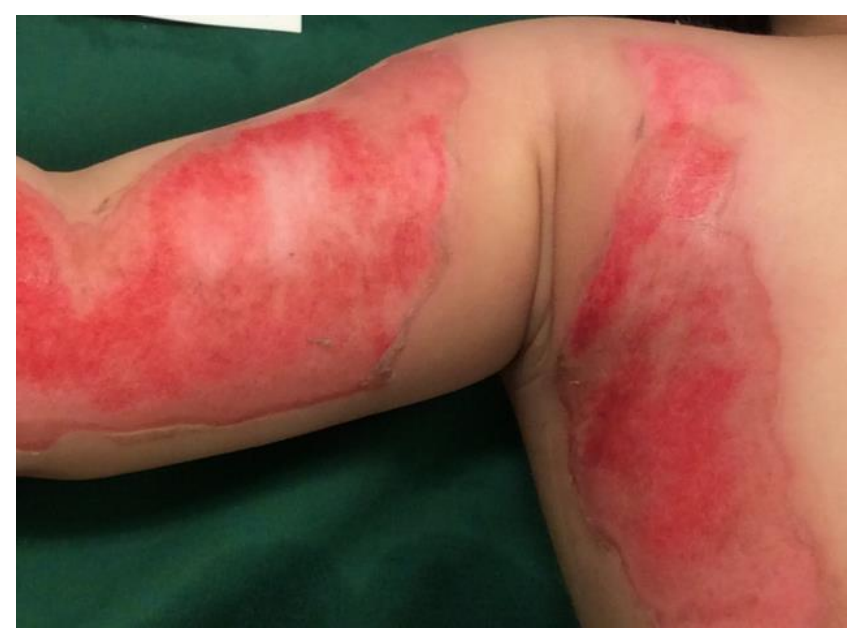

Figure 5. Areas of deep partial thickness wounds in a child participating in Study IV (images used after written consent from guardians) 


\section{Differences in healing between donor sites and partial thickness burns}

Donor sites and partial thickness burns, although affecting the same skin layers, are believed to heal differently, depending on the nature of the wound [38].

As the donor site is created under clean, controlled conditions and contains very little damaged skin, the remaining tissue is vital and can therefore supply nutrients to incoming fibroblasts and epithelial cells. This results in a healing process that starts within seconds after injury with the haemostasis phase, and aims at stopping the blood flow from the healthy capillaries being "cut off"[38]. The healing process is somewhat different for burns.

In 1953, Douglas Jackson published the article "The diagnosis of the depth of burning" in the British Journal of Surgery [33]. In this well-cited article, he describes the burn wound in terms of three different zones: coagulation, stasis, and hyperaemia (Fig. 6). These zones are three dimensional, and loss of tissue in the zone of stasis will lead to the wound deepening as well as widening. Jackson described these three zones as a result of examining biopsies that were harvested from 20 healthy volunteers with experimentally-controlled burns. Even though questions have been raised regarding how the zone of stasis was depicted from such biopsies, this model is still a prevalent basis of burn wound pathology.

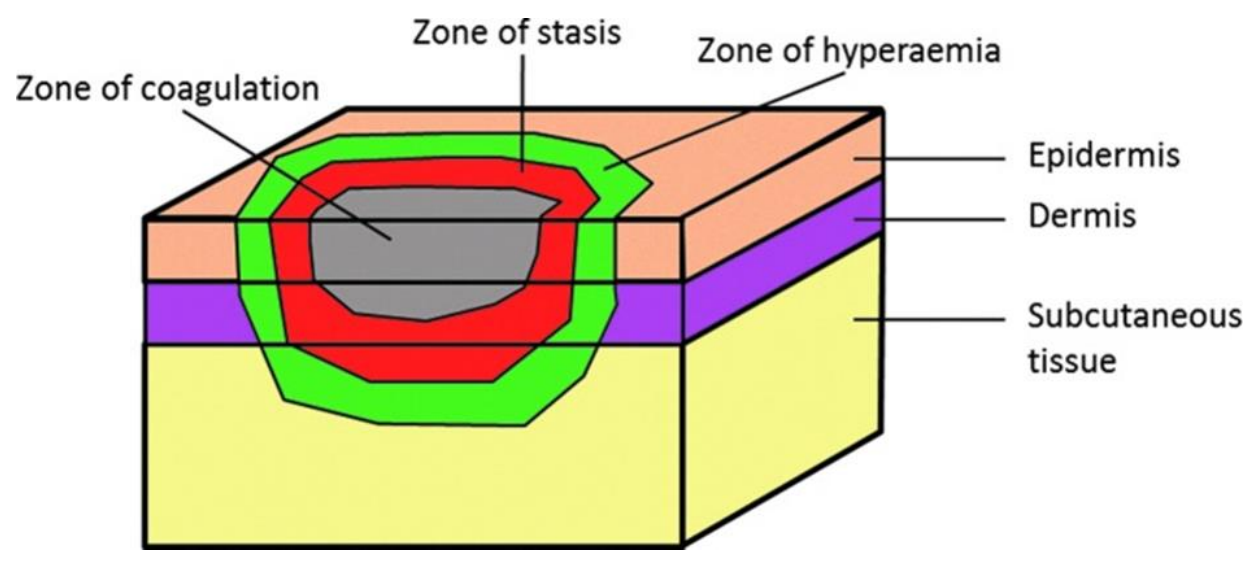

Figure 6. Jackson's burn wound model. The different zones of damage from a partialthickness burn are shown in profile through the layers of the skin ${ }^{4}$

\footnotetext{
${ }^{4}$ Republished with permission of Mary Ann Liebert, Inc. The Burn Wound Microenvironment, Rose LF, Chan RK, Mar 1;5(3):106-118, Copyright 2016, permission conveyed through Copyright Clearance Center, Inc
} 
The high heat accumulated in the centre of the tissue after a deep burn is thought to create the zone of coagulation. This zone is pale, painless, and capillaries have coagulated. This area lacks sufficient oxygen supply and so the tissue dies. For the wound to heal, the necrotic tissue needs to be removed and, depending on wound size, be replaced by a viable, autologous skin graft. Surrounding the zone of coagulation is the zone of stasis, an area where perfusion is decreased but tissue is still being perfused, which leads to fluid leakage from vessels and concomitant vascular damage. The zone of hyperaemia is the red zone, which surrounds the zone of stasis where the epidermis is partly or totally lost but the dermis remains. The vasculature is dilated and intact and the skin blanches at pressure [3840].

Whether the healing process can continue depends on whether the capillaries in the zone of stasis can provide the burned areas with nutrition and phagocytes. It is suspected that if the cells do not get access to the wounded areas, the zone of coagulation expands, and the depth of the burn increases. Studies have shown that in deep partial thickness burns apoptotic dermal cells are found in a much higher percentage than in superficial or full thickness burns, and this difference remains for weeks. This means that dermal cells continue to die in a "programmed manner" long after the injury and this is probably one of the reasons for the progression of a burn. The lack of blood flow inhibits neutrophil access, delaying the inflammatory phase, but studies have also shown that the survival of neutrophils is prolonged in burns patients, which also prolongs the inflammatory phase $[31,39]$. The exact mechanism underlying the progression of burns is not fully understood.

\section{Factors that delay wound healing and influence scar outcome}

There are several factors that influence the healing process. Some of the most commonly-mentioned systemic factors that are thought to have an impact on acute wound healing are older age [41, 42], diabetes [43], diseases that influence the circulation of the blood or mobilisation, drugs that inhibits haemostatic or immune response, or both [44], lifestyle-related factors such as smoking [45], alcohol misuse, obesity (and malnutrition, similarly) [46]. Some studies have shown that sex [41] and the levels of sex hormones have an impact on woundhealing potential. Oestrogen is thought to stimulate healing, and testosterone to induce it [47].

Local factors such as infection [42] and high levels of certain MMPs might also affect healing [27], highlighting the need for proper treatment. What "delayed wound healing" actually is can be discussed, but in acute wounds a healing time 
that extends beyond 4-6 weeks is referred to as delayed healing [1]. An acute wound that shows delayed healing can become a "chronic wound" depending on the supposed reason for the delay. Many clinicians report older patients with a "chronic wound" to the lower leg after an initial "traumatic skin injury". In these cases, perhaps an undiagnosed "vascular insufficiency" may have caused the conversion from an acute to a chronic wound.

A factor that has an impact on the wound healing process is, of course, the depth of the wound. A deeper wound requires more time for the ECM to build up, and in burns, the depth of the injury is one of the few validated factors to influence healing time [48]. The extent of the wound is another factor thought to influence healing time $[42,49]$.

Less is known about the factors that influence the outcome of scars. As pathological scars are common within burns care, most of our knowledge comes from this field. Pathological scarring refers to hypertrophic scars (HTS) or keloids. By definition, hypertrophic scars are confined within the margins of the original wound bed, whereas keloids extend beyond these borders [28]. Another, lesscommonly discussed pathological scar is the dyspigmented scar, which can be either a hypo-pigmented or hyper-pigmented. Not only is it of cosmetic importance to the patient, it also poses a problem as the pigment protects the skin from harmful UV radiation [50].

Factors thought to cause severe or pathological scarring include: healing time extending beyond 14 [51] or 21 days [52], deeper wounds, larger extent of the burn [53], wound infection [54], female sex, young age [55], dark skin type (nonwhite) [56], skin grafting [55], burn on trunk or upper limb [57] and high BMI (for which there is weak evidence) [58].

The choice of dressing treatment might have a direct impact on both healing times and scarring outcome as they can affect the local environment of the wound.

\section{Acute wound treatment}

\section{Cleaning and debridement}

The cleaning and debridement of necrotic tissues are the corner stones of modern wound treatment as they reduce the bacterial burden of the wound and stimulate 
healing $[59,60]$. The role of antiseptics in the cleansing of acute wounds is questionable and there is not enough evidence of it being effective $[11,61]$.

Donor sites do not normally require debridement as damaged or necrotic tissue is absent. For the partial thickness burn, the burned tissue is necrotic and surrounded by damaged tissue, all of which require accurate debridement, which includes cleansing of the wound and the removal of any necrotic tissue to stimulate healing. Deep dermal/partial thickness and full thickness wounds (involving the hypodermis and sometimes even the muscles and bones) usually need surgical or enzymatic debridement to get rid of the necrotic tissue $[59,61]$.

\section{Dressing treatments}

The choice of dressing depends mainly on the characteristics of the wound in focus.

What we consider to be an ideal dressing today is a dressing that creates a moist and clean, balanced environment for the wound. One of the first reports on the positive role of a moist healing environment in wounds was published by Hinman and Maibach in Nature in 1963 and since then, these concepts have become standard [62].

Moist wound healing is thought to; prevent pain by protecting free nerve endings, prevent the formation of dry scabs which may contain or promote the survival of micro-organisms, and also to prevent the loss of epidermal cells. This is particularly evident when dressings are changed. Closed moist dressings are further claimed to lower the risk of contamination from the surroundings[63]. Five systematic reviews on donor site dressings were found and in four of them the authors conclude that a moist wound environment is associated with better outcomes, as in faster re-epithelialisation, less pain, and fewer infections [30, 6467].

Seven systematic reviews for partial thickness burn wound dressings were found [68-74], showing strongly contradictory results, in which no conclusions regarding moist treatments can be drawn. Moist wound treatments have been reported to provide short healing times [70] but also to increase infection rates in burns in a recent clinical trial [75].

Examples of (claimed) moist dressings in clinical use include alginates, films, foams, hydrogels and hydrocolloid gel producing hydrofibre (cellulose)[65]. 
Moist wound dressings that have been evaluated for donor sites and burns in this thesis will be described in the Method section and discussed further in this thesis.

The properties of an ideal dressing for the two partial thickness wounds in focus in this thesis has been investigated in two worldwide surveys from 2012 [76] and 2013 [77] and the conclusions were that most clinicians thought that an ideal dressing does not yet exist.

The most desirable characteristics of an "ideal" donor site dressing that clinicians look for is a "one piece" dressing (composite) that is absorbent, pain-free, nonadhesive, easy to remove, and requires a minimum of changes, (no changes at all until complete healing is preferred) [77].

For burns, the desired characteristics in the ideal dressing are similar to those of donor site dressings with a few exceptions. Except for the above-mentioned characteristics, burn clinicians also ask for antimicrobial activity, and that the dressings should be available in a range of sizes. The dressing should be changed twice weekly, preferably [76]. These requests are most likely to be related to the suppression of immunity in patients with burns that leads to a high microbial burden [38] (described earlier in the section, Differences in healing between donor sites and burns).

Dressings with supposed antimicrobial activities have been investigated in our studies and will be presented and discussed later on in this thesis.

\section{How to evaluate dressing treatments?}

The most commonly-reported variable in wound research is the time it takes for the wound to heal, followed by variables such as infection, pain, costs, the use of resources, adverse events, mortality, and quality of life [78]. With partial thickness burns, two additional outcomes are regularly reported; Duration (or Length) of hospital stay (often referred to as LOS) and the need for operation [70].

All kinds of research designs can be seen in the evaluation of wound dressings, but to follow evidence-based medical research methods, only one design can be considered to be the proper one, the randomised controlled trial (RCT) [79].

RCTs are universally acknowledged to be the study design of choice to compare the effects of treatment, as they reduce sources of bias, such as selection bias and confounding bias. This is the reason why Cochrane reports only include RCTs [79]. 


\section{AIMS}

The following aims were addressed in this thesis:

To investigate if the choice of dressing treatment had an impact on:

The healing process of the split thickness skin graft donor site (Study I); scar outcome in the split thickness skin graft donor site (Study II, III); the healing of partial thickness burns (Study IV); scar outcome in partial thickness burns (Study V).

Our final aim, which evolved during the research project, was to investigate whether we could confirm the findings in other studies regarding factors that have affected healing time and scarring, by using the data collected in Studies I-V.

\section{Hypotheses}

In Study I we hypothesised that there was a superior type of dressing than our standard of care dressings at that time.

In Study IV we hypothesised that there was a superior type of dressing than our standard of care at that time. 


\section{METHODS}

\section{Study population}

All patients included in these studies were admitted to the Department of Hand Surgery, Plastic Surgery and Burns, at the Linköping University Hospital, Linköping, Sweden and all participated after given written informed consent.

The inclusion criteria in Studies I and IV and demographic data collected were selected with the aim of homogenising the study groups as much as possible.

Study II, III and V are follow-up studies that comprised patients originally recruited in the RCTs (Study I and IV), who participated again after providing informed consent.

Inclusion criteria for the study participants in Study I:

- In-patients planned for split thickness skin grafting from the thigh

- A planned donor site ranging from $30 \mathrm{~cm}^{2}$ to $400 \mathrm{~cm}^{2}$

- Graft to be harvested with dermatome at a standard depth

- 18 years or older

- Swedish speaking

- Written informed consent given

Inclusion criteria for study participants in Study IV:

- Admission within 72 hours after burn injury

- Children aged 6 months to 6 years

- Partial-thickness scalds, suitable for dressing within standard of care (SOC); a porcine xenograft, as judged by the burn surgeon on duty

- Written informed consent from guardians given

In Study I, the following data were collected; age, sex, weight, and height (BMI calculated), treatment with cortisone or anticoagulants, autoimmune diseases (systemic lupus erythematosus, Crohn's disease, ulcerative colitis, rheumatoid arthritis, and diabetes mellitus) and smoking habits.

In Study IV the following data were collected; age, sex, weight, previous illnesses, medications, allergies, depth of burn, and TBSA \%. 


\section{Design}

Study I. Dressing the split-thickness skin graft donor site: a randomised clinical trial, comprised 67 patients aged 18 years or older who had been admitted for elective surgery, in which split thickness skin grafts were harvested from the thigh. After giving written informed consent the patients were randomly assigned to be given one of the three different dressings: polyurethane foam (Allevyn, Smith \& Nephew, St Petersburg, Florida), hydrofibre (Aquacel, ConvaTec, Skillman, New Jersey) or porcine xenograft (Mediskin, Mölnlycke, Health Care AB, Gothenburg, Sweden). Patients were recruited between October 2008 and December 2009.

Study II. Scarring at donor sites after split-thickness skin graft: a prospective, longitudinal, randomised trial was a follow-up study investigating the outcome of scars in the patients originally recruited to Study I. All 34 patients who were still alive and registered in Sweden from the original RCT were contacted by letter and asked to participate. Twenty-seven patients completed the follow-up study. Study participants gave their subjective opinion on the outcome of donor site scars using a scar scale named the Patient and Observer Scar scale (POSAS), which will be explained later in this section. Patients were recruited in 2017, approximately eight years after participating in the original Study I.

Study III. Scarring at donor sites after split-thickness skin graft:

A prospective, longitudinal, randomised trial; the observer view consisted of 17 patients from Studies I and II. All living patients who had participated in Study II were contacted by letter and asked to participate in this last part of the donor site project. Donor site scar outcome was then evaluated using the scar scale POSAS and an instrument for measuring the firmness and elasticity of the skin (Cutometer® MPA 580), described in Paper III. Seventeen chose to return to our Department in 2018 for this last follow up.

Study IV. Superiority of silver-foam over porcine xenograft dressings for treatment of scalds in children: A prospective randomised controlled trial comprised 58 children between the ages of 6 months and 6 years, who were admitted with partial thickness scalds. After guardians gave written informed consent, the patients were randomly assigned one of two study dressings; porcine xenograft (EZderm, Mölnlycke Health Care AB, Gothenburg, Sweden) or silver-foam dressing (Mepilex Ag, Mölnlycke Health Care AB, Gothenburg, Sweden ). Patients were recruited between May 2015 and 2018. 
Study V. Burn scar outcome at 6 and 12 months after injury in children with partial thickness scalds: did the dressing treatment matter? was a follow up study investigating the outcome of burn scars in the children originally recruited to Study IV. Guardians gave informed consent to this follow-up study during the Study IV procedure and the patients were at the completion of this study scheduled for 6 and 12 months' scar evaluations (Study V). Thirty nine of the 58 children participated in the follow up at 6 months and 34 at 12 months. Scars were evaluated using the scar scales described later in this section.

\section{Variables and clinical assessments}

Variables chosen and investigated in this thesis are the ones commonly presented in systematic reviews and Cochrane reports for wound treatments [70, 78]. The following variables were investigated in both Studies I and IV: healing time, infection, pain and change of dressing times (part of the variable: ease of use in Study I) and dressing frequency (part of the variable: cost in Study I). In Study I, impact on everyday life and costs were also evaluated. In Study IV, the need for operation and LOS was also examined. These variables were added as they are considered to depict the ability of the dressing to reduce the need for both operation in partial thickness burns (not relevant in Study I), and in-patient hospital care.

\section{Healing time}

In Studies I and IV healing time was assessed by a plastic surgeon; complete wound closure also had to be confirmed by a nurse attending the change of dressings. In Study I healing was assessed at post-operative day 14 and 21. As the donor site wound was standardised and localised on a flat surface, wound tracing was used to calculate percentage of re-epithelialisation. Donor sites were evaluated as healed if re-epithelialised to $98 \%$ or more. As the calculation was done retrospectively patients not completely healed at day 14 also attended the day 21 visit. Healing times were corrected for the $98 \%$ limit and presented in Paper I. As the wounds were irregular and located at convex and concave sites in Study IV, wound tracing was abandoned for technical reasons and healed areas were calculated using the rule of the palm and then later a calculation of percentage of re-epithelialisation was done. Burns were considered healed if re-epithelialised to $97 \%$ or more. Children were followed until complete (100\%) wound closure.

\section{Infection}

In Studies I and IV infection was diagnosed based on clinical signs such as: redness, heat, swelling, pain, odour, fever, and a positive wound swab. In Study IV, we also assessed levels of C-Reactive Protein (CRP) with the help of a validated and calibrated instrument (Quick read go, Orion Diagnostica Oy, Espoo, Finland). 


\section{Pain}

In Study I pain was assessed at rest, during activity, and during dressing changes using a Numeric Rating Scale (NRS; 0-10). This scale has been validated and recommended as the "best practise" pain assessment instrument for dressing changes [80, 81].

In Study IV, conducted in small children, we used the Face, Legs, Activity, Cry, and Consolability (FLACC) scale (Table 1) [82] . The FLACC was used to assess pain before, during, and after dressing changes together with a Parents' Postoperative Pain Measure (PPPM) diary [83] in which guardians registered signs of their children's pain during the day. The FLACC scale contains five categories, each of which, is scored from 0 to 2 , to provide a total score ranging from 0 to 10 . It is clinically used and validated in a variety of settings such as pain after operation and injury in children up to the age of 7 (Study IV). However, it has not been validated for procedural pain in those under the age of five [82, 84].

In Study IV, also the need for analgesia was recorded. This, however, was not considered relevant for Study I, because it was thought to be problematic to differentiate between analgesia taken for pain at the donor site compared with analgesia taken for pain at the transplanted wound area.

Table 1. THE FLACC SCALE

\begin{tabular}{|c|c|c|c|}
\hline \multirow[t]{2}{*}{ Category } & \multicolumn{3}{|c|}{ Scoring } \\
\hline & $\mathbf{0}$ & 1 & 2 \\
\hline Face & $\begin{array}{l}\text { No particular expres- } \\
\text { sion or smile }\end{array}$ & $\begin{array}{l}\text { Occasional grimace } \\
\text { or frown, withdrawn, disinter- } \\
\text { ested }\end{array}$ & $\begin{array}{l}\text { Frequent to constant quiv- } \\
\text { ering chin, clenched jaw }\end{array}$ \\
\hline Legs & $\begin{array}{l}\text { Normal position or } \\
\text { relaxed }\end{array}$ & Uneasy, restless, tense & Kicking or leg drawn up \\
\hline Activity & $\begin{array}{l}\text { Lying quietly, normal } \\
\text { position, moves easily }\end{array}$ & $\begin{array}{l}\text { Squirming, shifting back and } \\
\text { forth, tense }\end{array}$ & Arched, rigid or jerking \\
\hline Cry & $\begin{array}{l}\text { No cry (awake or } \\
\text { asleep) }\end{array}$ & $\begin{array}{l}\text { Moans or whimpers; occasional } \\
\text { complaint }\end{array}$ & $\begin{array}{l}\text { Crying steadily, screams or } \\
\text { sobs, frequent complains }\end{array}$ \\
\hline Consolability & Content, relaxed & $\begin{array}{l}\text { Reassured by occasional touch- } \\
\text { ing, hugging or being talked to, } \\
\text { distractible }\end{array}$ & $\begin{array}{l}\text { Difficult to console or } \\
\text { comfort }\end{array}$ \\
\hline
\end{tabular}




\section{Dressing time}

In Study I and IV, the time taken to change dressings was measured using intervals of 10 minutes. This was noted in the Case Report form (CRF), by the nurse who was doing it. Frequency of dressing changes was recorded as a part of the cost variable in Study I, and separately in Study IV. We were able to do a cost calculation in Study I, as the donors sites were of similar sizes (the same size of dressing was required for all patients), on the same location in the body and applied in a similar procedure (dressings used after day 21 were not included in study). In Study IV, children had burns on different parts of the body and were followed up until complete wound closure. This resulted in differently-sized dressings and different timings for each change, so no cost calculations were done. Data on the number of dressing changes in Study IV, was extracted from the local Burn Unit Database (BUD) [85] and also confirmed in the the unit's medical records.

\section{LOS and operations}

In Study IV, data for the LOS and need for operation was extracted from BUD and the patients' medical records. The design of the Study I made it inappropriate to examine the need for operation (as this was an inclusion criteria) and LOS was also affected by the healing status of the transplanted area.

\section{Scar variables}

The variable investigated in Study II was the patient's subjective opinion of the donor site scar outcome. For this purpose, the patients used the Patient scale of the POSAS (Fig.7a). In Studies III and V, the Observer scale of POSAS was used to evaluate the scar outcomes (Fig.7b). We used a validated Swedish version of POSAS distributed by the Uppsala Burn Centre, Sweden in 2016.

Each scale contains six items that are scored numerically and when added, constitutes "Total Score" of the Patient and Observer Scale. Each of the six items on both scales has a 10-point range $(1-10)$, with 10 indicating the worst imaginable scar or sensation. The lowest score, " 1 " corresponds to the normal skin. The Patient Scale contains six questions that address the items: pain, itching, colour, stiffness, thickness and relief. The Observer rate addresses: vascularity, pigmentation, pliability, thickness, relief, and surface area. Besides the 10-step scale, category boxes are available to score nominal parameters (such as the type of pigmentation) for the observer. The patient and observer can also score their "Overall Opinion" on the scar compared to normal skin with a 10-step scale, with 10 indicating a scar very different from normal skin. POSAS is one of the most commonly-used scales for evaluating scars [86]. 


\section{POSAS Patient scale}

The Patient and Observer Scar Assessment Scale v2.0/ EN

\begin{tabular}{l} 
Date of examination: \\
Observer: \\
\hline Location: \\
Research / study:
\end{tabular}

Name of patient:

Date of birth:

Identification number:

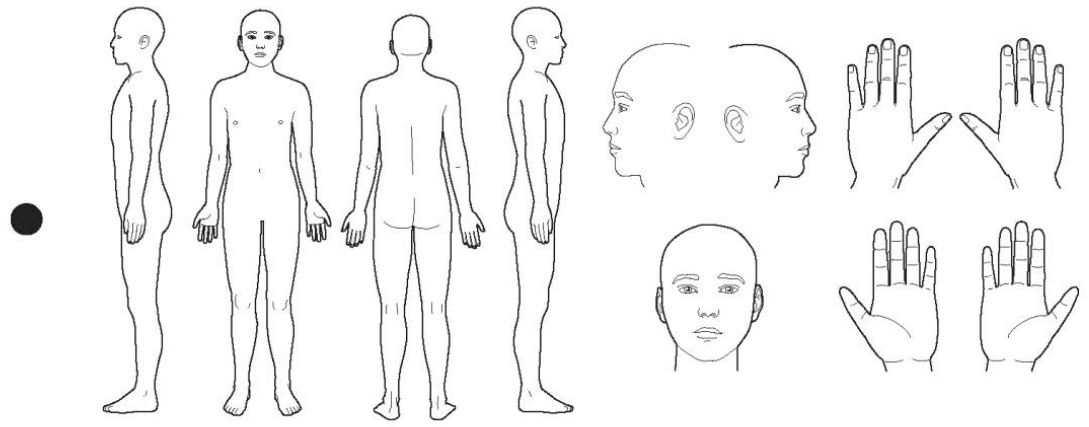

$1=$ no, not at all yes, very much $=10$

123456789

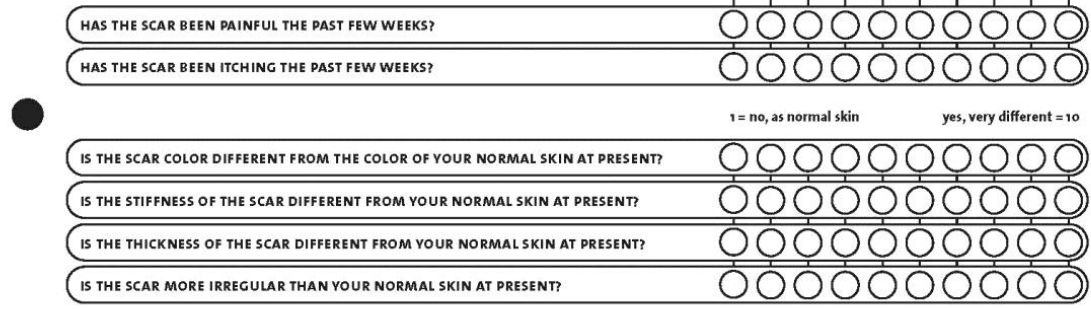

123456989

WHAT IS YOUR OVERALL OPINION OF THE SCAR COMPARED TO NORMAL SKIN?

0000000000

Figure 7a. The POSAS Patient scale used in Paper II. Permitted for reuse 23 of august 2019. Copyright holders P.P.M.van Zuijlen, Beverwijk-NL 


\section{POSAS Observer scale}

The Patient and Observer Scar Assessment Scale v2.0 / EN

\begin{tabular}{l} 
Date of examination: \\
Observer: \\
\hline Location: \\
Research / study:
\end{tabular}

Name of patient:

\section{Date of birth:}

Identification number

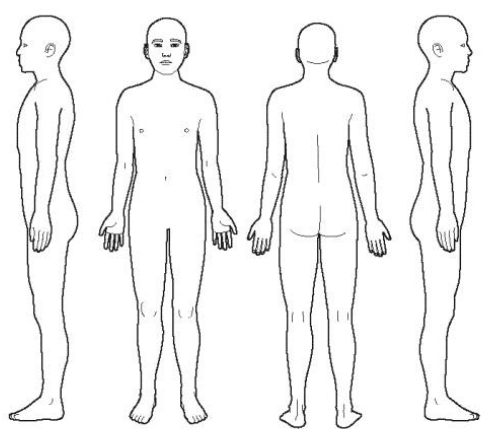

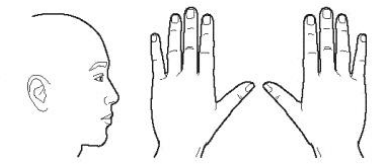
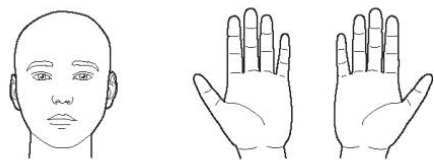

$1=$ normal skin

worst scar imaginable $=10$

PARAMETER

Explanatory notes on the items:

- vascularir Presence of vessels in scar tissue assessed by the amount of redness, tested by the amount of blood return after blanching with a piece of Plexiglas

- PICMENIATION Brownish coloration of the scar by pigment (melanin) apply Meriglas to the skin with moderate pressure to eliminate the

distance between the subcutical-dermal border and the epidermal surface of thescar

- RELEF The extent to which surface irregularities are present

(preferably compared with adjacent normal skin)

- PLIABIITY Suppleness of the scar tested by wrinkling the scar between

the thumband index finger

- SURFACE AREA Surface area of the scar in relation to the original wound area

Figure 7b. The POSAS Observer scale used in Paper III and V. Permitted for reuse 23 of august 2019.Copyright holders P.P.M.van Zuijlen, Beverwijk-NL 
In Study V, the scars were also examined with the other commonly-used scar scale, the Vancouver scar scale (VSS)[86]. This scale was developed in the 1990's and is based on four items: pigmentation, vascularity, pliability, and height of scar, and each is assessed independently, with an increasing score assigned to the more pathological condition. Normal skin has a score of 0 . The highest possible VSS total score is 13 (see Table 2)[87].

\begin{tabular}{lll}
\multicolumn{2}{l}{ Table 2. The Vancouver scar scale } \\
\hline $1 \quad$ Vascularity & Normal & 0 \\
& Pink & 1 \\
& Red & 2 \\
& Purple & 3
\end{tabular}

2. Pigmentation Normal 0

Hypopigmenation 1

Hyperpigmentation 2

3. Pliability Normal 0

Supple $\quad 1$

Yielding 2

Firm 3

Ropes 4

Contracture 5

4. Height Flat 0

$<2 \mathrm{~mm} \quad 1$

$2-5 \mathrm{~mm} \quad 2$

$>5 \mathrm{~mm} \quad 3$

In Study II, III and V, the scars were also evaluated for hypertrophic scarring (HTS). In Studies II and III, this was done with the help of two techniques: either a total score on POSAS above the median for the group and/or an individual score higher than 1 on the item thickness (POSAS). For Study V, we also included the combined opinion of two specialists, who had been blinded to the details of the dressings, where both had to agree whether or not the scarring was hypertrophic.

In Study III, the viscoelasticity of the donor site was also investigated using a Cutometer MPA580 (Courage + Khazaka electronic GmbH, Köln, Germany). This instrument is described in detail in Paper III. 


\section{Predictive factors for wound healing and scarring}

As described in the Aims section, we also decided to explore the predictive power of the variables we have examined, and their relation to the healing and scar development variables registered in the studies.

The following factors/variables were studied:

For healing time: Sex, age, infection, presence of autoimmune disease (systemic lupus erythematosus, Crohn's disease, ulcerative colitis, rheumatoid arthritis, and diabetes mellitus), use of systemic cortisone or anticoagulants, smoking habits, BMI (reflecting both the nutritional status and obesity), burn wound depth and extent (size) of donor site or burn.

For scarring (as diagnosed, or registered by POSAS and/or VSS scores): Sex, age, infection, healing times, the depth and extent of the burn, burns on trunk or upper limb, the skin type according to the Fitzpatrick skin type system (see Table 3) [88] and previous grafting. When examining predictive factors for scar outcome in the children (Study V) we used the highest total scores reported with POSAS and VSS. When a child had more than one scar, we chose the one with the highest score (worse scarring), a strategy which has been used in a similar study [51].

\section{Table 3. Fitzpatrick Skin Type Classification Scale Categories}

\begin{tabular}{|c|c|c|}
\hline $\begin{array}{l}\text { Skin } \\
\text { type }\end{array}$ & Skin colour & Characteristics \\
\hline 1 & White; very fair; red or blonde hair; blue eyes; & Always burns, never tans \\
\hline 2 & $\begin{array}{l}\text { White; fair; red or blonde hair; blue, hazel or green } \\
\text { eyes; }\end{array}$ & Usually burns, tans with difficulty \\
\hline 3 & Cream white; fair with any eye or hair colour & $\begin{array}{l}\text { Sometimes mild burn, gradually } \\
\text { tans }\end{array}$ \\
\hline 4 & Brown; typical Mediterranean Caucasian skin & Rarely burns, tans with ease \\
\hline 5 & Dark brown; Middle Eastern skin types & Very rarely burns, tans very easily \\
\hline 6 & Black & Never burns, tans very easily \\
\hline
\end{tabular}




\section{Variable description}

In the ensuing Tables 4 and 5, the dependent and independent/predictive variables used are described. We analysed data for adults (Study I) and children (Study IV) separately, with regards to predictive power, for healing and scarring (donor sites or burns). We also decided to investigate any factor proposed to have an effect on healing and/or scarring, regardless of the type of dermal wound investigated. For this purpose, the healing variable in Study IV, originally a continuous variable was converted to a categorical variable (Table 4).

Predictive variables collected for both adults and children were used, such as: healing times, sex, and infection. As no child presented with: autoimmune disease, use of systemic cortisone, or anticoagulants, or had smoked, these variables were left out. All children were of normal weight for their age (no obesity recorded) and because data were missing for their height in most, the estimate of BMI was not calculated. No data on Fitzpatrick skin type were collected for the adults (Studies I-III). The burn-specific predictive factors: TBSA \%, DDB, and skin grafting were not used for the donor site group for obvious reasons.

We examined age as continuous and also divided age groups into categories (in speared analyses). As there were few patients in each "age-group", the purpose of using "age categories" was to increase group sizes and improve power.

We examined donor site size (factor not used for burn group) as continuous and also divided size groups into categories (in speared analyses) for the same reasons as for the factor age.

In the section Statistical methods we describe the methods used to analyse relations between factors, criteria for inclusion in the models, and the significance levels chosen. 
Table 4. Variables used in the multivariate regression analysis for Healing time

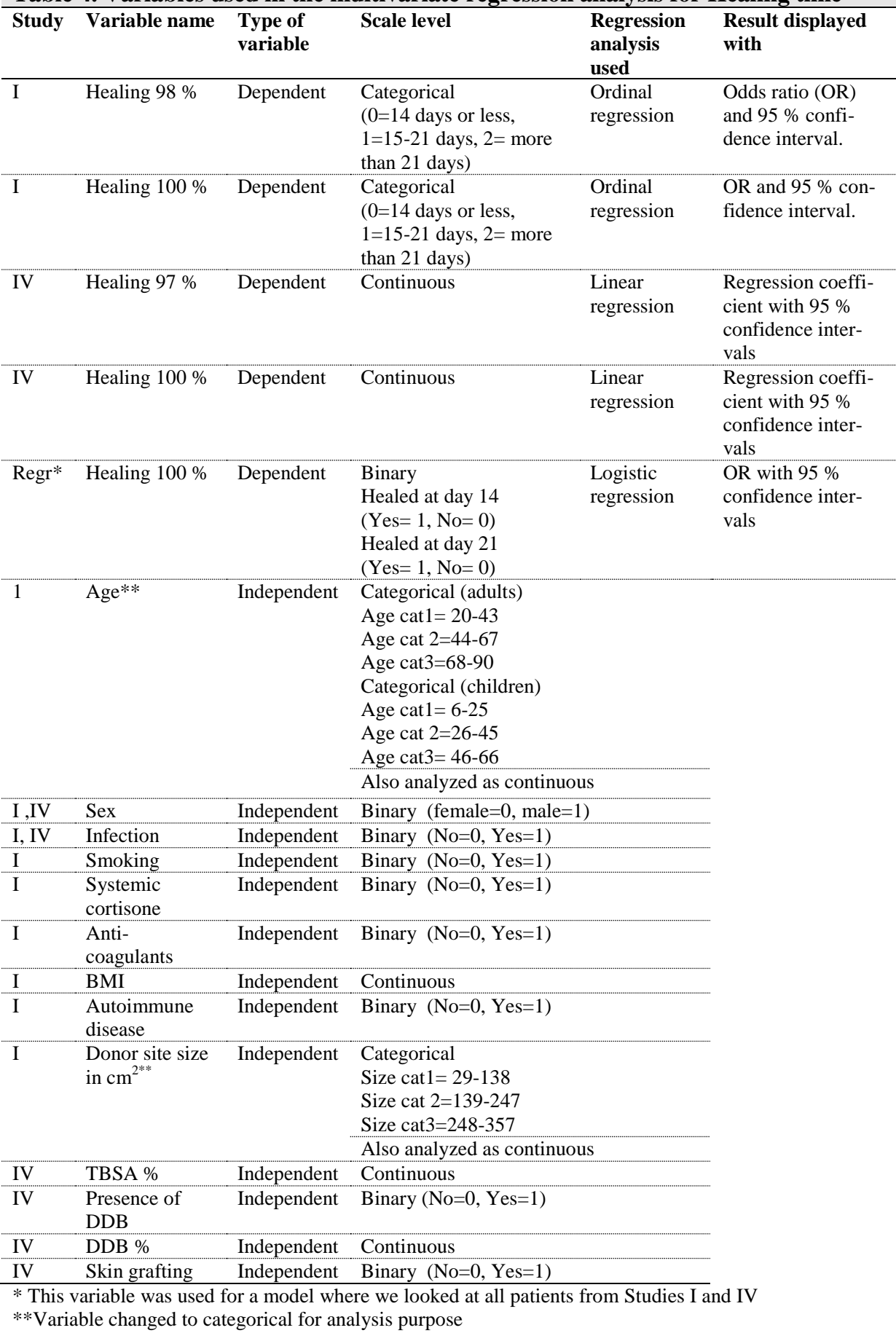


Table 5. Variables used in the multivariate regression analysis for Scarring

\begin{tabular}{|c|c|c|c|c|c|}
\hline Study & Variable name & $\begin{array}{l}\text { Type of } \\
\text { variable }\end{array}$ & Scale level & $\begin{array}{l}\text { Multivariate } \\
\text { analysis used }\end{array}$ & $\begin{array}{l}\text { Result displayed } \\
\text { with }\end{array}$ \\
\hline II & $\begin{array}{l}\text { POSAS Patient } \\
\text { part Total score }\end{array}$ & Dependent & Ordinal & Linear regression & $\begin{array}{l}\text { Regression coeffi- } \\
\text { cient with } 95 \% \\
\text { confidence intervals }\end{array}$ \\
\hline III, V & $\begin{array}{l}\text { POSAS Observ- } \\
\text { er part Total } \\
\text { score }\end{array}$ & Dependent & Ordinal & Linear regression & $\begin{array}{l}\text { Regression coeffi- } \\
\text { cient with } 95 \% \\
\text { confidence intervals }\end{array}$ \\
\hline $\mathrm{V}$ & VSS Total score & Dependent & Ordinal & Linear regression & $\begin{array}{l}\text { Regression coeffi- } \\
\text { cient with } 95 \% \\
\text { confidence intervals }\end{array}$ \\
\hline V & $\begin{array}{l}\text { Presence of } \\
\text { hypertrophic } \\
\text { scarring (HTS) }\end{array}$ & Dependent & $\begin{array}{l}\text { Binary } \\
(\mathrm{No}=0, \mathrm{Yes}=1)\end{array}$ & Logistic regression & $\begin{array}{l}\text { OR and } 95 \% \text { con- } \\
\text { fidence interval. }\end{array}$ \\
\hline $\begin{array}{l}\text { II,III, } \\
\text { V }\end{array}$ & Age* & Independent & $\begin{array}{l}\text { Categorical (adults) } \\
\text { Age cat } 1=20-43 \\
\text { Age cat } 2=44-67 \\
\text { Age cat } 3=68-90 \\
\text { Categorical (children) } \\
\text { Age cat } 1=6-26 \\
\text { Age cat } 2=27-47 \\
\text { Age cat } 3=48-66\end{array}$ & & \\
\hline
\end{tabular}

Also analyzed as continu-

ous

\begin{tabular}{|c|c|c|c|}
\hline $\begin{array}{l}\text { II , III, } \\
\text { V }\end{array}$ & Sex & Independent & Binary $($ female $=0$, male $=1)$ \\
\hline $\mathrm{I}, \mathrm{IV}$ & Infection & Independent & Binary $(\mathrm{No}=0$, Yes $=1)$ \\
\hline I & Healing time & Independent & $\begin{array}{l}\text { Categorical } \\
(0=14 \text { days or less, } 1=15- \\
21 \text { days, } 2=\text { more than } 21 \\
\text { days })\end{array}$ \\
\hline IV & Healing time & Independent & Continuous \\
\hline I & BMI & Independent & Continuous \\
\hline IV & Skin grafting & Independent & Binary $(\mathrm{No}=0, \mathrm{Yes}=1)$ \\
\hline IV & TBSA $\%$ & Independent & Continuous \\
\hline IV & Presence of DDB & Independent & Binary $(\mathrm{No}=0$, Yes $=1)$ \\
\hline IV & DDB \% & Independent & Continuous \\
\hline \multirow[t]{2}{*}{ V } & \multirow[t]{2}{*}{$\begin{array}{l}\text { Fitzpatrick* } \\
\text { skin type }\end{array}$} & \multirow[t]{2}{*}{ Independent } & $\begin{array}{l}\text { Categorical/binary } \\
\text { Skin cat } 1=\text { skin type } 1-3 \\
\text { Skin cat } 2=\text { skin type } 4-6\end{array}$ \\
\hline & & & $\begin{array}{l}\text { Also analyzed as continu- } \\
\text { ous }\end{array}$ \\
\hline V & $\begin{array}{l}\text { Burn on trunk or } \\
\text { upper limb }\end{array}$ & Independent & $\begin{array}{l}\text { Binary } \\
(\mathrm{No}=0, \mathrm{Yes}=1)\end{array}$ \\
\hline
\end{tabular}

*Variable changed to categorical for analysis purpose 


\section{Dressing materials evaluated in this thesis}

In this thesis we compared our current SOC dressings with other dressings of potential interest. When we started this project, we hypothesised that we did not always use the most optimal dressings for donor sites, and that there might be room for improvement. This was based on the observation that numerous patients returning to our outpatient clinic did so with unhealed donor sites long after 21 days postoperatively. Examination of our medical records from 2006 (data not published) showed that 41 out of the 184 patients who had had elective skin grafts returned after 21 days with an unhealed donor site.

\section{Dressing selection in Study I}

For the donor sites investigated in Study I, the current SOC was polyurethane foam (Allevyn $\left.{ }^{\circledR}\right)$, a non-adhesive, foam, absorbent dressing, that can absorb up to ten times its own weight ( $10 \mathrm{gr}$ of fluid/gram of dressing) [89]. It is claimed to preserve moisture as an occlusive dressing, and thus promotes moist wound healing. Allevyn ${ }^{\circledR}$ is multi-layered foam, comprising three layers, a polyurethane contact layer, a middle layer of absorbents, and an outer polyurethane film, the latter of which is claimed to be waterproof. It was used as a single dressing under fixation. The use of Allevyn ${ }^{\circledR}$ at donor sites has been previously reported [9092].

To critically examine our SOC we introduced hydrofibre (Aquacel ${ }^{\circledR}$ ) dressing covered with a semipermeable film (Tegaderm, 3M Health Care, St Paul, Minnesota), which is also claimed to create a moist wound healing environment. The advantages of a moist wound healing environment have been briefly described in the Introduction section of this thesis and will be further addressed in the Discussion section. Aquacel ${ }^{\circledR}$ is a primary non-adhesive wound dressing made from sodium carboxymethylcellulose and is produced as a textile fibre and presented in the form of a fleece held together by a needle bonding process. The dressing has a large fluid-absorption capacity, twice as high as Allevyn ${ }^{\circledR},(20$ gr flu$\mathrm{id} /$ gram of dressing) [89] and interacts with exudates from the wound to form a soft, hydrophilic, gas-permeable gel that provides a micro-environment claimed to facilitate healing. The vertical absorption properties help to maintain the moist area over the wound and reduce the risk of maceration. The use of Aquacel® at donor sites has been reported previously [93-95].

The third dressing we decided to use in these investigations was a biological dressing, a porcine xenograft (Mediskin $\left.{ }^{\circledR}\right)$ that was already in use for donor sites at our burn centre, with good clinical results. Mediskin ${ }^{\circledR}$ consists of meshed frozen epidermis and dermis from pigs. It primarily attaches to the wound bed, but 
is later rejected as re-epithelialisation occurs underneath. The use of porcine xenograft in donor site treatment was first reported in the 1970's [96-98].

\section{Dressing selection Study IV}

The SOC at our department for children with partial thickness burns for at least the last 20 years has been porcine xenografts, as described above. The use of porcine skin in burns is better documented than its use in donor sites [99, 100]. After 2013, the department stopped using Mediskin ${ }^{\circledR}$, and began to use a similar product, EZderm ${ }^{\circledR}$, that is produced by the same company. The EZderm ${ }^{\circledR}$ consists of aldehyde cross-linked dermis from pigs [98] and has the advantage compared to Mediskin ${ }^{\circledR}$, that it can be stored in room temperature.

In 2008-2009 a new synthetic silver-containing dressing was introduced in Sweden; the Mepilex®Ag. It is a silicone foam containing water soluble silver sulphate as a main layer, and a hydrophobic silicone membrane with micropores as a contact layer; the outer layer consists of a waterproof film such as that of the Allevyn ${ }^{\circledR}$ dressing. Mepilex ${ }^{\circledR}$ Ag can absorb about 10 times its own weight [89], as is seen also with Allevyn ${ }^{\circledR}$. The silver component is active for up to seven days, enabling its use without the need for daily dressing changes [101]. With the aim of lowering the bacterial burden in burn wounds and thereby stimulate healing this antimicrobial dressing was selected in Study IV.

In summary, we have investigated four dressings in this thesis, the hydrofibre with film, polyurethane foam with and without silver, and a biological dressing in the form of a porcine xenograft.

\section{Statistical methods}

The choice of research design of the included studies was clinical RCTs, which is the recommended way to evaluate the efficacy of treatment. Studies were analysed on an Intention-to-treat (ITT) basis, with the exception of patients who did not receive the allocated dressing at the initial visit. These patients were excluded from the study and no data was collected.

As the data in this thesis are mainly of a qualitative nature, non-parametric tests have been used primarily. Demographic data about participants are mainly described using median and percentiles or quartiles (where appropriate). When data are displayed with means ranges or standard deviations are used. Probabilities of 0.05 or below were accepted as significant. 
To detect any significant differences between the three study groups in Studies IIII, we used the Kruskal-Wallis one-way analysis of variance (ANOVA) for qualitative data and one-way ANOVA for those judged to be quantitative and normally distributed. If a significant difference was detected, we made a post hoc analysis with Tamhane's T2 test in Study I and for Study II, we used the Benjamini-Hochberg test. To detect differences between the two study groups in Studies IV and V, we used the Mann Whitney $\mathrm{U}$ test for independent samples. In Study V, we examined repeated measurements on the same group (pairwise comparison) and therefore used the Wilcoxon signed rank test. For all studies, we used the Chi squared tests (Fisher's exact test if expected numbers were below five) for nominal data (frequencies) When data contained ties (the same value given many times), the Chi squared test was used as a complement.

To analyse factors that affected scar outcomes in Study II, we used a multivariable regression model. Independent variables (predictors) selected were: age, sex, healing time, type of dressing, and the items from the POSAS evaluation. The cut-off point for inclusion of an item in the model was set at a $\mathrm{p}<0.05$, and the variables were added in a forward stepwise manner, except for: sex, age, and healing time, which were all kept in the model as its baseline.

For the purpose of investigating the relation between healing and scarring outcomes with potential predictive factors, we used multivariable regression models. Linear regression was used when examining continuous dependent variables.

Prior to the analyses normal distribution of residuals, extreme outliers and linear correlation (with scatter plot) were checked. Ordered logistic regression was applied when dependent variables were categorical/ordinal and when three categories were analysed. Ordered logistic analysis was only carried out for variables if they were significant $(\mathrm{p} \leq 0.05)$ in the presiding Chi squared test. Dependent variables of an ordinal type, such as a POSAS or VSS total scores, with more than three categories, were examined with linear regression to enable us to better interpret the results. Logistic regression was used if the dependent variables were binary.

For linear regression models, coefficients with $95 \%$ confidence intervals are presented. Only models with a p-value $\leq 0.05$ are displayed. Odds ratios (OR) with $95 \%$ confidence intervals are used for logistic regressions. In our prediction models, we decided to include only variables that independently had a significant relation with the dependent variables, such as healing times or scarring. With the aim of having a maximum number of variables, not exceeding $10 \%$ of the number of observations in the model, a manual backward elimination of predic- 
tive/independent variables in the models was conducted, excluding the nonsignificant variables first, and then if needed, the remaining variables that were the least significant. Linear regression models were checked for multicollinearity using Variance inflation factor (VIF). A VIF higher than 5 indicates multicollinearity but as the aim of the regression models are "prediction", models are displayed regardless of multicollinearity or variables being non-significant in the model.

For the logistic regression models the Hosmer-Lemeshow test, a goodness of fit test, was used. Small p-values means that the model is a poor fit and only models with a p-value $>0.05$ are displayed. To estimate the coefficient of determination in these models the Nagelkerke's $R^{2}$ was used.

\section{Statistical software}

Study I: Statistical Package for the Social Sciences (SPSS) version 17.0 (SPSS Inc, Chicago, IL, USA).

Study II: STATA version 12.0 (Stata Corp, College Station, Texas, USA)

Study III: STATA version 14.0 (Stata Corp, College Station, Texas, USA)

Study IV: STATA version 15.0 (Stata Corp, College Station, Texas, USA)

Study V and regression analyses: SPSS version 25.0 (IBM Corporation, Armonk, NY, USA)

\section{Ethical considerations}

All studies (I-V) were approved by the Regional Ethics Review Board and conducted in compliance with the Guidelines of International Conference on Harmonisation of Good Clinical Practise, ICH-GCP. Studies III and IV, was registered in the public register: clinicaltrials.gov. Regarding the choice of dressings, they were all CE-marked ${ }^{5}$ in Europe, and used according to their indicated purpose. There were ethical considerations regarding the use of the porcine xenografts that are described in Study IV. Regarding the choice of keeping our SOC for donor sites in the RCT, even though the examination of medical records showed poor healing results, the RCT was done to find evidence for the association between poor' healing outcomes and the dressing.

\footnotetext{
${ }^{5} \mathrm{CE}$ (Conformité Européenne) marking is a certification mark that indicates conformity with health, safety, and environmental protection standards for products sold with the European Economic Area (EEA)
} 


\section{RESULTS}

\section{Study I}

\section{Dressing the split-thickness skin graft donor site: a randomised clinical trial}

A total of 73 donor sites were included in this study; 24 were randomly assigned to Aquacel ${ }^{\circledR}$ (hydrofibre), 25 to Allevyn ${ }^{\circledR}$ (polyurethane foam) and 24 to Mediskin ${ }^{\circledR}$ (porcine xenograft). The three groups compared were similar in distribution of sex, age, BMI, main diagnosis, medication, smoking habits, and size of the donor sites.

Regarding the primary outcome variable: Healing time, the Aquacel ${ }^{\circledR}$ and the Mediskin ${ }^{\circledR}$ showed significantly shorter healing times than the Allevyn ${ }^{\circledR}$ $(\mathrm{p}=0.01)$.

At two weeks (14 days), 15 donor sites were healed in the Aquacel® group, 12 in the Mediskin ${ }^{\circledR}$ group and 6 in the Allevyn ${ }^{\circledR}$ group. At the next, and last visit (day 21) two additional donor sites were healed in the Aquacel® group (a total of 17 donor sites healed), 11 in the Mediskin ${ }^{\circledR}$ group (a total of 23 donor sites healed) and 8 in the Allevyn ${ }^{\circledR}$ group (a total of 14 donor sites healed). This means that in the Aquacel@group four donor sites were not healed at 21 days, one in the Mediskin ${ }^{\circledR}$ group, and nine in the Allevyn ${ }^{\circledR}$ group.

For the secondary outcome: pain, infection, impact on everyday life, ease of use, and costs some additional differences were found. At day 14, pain was significantly higher at dressing changes for the Allevyn ${ }^{\circledR}$ group than for the Aquacel ${ }^{\circledR}$ group $(\mathrm{p}=0.002)$. Aquacel ${ }^{\circledR}$ was reported as significantly easier to apply and remove than the other two dressings on this occasion (Aquacel ${ }^{\circledR}$-Allevyn ${ }^{\circledR}$ $\mathrm{p}=0.001$ and Aquacel ${ }^{\circledR}-$ Mediskin $\left.{ }^{\circledR} \mathrm{I} p=0.002\right)$. Aquacel $\AA$ also took less time to apply and remove than the other two dressings (Aquacel® -Allevyn ${ }^{\circledR} \mathrm{p}=0.03$ and Aquacel ${ }^{\circledR}$-Mediskin ${ }^{\circledR} \mathrm{p}=0.007$ ). Results for secondary outcomes (published and unpublished) are presented in Table 6. 
Table 6. Secondary outcomes in Study I

\begin{tabular}{|c|c|c|c|c|}
\hline & Aquacel® & Allevyn® & Mediskin ${ }^{\circledR}$ & $\mathrm{p}$ values \\
\hline Infection & 4 & 3 & 0 & 0.236 \\
\hline \multicolumn{5}{|l|}{ Pain at day 3} \\
\hline Rest & $0(0-1)$ & $0(0-2.5)$ & $0(0-1)$ & 0.954 \\
\hline Activity & $0(0-2.8)$ & $1(0-3.5)$ & $1(0-3.8)$ & 0.161 \\
\hline \multicolumn{5}{|l|}{ Pain at day 14} \\
\hline Rest & $0(0-0)$ & $0(0-2)$ & $0(0-1)$ & 0.264 \\
\hline Activity & $1(0-2)$ & $1(0-5)$ & $1(0-3.8)$ & 0.258 \\
\hline Dressing change & $1(0-2.5)^{* *}$ & $4(1.5-5)^{* *}$ & $1.5(0-4)$ & $0.009 *$ \\
\hline \multicolumn{5}{|l|}{ Pain at day 21} \\
\hline Rest & $0(0-3)$ & $0(0-0.5)$ & $0(0-0)$ & 0.755 \\
\hline Activity & $0(0-4.5)$ & $0(0-2.5)$ & $0(0-0)$ & 0.245 \\
\hline Dressing change & $0.5(0-1.3)$ & $0(0-4)$ & $0(0-0)$ & 0.185 \\
\hline \multicolumn{5}{|l|}{ Impact on everyday } \\
\hline \multicolumn{5}{|l|}{ life } \\
\hline Day 3 & $0(0-0)$ & $0(0-1)$ & $0(0-1)$ & 0.880 \\
\hline Day 14 & $0(0-0)$ & $1(0-4)$ & $0(0-2.25)$ & 0.051 \\
\hline Day 21 & $0(0-1.5)$ & $0(0-0.5)$ & $0(0-0)$ & 0.265 \\
\hline \multicolumn{5}{|l|}{ Ease of use $(0-5)$} \\
\hline Day 3 & $1(0-1)$ & Not changed & $1(0-2.25)$ & 0.202 \\
\hline Day 14 & $0(0-0) * * *$ & $1(1-3) * * *$ & $1(0-2) * * *$ & $<0.001 *$ \\
\hline Day 21 & $1(0-1)$ & $0(0-2)$ & $0(0-0)$ & 0.077 \\
\hline $\begin{array}{l}\text { Total cost in US dol- } \\
\text { lars }\end{array}$ & 114 & 57 & 261 & $0.001 *$ \\
\hline
\end{tabular}




\section{Study II}

Scarring At Donor Sites After Split-Thickness Skin Graft: A Prospective, Longitudinal, Randomised Trial

The study participants (consisting of patients who were originally recruited in Study I) were evaluated with regards to their scar outcome. The three dressing groups (a total of 29 donor sites), were similar in: sex distribution and age, but, as in the original RCT group, the healing times were significantly longer for the Allevyn ${ }^{\circledR}$ group $(p=0.046)$, than the Aquacel ${ }^{\circledR}$ group $(p=0.018)$, but no other differences were found with regard to healing time.

As for the donor site scar outcome, the Aquacel ${ }^{\circledR}$ group was significantly more satisfied with their scars $(\mathrm{p}=0.03)$. Correction with Benjamin-Hochberg showed that the Aquacel® group scored better on the POSAS than the Allevyn ${ }^{\circledR}(\mathrm{p}=$ $0.03)$ and the Mediskin ${ }^{\circledR}(\mathrm{p}=0.02)$ groups. There were no significant differences between the latter two $(\mathrm{p}=0.47)$.

The multivariable analysis showed that treatment with Mediskin ${ }^{\circledR}$ was associated with a higher overall opinion (less like normal skin) on the POSAS score than the other two dressings. The "pigmentation" item was the only item that affected the overall POSAS scores. 


\section{Study III}

\section{Scarring At Donor Sites After Split-Thickness Skin Graft: The Observer view}

In this study, participants from study II were evaluated regarding the scar outcome from the observer's perspective and compared with the patient's own experience. The group consisted of 17 donor sites, five from the Aquacel® group, six from the Allevyn ${ }^{\circledR}$ and Mediskin ${ }^{\circledR}$ groups. They were similar in age and sex distribution and also, contrary to the two previous studies, in healing time of the donor site. A figure showing the eligibility of patients assessed for the long-term follow ups studies (Study II and III) is shown in Paper III.

Results showed no differences between the groups with regard to any of the items used in POSAS, or firmness and elasticity (measured with the Cutometer ${ }^{\circledR}$ MPA 580). When regrouping participants (regardless of previous dressing treatment) according to their healing time (categorised as follows: $0=14$ days or shorter, $1=15$ to 21 days, and $2=$ longer than 21 days) there were no differences for any of the POSAS items or Cutometer ${ }^{\circledR}$ values. 


\section{Study IV}

Superiority of silver-foam over porcine xenograft dressings for treatment of scalds in children: A prospective randomised controlled trial.

A total of 58 children were included in this study, 30 randomly assigned to porcine xenograft (EZderm $\left.{ }^{\circledR}\right)$ and 28 to silver-foam (Mepilex $\left.{ }^{\circledR} \mathrm{Ag}\right)$. The two treatment groups were similar in sex distribution, age, weight, previous illnesses, TBSA\% burned, and depth of burn.

Regarding the primary outcome Healing time, the median (10th-90th percentiles) time to $97 \%$ healing for the silver-foam group was 9 (7-23) days compared to 15 (9-29) days in the porcine xenograft group $(\mathrm{p}=0.004)$. The median time to complete healing for the silver-foam group was 15 (9-29) days and for the porcine xenograft group $20.5(11-42)$ days $(\mathrm{p}=0.010)$, this significance remained when we excluded children with TBSA \% more than $10 \%$, and $20 \%$, respectively ( $\mathrm{p}=0.045$ and $\mathrm{p}=0.034$, respectively).

The silver-foam dressing group also showed better outcomes in time for application and removal and number of dressing changes required $(p=0.03$ and $p$ $=0.03$, respectively). For the secondary outcome variables: Infection, Pain, Duration of hospital stay and need for operations, the results were similar between groups. See Table 7 below.

Table 7. Secondary outcomes in Study IV

\begin{tabular}{lccc}
\hline & Porcine xenograft & Silver-foam dressing & p values \\
Operations & 4 & 2 & 0.671 \\
Infection & 9 & 10 & 0.643 \\
Antibiotic use & 11 & 12 & 0.630 \\
Duration of hospital stay (days) & $2(0-13)$ & $3(0-8)$ & 0.944 \\
Number of dressing changes & $5(3-9)$ & $4(3-8)$ & $0.031^{*}$ \\
Dressing time (minutes) & $20(10-50)$ & $20(10-30)$ & $0.030^{*}$ \\
\hline
\end{tabular}

Data are number, or median (10-90 percentiles). * Significant values 


\section{Study V}

Burn scar outcome at six and 12 months after injury in children with partial thickness scalds: did the dressing treatment matter?

A total of 39 children from Study IV returned for scar follow up at six months and 34 for the 12 months' follow up.

As in the original RCT group (Study IV), the two treatment groups in this follow up study of scars were similar in sex distribution, age, weight, previous illnesses, TBSA\% burned, and depth of burn. Unlike the original RCT study (Study IV) they were also similar in healing times.

The results for the evaluation of burn scar outcomes, at six and 12 months' follow up, did not show any differences between dressing groups regarding POSAS or VSS total scores, or the incidence of hypertrophic scarring or dyspigmentation.

For the 27 children returning for both scar follow ups, there was a significant reduction $(\mathrm{p}<0.001)$ in total scores for both POSAS and VSS between six and 12 months, indicating that scars got better with time according to the Observer.

There was a significant correlation between days required to complete healing and final scar outcome, in which longer healing times gave higher scar scores and increased the risk of HTS. 


\section{Results for regression analyses looking at predictive factors for healing and scarring outcomes}

Predictive factors for healing times, burn scar scores and hypertrophic scarring were analysed using regression analysis.

All variables and $\mathrm{p}$ values including coefficients or OR and $95 \%$ confidence intervals are displayed in result tables. Only models showing significance $(\mathrm{p}<0.05)$ are shown.

\section{Healing time outcome models}

\section{Study I $(n=73)$}

When using the Chi squared test for all potential predictive variables; age categories, sex, infection, smoking, the use of cortisone or anticoagulants, BMI, autoimmune disease and donor site size, none of the variables were found to be affecting the time to healing of the donor sites (time categorised: $0=14$ days or shorter, $1=15$ to 21 days, and $2=$ longer than 21 days). We therefore decided to create two new binary variables, healed at day 14 , and 21 , and we looked for associations between the dependent variable (healing at day 14 or 21) and the predictive variables listed above.

\section{Healed at day 14}

When analysing potential predictors for donor sites that had healed at day 14 , the logistic regression showed that men had a 3.6 times higher chance (OR $3.695 \%$ CI 1.14 to 11.34 , p value $=0.029$ ) of having their donor site healed at day 14 than women. No other variable was independently related to complete healing of the donor site at day 14 .

\section{Healed at day 21}

When analysing potential predictors for donor site healed at day 21 , none of the variables turned out to be significant. 


\section{Study IV (n=58)}

When analysing potential predictors for longer healing times for the 58 children with scalds in Study IV, there were three variables that were independently associated with healing time (97\% healed); larger TBSA \%, presence of DDB and skin grafting, all prolonged healing. When adding the significant variables into the model, variable DDB and skin grafting remained significant (Table 8).

When looking at complete healing (100\% healed) of the burn, the same three variables remained significant and the variable, infection, also had a significantly negative impact on healing, but as with the former model, only the presence of DDB and skin grafting remained significant when adding the variables to the model.

When we excluded children who had had skin grafts $(n=6)$ or outliers (two with healing times beyond 42 days), TBSA $\%$ and DDB remained as independently related variables, but only the presence of DDB remained significant when the variables were added together (Appendices 1 and 2).

As the presence of DDB had an impact on healing time in all groups and we had data to show the percentages of DDB in all children from the Lund and Browder charts, an examination of this variable was done independently to see how much each per cent of DDB affected the number of days to complete healing.

When looking at all children (58), each per cent of DDB increased the number of days to $97 \%$ healing with 2.4 days $(95 \%$ CI 0.77 to $3.92 \mathrm{p}=0.004)$ and to complete healing with 4.9 days (95 CI \% 3.4 to 6.6 p $<0.001$ ), respectively. For the group that did not have skin grafts the results were similar: for $97 \%$ healing each per cent added 2.5 days (95\% CI 1.0 to $4.0 \mathrm{p}=0.001$ ) and for complete healing 4.6 days ( $95 \%$ CI 2.8 to $6.5 \mathrm{p}<0.001)$, respectively.

Sex and age were not found to be significant in all models, regardless if age was used as a categorical or a continuous variable.

Calculation of VIF showed no signs of multicollinearity in the healing models seen in Table 8 (VIFs below 1.44). 
Table 8. Predictors for longer healing times in Study IV for all children

\begin{tabular}{|c|c|c|c|c|}
\hline & & Coefficient & $95 \% \mathrm{CI}$ & $\mathrm{p}$ value \\
\hline \multicolumn{5}{|l|}{ Independently related } \\
\hline \multirow[t]{3}{*}{ (Days to $97 \%$ healing) } & TBSA $\%$ & 0.62 & 0.08 to 1.17 & 0.026 \\
\hline & DDB & 8.99 & 3.69 to 14.28 & 0.001 \\
\hline & Skin grafting & 18.03 & & $<0.001$ \\
\hline \multicolumn{5}{|l|}{ In a model } \\
\hline \multirow[t]{3}{*}{ (Days to $97 \%$ healing) } & TBSA $\%$ & -0.08 & -0.64 to 0.48 & 0.769 \\
\hline & DDB & 6.718 & 1.35 to 12.82 & $0.015 *$ \\
\hline & Skin grafting & 15.66 & 7.01 to 24.31 & 0.001* \\
\hline Model & & & & $<0.001$ \\
\hline Adjusted R square & & & & 0.314 \\
\hline \multicolumn{5}{|l|}{ Independently related } \\
\hline \multirow[t]{4}{*}{ (Days to complete healing) } & TBSA $\%$ & 1.37 & 0.78 to 1.96 & $<0.001$ \\
\hline & DDB & 14.30 & 8.39 to 20.22 & $<0.001$ \\
\hline & Skin grafting & 21.67 & 11.73 to 31.61 & $<0.001$ \\
\hline & Infection & 8.27 & 1.14 to 15.41 & 0.024 \\
\hline \multicolumn{5}{|l|}{ In a model } \\
\hline \multirow[t]{4}{*}{ (Days to complete healing) } & TBSA $\%$ & 0.592 & -0.02 to 1.21 & 0.059 \\
\hline & DDB & 9.556 & 3.76 to 15.35 & $0.002 *$ \\
\hline & Skin grafting & 11.649 & 1.69 to 21.61 & $0.023 *$ \\
\hline & Infection & 2.880 & -3.08 to 8.84 & 0.337 \\
\hline Model & & & & $<0.001$ \\
\hline Adjusted R square & & & & 0.445 \\
\hline
\end{tabular}

* Significant in the model

\section{Healing times Study I and IV.}

As part of the analysis we chose to examine all participants from study I and IV with regards to potential predictors of dermal wound healing (both donor sites and partial thickness burns). For this purpose, healing times for burns in study IV were reorganised to: $0=14$ days or shorter, $1=15$ to 21 days, and $2=$ longer than 21 days. Unpublished data on time to complete (100\%) healing of donor sites was used for this purpose.

A total number of 127 study participants had data on complete $(100 \%)$ healing.

Neither sex, nor infection were independently or together significantly related to time to complete healing. 


\section{Scar outcome models}

\section{Study II}

POSAS Total score - Patient's opinion $(n=29)$

When analysing potential factors for the patient's opinion on donor site scarring, we found that only sex was independently associated with subjective opinion. Female patients provided higher POSAS values, meaning that they were less satisfied with the outcome (Table 9). The remaining variables analysed were; age, healing time, infection (at donor site) and BMI, and none was significant.

\section{Study III}

POSAS Observer - Study III

When analysing potential factors for the observer's opinion on scarring at donor sites, we had a similar finding; only sex was independently associated. Female patients had, according to the observer, more severe scarring (higher scores). Sex explained about $25 \%$ of the variation in total scores (Table 9). There was a tendency $(p=0.053)$ for older patients to rate higher than those of a younger age (coefficient $2.10,95 \%$ CI -0.03 to 4.23 ).

The remaining variables analysed; age, healing time, infection (at donor site) and BMI were not significant.

Table 9. Predictor models of scarring in Study II, III

\begin{tabular}{|c|c|c|c|c|}
\hline & & Coefficient & $95 \% \mathrm{CI}$ & $\mathrm{p}$ value \\
\hline \multicolumn{5}{|l|}{ Study II $(n=29)$} \\
\hline \multicolumn{5}{|c|}{ POSAS Patient total score } \\
\hline & $\operatorname{Sex}(1=$ male $)$ & -7.36 & -12.62 to -2.12 & 0.008 \\
\hline Model, R Square & & & & 0.235 \\
\hline \multicolumn{5}{|l|}{ Study III (n= 17) } \\
\hline \multicolumn{5}{|c|}{ POSAS Observer total score } \\
\hline & $\operatorname{Sex}(1=$ male $)$ & -3.129 & -6.15 to -0.11 & 0.043 \\
\hline Model, R Square & & & & 0.246 \\
\hline
\end{tabular}




\section{Study V}

For all scar analyses of children in Study V, we used the measure days to complete $(100 \%)$ healing of the burn (healing time in days).

\section{POSAS scores at six months}

\section{POSAS Observer total scores at six months in Study $V$}

There were several factors independently related to higher scar scores at the six months' follow up; longer healing times, previous infection, larger TBSA $\%$, DDB, and skin grafting (Table 10). Sex, age, burns on trunk or upper limb and Fitzpatrick skin type (regardless of being used as categorical or continuous variables) were not found to be related to POSAS scar scores.

\section{Prediction model for six months' scar scores}

Healing time, DDB and skin grafting remained significant predictors when added into the model. The variables together explained $55 \%$ of the variation in the $\mathrm{Ob}-$ server's scores on the POSAS. As the variables TBSA \% and infection were the least significant, they were excluded from the model (maximum of three variables) (Table 10). Exclusion of the outliers (two children with healing times that exceeded 42 days) did not alter the findings.

Exclusion of the six children with skin grafts showed that healing time, infection, and DDB were significantly related to higher scar scores. When the variables were added into the model, only infection remained significant. The variables together explained $44 \%$ of the variation in POSAS Observer's scores for children who had healed spontaneously (Appendix 3).

\section{POSAS scores at 12 months}

\section{POSAS Observer total scores at 12 months in Study V}

Having longer healing times, larger TBSA\%, DDB, and skin grafting were independently related to higher scar scores at the 12 months' follow up (infection was not to be significant) (Table 10). Sex, age, burns on trunk or upper limb and Fitzpatrick skin type (whether being used as a categorical or a continuous variables) were not found to be related to POSAS scar scores. 
Prediction model for 12 months' scar scores

When the significant variables were added into the model, none remained significantly related to the scar score; even though the model itself was significant $(p=0.001)$. As DDB was the least significant of the four significant variables, it was excluded from the model (maximum of three variables). There was a tendency $(\mathrm{p}=0.051)$ in the model for longer healing time to result in higher scar scores (Table 10). Excluding the outliers showed similar results as for the entire group, except for healing time, which remained significant ( $\mathrm{p}=0.047$ ). Excluding children who had had skin grafts, the only variable significantly related to scar scores was healing time. This variable alone explained $27 \%$ of the variation in the POSAS Observer's scores for children who had healed spontaneously (Appendix 4).

Calculation of VIF showed no signs of multicollinearity in the POSAS models seen in Table 10 (VIFs below 1.68)

\begin{tabular}{|c|c|c|c|c|c|c|}
\hline & \multicolumn{3}{|c|}{6 months $(n=39)$} & \multicolumn{3}{|c|}{12 months $(n=34)$} \\
\hline & Coefficient & $95 \%$ CI & p value & Coefficient & $95 \%$ CI & p value \\
\hline \multicolumn{7}{|l|}{ Independently related } \\
\hline Healing time (days) & 0.38 & 0.19 to 0.57 & $<0.001$ & 0.25 & 0.12 to 0.38 & $<0.001$ \\
\hline Infection & 8.41 & 3.46 to 13.36 & 0.001 & \multicolumn{2}{|c|}{ Non-significant } & \\
\hline TBSA $\%$ & 0.68 & 0.26 to 1.09 & 0.002 & 0.62 & 0.23 to 1.02 & 0.003 \\
\hline DDB & 9.10 & 4.55 to 13.66 & $<0.001$ & 6.04 & 1.89 to 10.19 & 0.006 \\
\hline Skin grafting & 13.38 & 7.27 to 19.49 & $<0.001$ & 8.29 & 2.96 to 13.61 & 0.003 \\
\hline \multicolumn{7}{|l|}{ In a model } \\
\hline Healing time (days) & 0.18 & 0.02 to 0.34 & $0.030^{*}$ & 0.16 & -0.00 to 0.32 & 0.051 \\
\hline Infection & \multicolumn{2}{|c|}{ Excluded in this model } & & \multicolumn{2}{|c|}{ Non-significant } & \\
\hline TBSA $\%$ & \multicolumn{2}{|c|}{ Excluded in this model } & & 0.29 & -0.16 to 0.73 & 0.196 \\
\hline DDB & 5.08 & 0.89 to 9.26 & $0.019 *$ & \multicolumn{2}{|c|}{ Excluded in this model } & \\
\hline Skin grafting & 7.91 & 2.06 to 13.76 & $0.009 *$ & 2.76 & -3.54 to 9.05 & 0.379 \\
\hline Model & & & $<0.001$ & & & 0.001 \\
\hline Adjusted R Square & & & 0.548 & & & 0.342 \\
\hline
\end{tabular}

*Significant in the model

\section{VSS scores at six months}

\section{VSS total scores at six months in Study V}

The same five predictors as for the POSAS scores remained independently related to the total VSS scores at six months; longer healing times, previous infection, larger TBSA\%, DDB, and skin grafting (Table 11). Sex, age, burns on trunk or 
upper limb and Fitzpatrick skin type (regardless of being used as categorical or continuous variables) were not found to be related to VSS scar scores.

\section{Prediction model for six months' scar scores}

When adding the significant variables into the model, only DDB remained significantly related to the VSS scar score. The three variables together explained 44\% of the variation in the Observers' scores (Table 11). Because infection and TBSA $\%$ were the least significant of the five variables, they were excluded from the model (maximum of three variables). The exclusion of outliers showed similar results as those for the entire group of 39 children, but no variable turned out to be significant when added into the model.

When repeating the analysis for children who had not required skin grafts $(\mathrm{n}=$ 33) the variables of healing time and DDB were independently related. Adding them into the model showed that only healing time remained significantly related to the scar scores for children who had healed spontaneously (Appendix 5).

\section{VSS scores at 12 months}

\section{VSS total scores at 12 months in Study V}

Longer healing times, larger TBSA\%, DDB, and skin grafting remained independently related to the total VSS scores at 12 months' follow up. Sex turned out to be significantly related to scar scores; in which boys had scored higher than girls (Table 11). Age, burns on trunk or upper limb and Fitzpatrick skin type (regardless of being used as categorical or continuous variables) remained nonsignificant.

\section{Prediction model for 12 months' scar scores}

When adding variables into the model, only healing time remained a significant predictor. The variables together explained $39 \%$ of the variation in VSS scores (Table 11). As TBSA \% and sex were the least significant of the five variables, they were excluded from the model (maximum of three variables).

Excluding children who had had skin grafts, the factors of longer healing times and male sex were independently related to higher scar scores at the 12 months' follow up; only healing time remained significant when added into the model (Appendix 5).

Calculation of VIF showed no signs of multicollinearity in the VSS models seen in Table 11 (VIFs below 1.71) 
Table 11. Predictors for scarring at 6 and 12 months for all children in Study V using VSS scores

\begin{tabular}{|c|c|c|c|c|c|c|}
\hline & \multicolumn{3}{|c|}{6 months $(n=39)$} & \multicolumn{3}{|c|}{12 months $(n=34)$} \\
\hline & Coefficient & $95 \% \mathrm{CI}$ & p value & Coefficient & $95 \% \mathrm{CI}$ & p value \\
\hline \multicolumn{7}{|l|}{ Independently related } \\
\hline Healing time (days) & 0.13 & 0.08 to 0.19 & $<0.001$ & 0.12 & 0.07 to 0.18 & $<0.001$ \\
\hline Infection & 2.44 & 0.34 to 4.55 & 0.024 & \multicolumn{3}{|c|}{ Non-significant } \\
\hline TBSA $\%$ & 0.26 & 0.10 to 0.43 & 0.003 & 0.21 & 0.02 to 0.39 & 0.030 \\
\hline DDB & 3.65 & 1.85 to 5.45 & $<0.001$ & 2.70 & 0.86 to 4.55 & 0.005 \\
\hline Skin grafting & 4.24 & 1.60 to 6.90 & 0.003 & 3.23 & 0.77 to 5.68 & 0.012 \\
\hline $\operatorname{Sex}($ male $=1)$ & \multicolumn{3}{|c|}{ Non-significant } & 2.00 & 0.02 to 3.98 & 0.047 \\
\hline \multicolumn{7}{|l|}{ In a model } \\
\hline Healing time (days) & 0.07 & -0.00 to 0.14 & 0.053 & 0.09 & 0.02 to 0.16 & $0.013 *$ \\
\hline Infection & \multicolumn{3}{|c|}{ Excluded in this model } & \multicolumn{3}{|c|}{ Non-significant } \\
\hline TBSA $\%$ & \multicolumn{3}{|c|}{ Excluded in this model } & \multicolumn{3}{|c|}{ Excluded in this model } \\
\hline DDB & 2.27 & 0.43 to 4.12 & $0.017 *$ & 1.32 & -0.48 to 3.12 & 0.145 \\
\hline Skin grafting & 2.00 & -0.58 to 4.58 & 0.124 & 0.81 & -1.71 to 3.33 & 0.517 \\
\hline Sex $($ male $=1)$ & \multicolumn{3}{|c|}{ Non-significant } & \multicolumn{3}{|c|}{ Excluded in this model } \\
\hline Model, & & & $<0.001$ & & & $<0.001$ \\
\hline Adjusted R Square & & & 0.444 & & & 0.392 \\
\hline
\end{tabular}

*Significant in the model

\section{Hypertrophic scarring in Study V}

Children who had healed within 14 days showed no hypertrophic scarring. Five of the six children who had had skin grafts showed hypertrophic scarring at the grafted areas. The 15 children that showed HTS at the six months' follow up had persistent HTS at the 12 months' follow up, which was in contrast to the findings of Study V for POSAS and VSS scores that were significantly lower at 12 months than at six months. All children who had hypertrophic scars had been prescribed pressure garments within the first two months after injury. None of the children with Fitzpatrick skin type 4-6 showed HTS (there were few observations, however).

The predictive factors for scarring, as registered with POSAS and VSS, also remained independently significant for hypertrophic scarring; healing time, DDB, TBSA \%, infection, and skin grafting (Table 12). Sex, age, burns on trunk or upper limb and Fitzpatrick skin type (regardless of being used as categorical or continuous variables) were not found to be related to HTS. 


\section{Prediction models for six months' HTS}

The model could perfectly predict non-HTS using the variable of skin grafting (all observed non-HTS also predicted by the model). Converting the healing time variable to "not healed by day 14 " showed that the model could perfectly predict HTS also (all observed HTS were also predicted by the model). For this reason, these variables could not be analysed and were excluded from the models even though they were perfect predictors.

As TBSA \% was the least significant (maximum of three variables) it had to be excluded. Adding significant variables into the model showed that only infection remained a significant predictor. Having had a previous infection increased the risk of HTS at the six months' follow up by more than nine times. Excluding outliers showed similar results as those of the entire group of 39 children.

For the children who did not have grafts, healing time and infection remained significantly related to HTS, when added into the model only healing time remained a significant predictor. For each day required to heal, the risk of HTS increased by $12 \%$ (Appendix 6).

\section{Prediction models for 12 months' HTS}

At the 12 months' follow up, only healing time and DDB remained significant. Converting healing time to "not healed by day 14 " showed that having a healing time that exceeded 14 days increased the risk of HTS by more than 15 times (Table 12). Skin grafting remained a perfect predictor (all observed non-HTS had been predicted in the model). Adding the variables of healing time and DDB into the model showed a significant Hosmer and Lemenshow goodness of fit test $(p=0.007)$. Therefore, we used the converted healing time variable of "not healed by day 14" instead in the model, and the converted variable was the only significant predictor. Not being healed by day 14 increased the risk of HTS by more than 10 times (Table 12). Excluding outliers showed similar results as those of the entire group of 34 children.

For the children who did not have grafts, the only significant predictor of HTS was longer healing time (Appendix 6). 
Table 12. Predictors for HTS at 6 and 12 months for all children 6 months $(n=39)$

12 months $(\mathrm{n}=34)$

\begin{tabular}{|c|c|c|c|c|c|c|}
\hline & OR & $95 \% \mathrm{CI}$ & p value & OR & $95 \% \mathrm{CI}$ & p value \\
\hline \multicolumn{7}{|l|}{ Independently related } \\
\hline Healing time (days) & 1.13 & 1.04 to 1.23 & 0.006 & 1.18 & 1.04 to 1.32 & 0.008 \\
\hline Not healed by day 14 & \multicolumn{3}{|c|}{$\begin{array}{l}\text { Perfect prediction of HTS } \\
\text { (not possible to analyse) }\end{array}$} & 15.56 & 1.69 to 143.17 & 0.015 \\
\hline Infection & 10.00 & 2.19 to 45.64 & 0.003 & \multicolumn{3}{|c|}{ Non-significant } \\
\hline TBSA $\%$ & 1.24 & 1.01 to 1.54 & 0.045 & \\
\hline DDB & 6.66 & 1.47 to 30.21 & 0.014 & 6.86 & 1.43 to 33.01 & 0.016 \\
\hline Skin grafting & \multicolumn{3}{|c|}{$\begin{array}{l}\text { Perfect prediction of non HTS } \\
\text { (not possible to analyse) }\end{array}$} & & & \\
\hline \multicolumn{7}{|l|}{ In a model } \\
\hline Healing time (days) & 1.10 & 0.99 to 1.23 & 0.070 & 10.46 & 1.05 to 103.82 & $0.045 * *$ \\
\hline Infection & 9.24 & 1.40 to 60.93 & $0.021 *$ & \multicolumn{3}{|c|}{ Non-significant } \\
\hline TBSA \% & \multicolumn{3}{|c|}{ Excluded in this model } & \multicolumn{3}{|c|}{ Non-significant } \\
\hline DDB & 3.56 & 0.50 to 25.60 & 0.207 & 4.28 & 0.77 to 23.85 & 0.097 \\
\hline Model. & & & $<0.001$ & & & 0.002 \\
\hline \multicolumn{3}{|l|}{ Model prediction $\%$} & 79.5 & & & 73.5 \\
\hline \multicolumn{3}{|c|}{ Nagelkerke R Square } & 0.557 & & & 0.400 \\
\hline \multicolumn{3}{|c|}{ Hosmer-Lemenshow goodness of fit } & 0.104 & & & 0.609 \\
\hline
\end{tabular}

* Significant in the model ** Converted variable "Not healed by day 14".

\section{Deep dermal burns}

A diagnosis of DDB was a significant predictor of POSAS and VSS scores at both six and 12 months' follow up, and for HTS. As data on percentage body surface area of DDB were available for all children, separate analyses were made looking at the relation between DDB \% and scar outcomes. Each percentage body surface area of DDB had a significant impact on all scar score outcomes. Each percentage body surface area of DDB increased the risk of HTS by four times (Table 13).

Table 13. Percentage of DDB as a predictor of scar outcomes

\begin{tabular}{|c|c|c|c|c|c|c|}
\hline & \multicolumn{3}{|c|}{6 months $(n=39)$} & \multicolumn{3}{|c|}{12 months $(n=34)$} \\
\hline & Coefficient & $95 \% \mathrm{CI}$ & p value & Coefficient & $95 \% \mathrm{CI}$ & $p$ value \\
\hline \multicolumn{7}{|l|}{ POSAS } \\
\hline DDB $\%$ & 2.39 & 1.25 to 3.54 & $<0.001$ & 1.84 & 0.77 to 2.90 & 0.001 \\
\hline \multicolumn{7}{|l|}{ VSS } \\
\hline \multirow[t]{2}{*}{ DDB $\%$} & 0.97 & 0.52 to 1.42 & $<0.001$ & 0.84 & 0.37 to 1.31 & 0.001 \\
\hline & OR & $95 \%$ CI & p value & OR & $95 \%$ CI & p value \\
\hline \multicolumn{7}{|l|}{ HTS } \\
\hline DDB $\%$ & 4.18 & 1.71 to 10.21 & 0.002 & 4.00 & 1.55 to 10.32 & 0.004 \\
\hline
\end{tabular}




\section{DISCUSSION}

In this thesis, I have studied factors that affect wound healing, and those that could lead to long-term scarring. The two wound models chosen were split thickness skin graft donor sites and partial thickness scalds in children. Different types of dressings were studied to investigate their effect on healing and scarring, using randomised controlled clinical trials with follow-up that ranged between one and eight years.

\section{Wound healing - donor sites}

\section{Study I (Hydrofibre/Aquacel®)}

In Study I (on split thickness donor sites) the hydrofibre (Aquacel®) covered with film and porcine xenograft (Mediskin $\left.{ }^{\circledR}\right)$ provided shorter healing times than our standard of care dressing, which was, at that time, polyurethane foam (Allevyn $\left.{ }^{\circledR}\right)$. As a result of this, the ease of application, and lower cost, we implemented the hydrofibre (Aquacel $\left.{ }^{\circledR}\right)$ into our clinical practice as the new standard of care.

To the best of our knowledge, there are four RCTs examining the Aquacel® dressing as a donor site dressing and they were done by Barnea et al. in 2004 [93], Dornseifer et al. in 2011 [94], Brölmann et al. in 2013 [95] and Brenner et al. in 2015 [92]. See Table 14 where the data from our Study I is also presented.

In these studies, the depths of harvested grafts and the locations of donor sites were similar, and also comparable to those of Study I. However, donor sites differed considerably in average size (from $37.5 \mathrm{~cm}^{2}$ to $233 \mathrm{~cm}^{2}$ ), as did the healing criteria used, which made a more detailed comparison difficult.

\section{Healing time}

In the study by Barnea et al. [93] healing was evaluated at days three, seven, 10, and 14. The donor site treated with Aquacel ${ }^{\circledR}$ healed up to seven days earlier than its comparator, paraffin gauze, and was found to be superior overall. The mean percentage of re-epithelialisation at day 15 was about $96 \%$ at donor sites treated with Aquacel ${ }^{\circledR}$ compared with $83 \%$ at day 14 in in our Study I. Dornseifer et al. [94] evaluated Aquacel ${ }^{\circledR}$ at day 10 in which $54.5 \%$ of the donor site halves that had been treated with Aquacel ${ }^{\circledR}$ were healed, similarly to the to $71 \%$ that we found at day 14 in our Study I. The comparator, polyurethane film, was considered to be superior, however, as $86.4 \%$ healing was seen at day 10. In the 
study by Brölmann et al. [95] the Aquacel ${ }^{\circledR}$ group had a median time to complete healing of 22 days, similar to the 21 days seen in our Study I. They concluded that of the six comparators, hydrocolloids were superior because they had the shortest healing time of all, with a median of 16 days. Brenner et al. [92], on the other hand, showed a short mean healing time of only 8 days for the Aquacel® group. The short healing time was assumed to be related to the fact that the study participants were young and healthy children. Brenner et al. concluded that Aquacel ${ }^{\circledR}$ and Kaltostat ${ }^{\circledR}$ (with 0.5 days shorter healing time than Aquacel $®$ ) were suitable for dressings at donor sites, but Kaltostat ${ }^{\circledR}$ was preferred, as it is less costly.

\section{Infection rates}

The infection rates reported at donor sites treated with Aquacel ${ }^{\circledR}$ in these four studies were all lower than those we saw in Study I (17 \%). Barnea et al. reported no infections compared with Brenner et al. (5\%), Dornseifer et al.(6\%) and Brölmann et al. (15\%), respectively, the latter two did not state the criteria for the assessment of infection or the incidence of microbial swabbing [92-95].

\section{Pain scores}

In our study (Study I) NRS 0-10 was used, whereas Barnea et al. and Brölmann et al. used a Visual Analogue Scales (VAS) [93, 95]. Dornseifer et al.used a Likert scale from 0 - 5 [94] and Brenner et al. FLACC and the Wong Baker faces [92]. All but the study by Barnea et al. showed similar results to those found in our Study I; consistently low pain scores for the area treated with Aquacel® (median scores $\leq$ of 1 ). Barnea et al. reported VAS values of up to 2.5 and although higher, they are still in the low range [93].

\section{Dressing application technique}

It is noteworthy that in none of the above described RCTs was the Aquacel@ applied under a semi-occlusive secondary dressing, such as the Tegaderm ${ }^{\circledR}$ used in our Study I, but a dry gauze was used instead. The Tegaderm ${ }^{\circledR}$ applied on top of the Aquacel® helped to keep the wound moist by blocking $98 \%$ of the evaporation [102]. In 2010, Blome-Eberwein et al. [103] compared Aquacel ${ }^{\circledR}$ Ag covered with film (referred to as "gelled") with Aquacel ${ }^{\circledR}$ Ag covered with gauze (adherent) (Table 14). As the Aquacel ${ }^{\circledR} \mathrm{Ag}$ (including silver) was used, the results may have been affected by the exposure of the wound to the silver. Interestingly, though, the design and results for the "gelled" variant were similar to those seen in our Study I, and, the "gelled" version resulted in significantly more healed donor sites at day 14 than the dry version. This supports our use of a semiocclusive technique. 


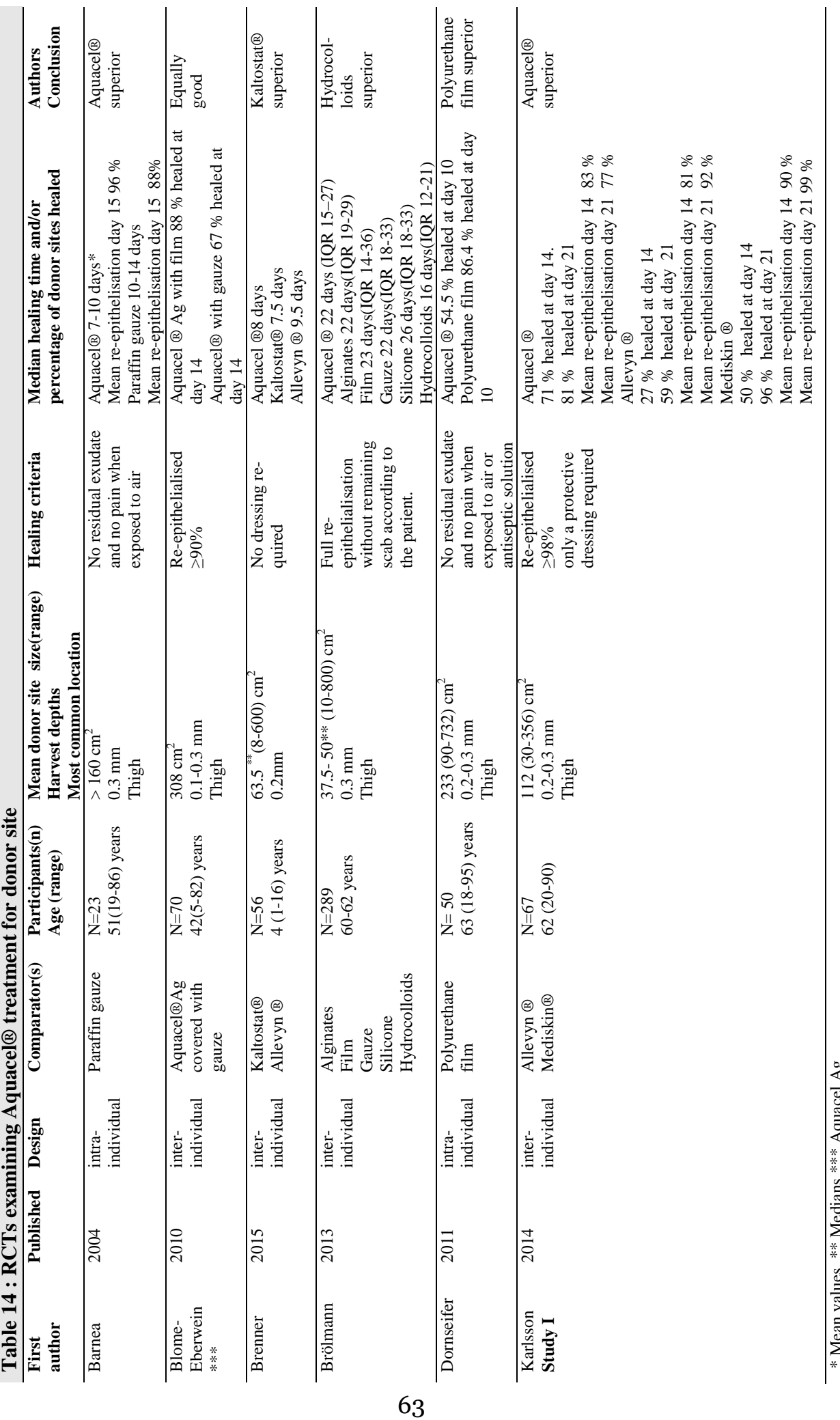




\section{Study I (Porcine xenografts)}

The use of porcine xenograft (PX) provided the most amount of healed donor sites at 21 days. As the PX used in the study was meshed and therefore allowed fluid to come out of the wound, we think that it did not completely fulfil the criteria of a moist-wound dressing [104]. As we were unable to find any RCTs using porcine xenografts for the dressing of donor sites, the studies reported below may be considered to be of lower quality.

We found five studies that examined the use of PX dressings at donor sites: Salisbury et al. [96] and Chang et al. in 1973 [105], Breach et al. in 1979 [97]and Vanstraelen [98] and Gao et al. in 1992 [106]. Only Vanstraelen reported the type of the PX used (EZderm®) [98]. In Study I Mediskin ${ }^{\circledR}$ was used. See Table 15 where the data from our Study I is also presented.

\section{Healing time}

Healing criteria were described only by Gao et al., as spontaneous detachment of the PX dressing and complete re-epithelialisation [106]. Comparisons of healing are therefore difficult. Complete healing in all donor sites were reported at day 10 by Breach et al.[97], whereas Chang et al. reported 5-14 days for the PX, which is 3-7 days shorter than the comparator Xeroform ${ }^{\circledR}$ [105]. Vanstraelen described a mean healing time of 11.3 days for PX, three days longer than that seen when using the comparator Kaltostat ${ }^{\circledR}$ [98]. Gao et al. presented a mean time of 10.3 days, which was four days shorter than the comparator petroleum jelly [106]. The reported healing times in these studies were all shorter than those seen in Study I, in which $50 \%$ were reported as healed at day 14 .

\section{Infection \& Pain scores}

As in our Study I, low infection rates was reported by Salisbury et al. [96], Breach et al. [97] and Gao et al.[106]. Vanstraelen reported a $20 \%$ infection rate at day 7 in donor sites treated with PX [98]. The criteria for the assessment of infection are not stated in any of these studies. The incidence of microbial swabbing is reported by Salisbury et al. and Vanstraelen. Pain in areas treated with PX was reported in two studies as "not less than with other dressings"[96] and "eliminated"[105]. Consistently low pain scores were reported in our Study I for the PX group (median VAS $\leq 1.5$ ).

The reason for not recommending PX, apart from longer healing times, was related to biopsy findings of incorporation of the PX or a marked inflammatory reaction in the area in which it was used, or both [96-98]. 


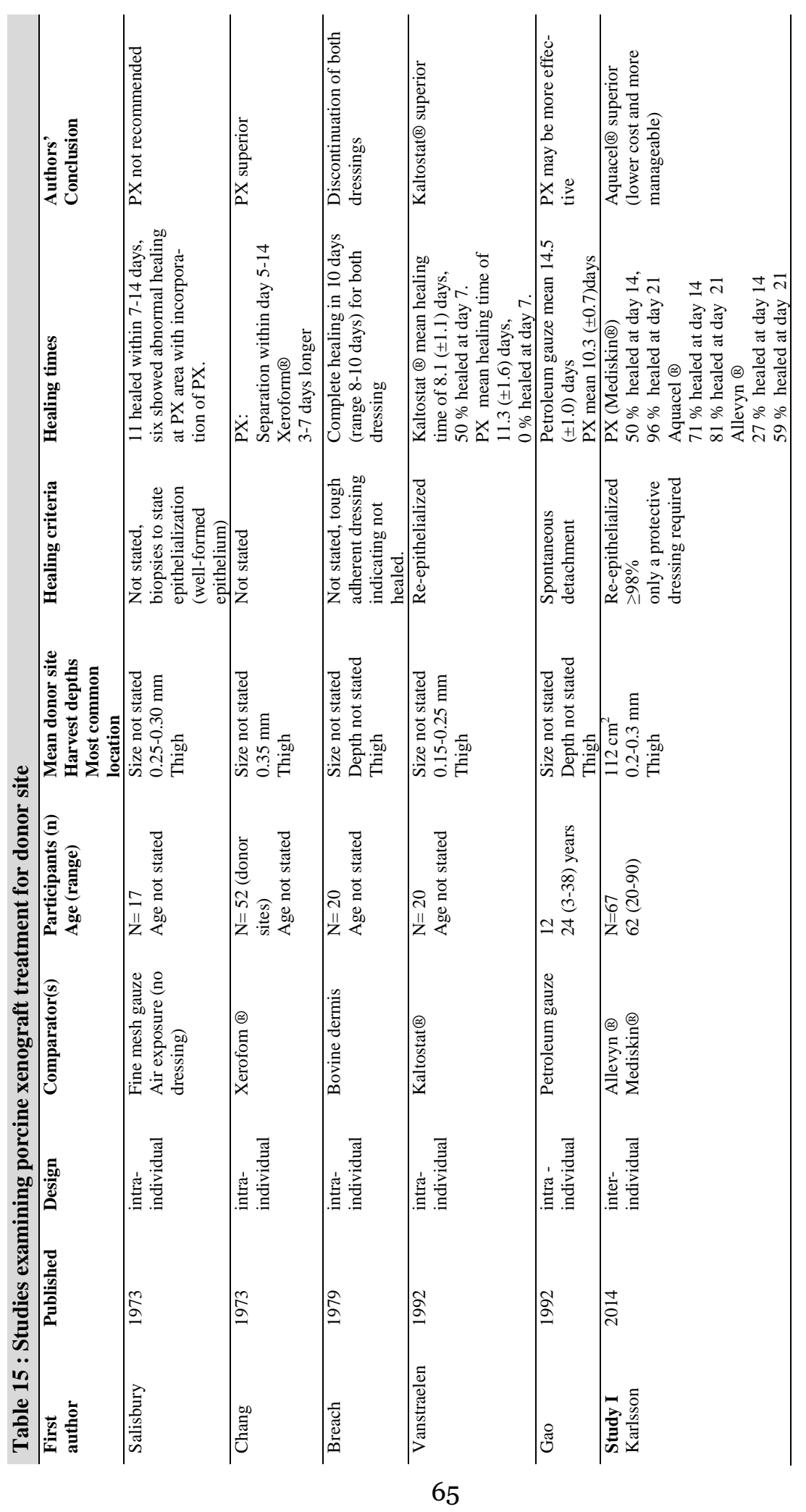




\section{Cytotoxicity of Aquacel $\circledR^{\text {and }}$ Mediskin ${ }^{\circledR}$}

Regarding cytotoxicity, Aquacel ${ }^{\circledR}$ has shown a small, but significant cytotoxic effect on keratinocyte survival and proliferation in "in vitro"[107] testing. In vitro studies evaluating the cytotoxicity of Tegaderm ${ }^{\circledR}$ have concluded that the film had no impact on the survival or proliferation of human keratinocytes or fibroblasts, and could be classified as non-toxic [108, 109]. No study evaluating the cytotoxicity of Mediskin ${ }^{\circledR}$ was found.

\section{Study I. Predictive factors for donor site healing}

As described in the introduction section, there are several factors, either known or suspected, that influence wound healing. Analyses of the variables involved in the outcome of wound healing in Study I showed that female sex was related to longer healing times at the donor sites. A clinical study from 2016 on donor site healing found similar results [41]. It may be debated if this result is related to sex hormones, because oestrogen and testosterone are both thought to affect healing. In our studies, both women and men had a high median age suggesting that the corresponding sex hormone levels (oestrogen/testosterone) were low, which may be claimed as potentially good for males (there are less unfavourable effects of testosterone as it decreases) and negative for females (because of the less positive effects of the reduction of oestrogen) [110].

\section{Wound healing - partial thickness burns}

\section{Study IV (Silver foam)}

In Study IV, the silver foam dressing (Mepilex ${ }^{\circledR} A g$ ) provided a shorter healing time than the standard of care dressing at that time; porcine xenograft $\left(\right.$ EZderm $\left.{ }^{\circledR}\right)$. As a result of this, we implemented the silver foam dressing (Mepilex ${ }^{\circledR} \mathrm{Ag}$ ) into clinical practice as the new standard of care.

Mepilex®Ag (silver foam) was evaluated for its efficacy in the treatment of partial thickness burns in three RCTs (Table 16) published by Silverstein et al. in 2011[111], Gee Kee et al. 2015 [112] and Hundeshagen et al. 2018 [113]. In the RCTs from 2011 and 2015, Mepilex®Ag was compared with other dressings that contained silver [111, 112] and in 2018 with Suprathel®) (polylactic acid membrane) [113]. Mepilex ${ }^{\circledR} \mathrm{Ag}$ was the preferred dressing in the studies to compare silver-containing dressings [111, 112], and was evaluated to be equally as good as Suprathel® [113]. 


\section{Healing time}

Similar healing criteria as in Study IV were used in these RCTs. The average TBSA \% was similar to that of the $5 \%$ reported in Study IV, except in the study by Gee Kee et al, in which it was considerably lower at 0.5-1\% TBSA [112].

Silverstein et al. [111] reported a mean time to complete healing of 13 days in the Mepilex® Ag group, a similar result to that of 15 days seen in our Study IV, and 3.5 days shorter than the comparator silver sulfadiazine (SSD). Hundeshagen et al. [113] presented a median time to complete healing of 12 days for both Mepilex® Ag and Suprathel®, which was three days shorter than in our Study IV. As for the study by Gee Kee et al. [112], in which TBSA \% was smaller and the healing criteria set to burns that had re-epithelialised to $95 \%$, median time to healing was only seven days.

\section{Rates of infection}

The reported rate of infection in Study IV was considerably higher than those described in the other RCTs. Silverstein et al. reported one case of infection in 49 patients $(0.02 \%)$ [111], compared with 10/28 (35\%) in our Study I. Gee Kee et al. reported no infections in 96 children [112], and Hundeshagen et al. presented no infections in 30 patients (adult and children) [113]. Initial swabs were taken in the study by Silverstein et al., and only $14 \%$ contained microbial growth [111], compared with $86 \%$ prevalence of growth in our Study IV. Silverstein et al. did not specify at which time the swab had been taken (before or after cleansing) or which cleansing agents were used. It is not stated in the protocol [114] or the final publication [112] by Gee Kee et al. how burns were cleaned or if any antibiotics were used. In this trial, children who presented with colds, flu, or viral symptoms (such as upper respiratory tract infections) were excluded, but such children were not excluded in our Study IV. It is noteworthy that in none of these studies were microbial swabs taken regularly, but only on clinical signs or suspicion of infection, and no CRP levels were presented. This could potentially have been the reason for a higher reported incidence of infections seen in our Study IV.

\section{Pain scores}

Silverstein et al. used different pain scales, none of which were the FLACC that we used in Study IV [111]. As for the study by Gee Kee et al. the FLACC scale was used, together with several other pain scales, and only differences in pain scores between the dressing groups were shown [112]. In this study in which 
Mepilex ${ }^{\circledR} A g$ was compared with Mepitel $₫ / A c t i c o a t \circledR ~$ and Acticoat ${ }^{\circledR}$ alone; the use of Mepilex®Ag and Mepitel ${ }^{\circledR}$ reduced pain significantly more than Acticoat ${ }^{\circledR}$. This is suggested by the authors to be a result of the Safetac ${ }^{\circledR}$ technology used in the dressings. In the study by Hundeshagen et al. the children rated their pain using the face-scale Wong-Baker Faces. Pain was initially rated lower in the Suprathel ${ }^{\circledR}$ group (first five days) [113]. Similarly to our Study IV, the authors noted a steady decline in pain in both groups over time.

\section{LOS, costs and dressing time}

In the study by Silverstein et al, the median LOS for the Mepilex ${ }^{\circledR} A g$ group was three (range 1-30) days [111], which was similar to our Study IV, which had a median LOS of 2.5 (10-90 percentiles 0-8) days. Treatment with Mepilex ${ }^{\circledR} \mathrm{Ag}$ was reported to be less expensive than its comparator in two of the RCTs, which is the same conclusion as in our Study I [111, 113]. Regarding change of dressing times, the Mepilex ${ }^{\circledR} \mathrm{AG}$ group in the study by Gee Kee et al. required a median of five minutes, which was shorter than the 10 minutes reported in the other groups [112] and considerably shorter than the 20 minutes seen in our Study IV. The reason was most likely to be a result of the more extensive burns seen in Study IV.

Cytotoxicity of Mepilex®Ag

In "in vitro" studies from 2015, 2017, and 2018, it was shown that Mepilex® Ag was highly effective against some of the most common bacterial pathogens in burns, such as staphylococcus aureus and pseudomonas aeruginosa [115-117]. However, it has also shown to have a negative effect on cell survival $[115,118]$. In 2017, Mepilex ${ }^{\circledR}$ Ag was compared with three other silver foams (Betafoam®, PolyMem-Ag® and Allevyn-Ag®) and the survival of mouse fibroblasts was examined after exposure to the dressing. Mepilex ${ }^{\circledR} \mathrm{Ag}$ showed the second largest reduction of fibroblast survival, with a reduction in cell count of 75\% [115]. "In vitro" studies, such as the ones described, must however be interpreted with caution, as they might not be the most accurate way to evaluate antimicrobial properties or cytotoxic effects "in vivo" on human skin. 


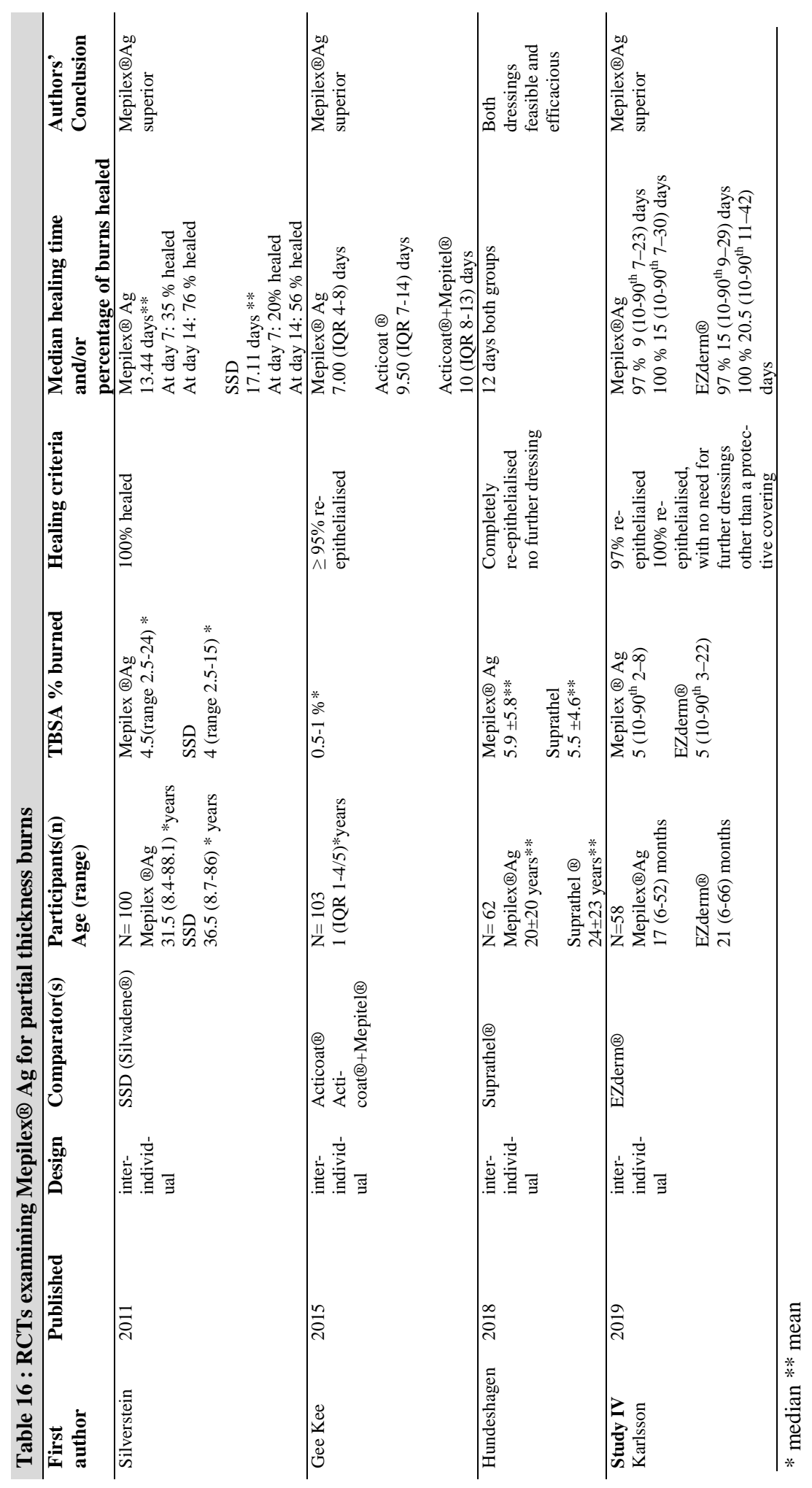




\section{Study IV. Factors affecting the healing time of partial thickness burns}

When important factors for predicting the healing times of burns were sought, several potentially predictive factors were found. Children with larger TBSA burned, DDB, infected burns, and skin grafts showed longer healing times. Including them in the analysis showed that the only two variables associated with healing time in the final model, were DDB and skin grafting. Each percentage of body surface DDB increased the number of days to complete healing of the burn by up to five days. As a DDB might require operation, we also excluded the children who had skin grafts, and the association between DDB and longer healing time remained. Infection was associated with longer healing times, when examining the entire group until complete healing, (including children with skin grafts), but not otherwise.

\section{Scarring outcome}

\section{Study II}

In Study II, it was concluded that patients in the hydrofibre group were the most satisfied with their donor site scars, according to the subjective evaluation done with the POSAS Patient scar scale instrument.

To our knowledge, three RCTs have reported on scarring outcomes with the use of Aquacel ${ }^{\circledR}$ on donor sites. Barnea et al. evaluated scar outcome at 30, 60, 90 days, and 1 year after surgery using a modified VSS [93]. Aquacel® was found to be superior at all time points compared to paraffin gauze. Dornseifer et al. reported on a 60 day scar follow up using VSS where Aquacel ${ }^{\circledR}$ gave similar good results as polyurethane film [94]. Brölmann et al. reported on a three months' follow up where POSAS was used [95]. The Aquacel ßgroup in that study had a median POSAS score of 10 (IQR 7-15), which was similar to that seen for alginates, film, gauze, silicone, and hydrocolloids, and similar to Study II where the median score for the Aquacel® group was 8 (7-11).

Surprisingly, in Study II, the PX group had the highest scar scores, which indicated that they were the least satisfied with their scar. Previous studies (though not RCTs), have also reported on less satisfactory scarring seen after the use of PX $[97,98]$.

To our knowledge, two studies (one RCT) have reported on scar outcomes with the use of Allevyn ${ }^{\circledR}[90,119]$, none of the supporting the less satisfactory scarring seen with Allevyn ${ }^{\circledR}$ in our Study II. In both studies Allevyn ${ }^{\circledR}$ was com- 
pared with Acticoat ${ }^{\circledR}$ regarding scar outcome at 1,2 and three months after surgery using VSS. Dressings were found equally good in one [90] and Allevyn ${ }^{\circledR}$ superior at one and two months in the other study [119].

The overall opinion of the scar compared with normal skin (on a scale of 1-10 where $1=$ scar like normal skin) rated by the patient in Study II (not used by the observer in Study III) was 1 in the Aquacel ${ }^{\circledR}$ group, 2 in the Allevyn ${ }^{\circledR}$ group and three in the PX group. This gave a significant difference in POSAS total score in which Aquacel ${ }^{\circledR}$ had a median score of nine, Allevyn ${ }^{\circledR} 15$, and PX 19.

A multivariable regression analysis showed that a higher overall opinion (scar less like normal skin) was significantly associated with treatment with PX and abnormal pigmentation. Healing time, age and sex did not contribute significantly to this model, which could explain $47 \%$ of the variance in overall opinion score.

What the actual reasons were for patients in the two latter groups recording worse overall opinions in Study II can only be guessed. The groups were small, 11 patients in the Aquacel ${ }^{\circledR}$ group and nine patients in the other two. Even though not significant in the regression model sex might have influenced the overall opinion as the percentage of women was somewhat higher in the two latter groups, $56 \%$ (Allevyn ${ }^{\circledR}$ ) and $44 \%$ (PX) compared with $36 \%$ in the Aquacel ${ }^{\circledR}$ group. As seen in the result section female sex was significantly related to the total scores on POSAS given by the patients.

Regarding age, also non-significant in the model, the PX group were more than 17 years younger than the other two groups in Study II, which could have affected the overall opinion scores. Older age has been shown to be associated with lower scar scores [120] (something that we found a tendency towards $(\mathrm{p}=0.053)$ in Study III.

Several donor sites in Study II where suspected to be HTS, using two earlier suggested models on what defines a hypertrophic scar (which are described in Paper II and III) but at the last evaluation, the scars were judged not to be hypertrophic. This highlights the need for detailed visual inspection of scars to diagnose HTS properly, and that measurements of height are needed for a proper diagnosis.

\section{Study III}

In Study III the donor sites that were assessed by the patient in Study II were further evaluated by a blinded observer, and with the use of a Cutometer ${ }^{\circledR}$ MPA 580. Neither the Observer POSAS, or the Cutometer could help to confirm the 
previous satisfying scar results (hydrofibre), nor the unsatisfying results for PX, or polyurethane foam such as those described by the patients in Study II. No differences in any of the items could be seen between dressing groups.

As discussed in Study III, a potential reason for not being able to confirm previous results may be that the patients who returned for the last part (Study III) were not fully representative of the group examined in Study II. The ones returning in the hydrofibre (Aquacel囚) group, (such as those who had higher patient-reported scores than those in the other two groups, in which the returners had lower patient-reported scores than the non-returners).

Looking closer at the scores given by the patients in Study II confirmed that consistently lower scores (median $=1$ ) were given for all items except pigmentation, in which the median was three (on a scale of 1-10) for the Aquacel ${ }^{\circledR}$ group, and five in the other two groups. The pigmentation item (together with surface area) was the only one that was rated higher than $1(1=$ normal $)$ by the Observer.

Hypopigmentation has been reported earlier in a donor-site study, but with a lower incidence than was noted in Study III. Melanin levels have been reported to be lower, but not significantly so in donor sites compared with uninjured skin [121].

There are several possible causes that can explain the high incidence of hypopigmentation. One could be that the surgeons harvested skin grafts deeper than was thought (removing the epidermal skin appendages from the donor site [122, 123]. An (animal) study showed that in biopsies from partial thickness wounds, melanin is found mainly at the level of the basal membrane, and not at all in epidermal layers, as is seen in healthy uninjured skin, which could potentially result in macroscopic hypopigmentation [124]. In 2001,Velangi et al [125], presented a study in which biopsies were taken from long-term hypopigmented scars in humans and they found that there were no differences in the number or activity of melanocytes in pale scars compared with those of healthy skin in the same individual. Instead, their theory was that the pale outcome could have been related to reduced vascularity, or a second possibility was that abnormal organisation of collagen within the dermis, or epidermal changes, or both, could have resulted in a greater reflection of light back towards the observer. 


\section{Factors predicting the development of scarring at donor sites}

As reported in the result section, we found that female sex was the only factor that seemed to negatively influence the self-reported total POSAS scar scores. Two recent studies, from 2018 and 2019 [120, 126], supported this finding, showing that women rated their overall scar score significantly higher than men. Another study from 2014, showed that women least preferred donor sites on the thigh, compared with all other locations [127]. This might indicate that the women in this study were unsatisfied with the location of the scar, which led to a higher POSAS score. Interestingly, when analysing factors that are important for the prediction of the observer's view on the scarring at donor sites (Study III), a similar finding was made; that is to say, only sex was independently associated with a worse scar estimate. Female patients (according also to the observer), had more severe scarring (higher scores). It must, however, be stressed that scar scores were relatively low and severe scarring was hardly described at all. The main scarring issue reported was, as has been discussed, hypopigmentation.

Werdin et al presented in 2018 [128] a donor site scar follow up at three and 12 months on a population similar to that of Studies II and III. They found that there was a linear relation between healing time and scarring, a finding that could not be reproduced in this study. It could possibly depend on the smaller sample size, or the fact that only three possible healing times were evaluated in our Study I (less than 14, 14 to 21 , and more than 21 days) or that scars actually got better with time. In the study by Werdin et al., no scar evaluation was made beyond 12 months.

\section{Study $V$}

In Study V burn scar outcomes for the children participating in Study IV were evaluated. The data suggested that neither dressing had a more favourable impact on scar outcome, and this was supported by the fact that no significant differences were found in POSAS or VSS scores, or the incidence of HTS.

Only two RCT studies could be found with follow up on scar outcomes after dressing treatments for partial thickness burns $[129,130]$ and none of these were undertaken with follow up as long as 12 months after injury, such as we did in Study IV. In 1989 Cockington compared [130] scar outcomes for up to three months after injury in an unknown number of children treated with SSD, paraffin gauze or transparent adhesive film. It was concluded that all scars were similar, and that dyspigmentation persisted in a few scars up to three months after injury. 
This is in contrast to our findings in Study V. The lower incidence of dyspigmentation might have been related to the short healing times reported in the study by Cockington, in which all children were healed at three weeks after injury.

In 2016, Gee Kee et al [129] did a follow up on 43 children who had been recruited originally in an RCT study [112] in which Mepilex ${ }^{\circledR}$ Ag was compared with Acticoat ${ }^{\circledR}$ or Mepitel ${ }^{\circledR}$ with Acticoat ${ }^{\circledR}$ on top. The dressing type was identified as having a significant effect on the POSAS scores. Other important factors were healing time, burn depth, and TBSA \%. However, as multicollinearity was noted and the dressing type in itself, was finally ruled out as being unimportant for the scar outcome. This statement closed the discussion in this study and, surprisingly, it was not further commented upon or explained. In the same study, burn scar thickness was also evaluated and no relation between the type of dressing and the thickness of the scar was found.

\section{Factors predicting scarring of partial thickness burns (Study V)}

When examining factors that were important in the development of scarring, findings from similar populations were confirmed. Longer healing times were associated with higher POSAS and VSS scar scores and higher incidences of hypertrophic scarring in burns [51-53, 55, 57, 129, 131-133]. Also, the model confirmed that a larger TBSA \% and deeper burns had a negative effect on scarring, as had also been reported before [51, 53, 55]. Interestingly, infection seemed to be related to both higher scar scores and incidences of HTS at six months' follow up. This could, however, not be confirmed at the 12 months' follow up,

As reported in earlier studies [55, 57, 132], skin grafting had a major impact on scar scores and the rate of hypertrophic scarring in the children in Study V.

They presented with significantly worse and hypertrophic scars. Lonie et al. [57] found that skin grafting offered no protection from HTS in children who had healed after 22-30 days. It seems to suggest that if skin grafting is not done in an early stage so that the child is healed within $<21$ days it might be a better alternative to leave the burn to heal spontaneously, even if the healing time is significantly longer. Finlay et al. showed in 2017 [132] that surgical interventions had a significant impact on scarring, but did not impose the same influence that healing time does on scar scores. This suggested that operation should be done at an early stage to shorten the healing time[132]. Animal models (porcine) have indicated the same thing, and that early skin grafting (at day three) lowers the risk of HTS scarring compared with delayed operation $>14$ to 21 days)[134] . 
The children in our Study IV were given split skin grafts rather late (days six, 14, 15 , and 21 after injury) when looking at the suggested healing times to lower the risk of HTS.

In 2006 Cubison et al presented data on 281 children with scalds. They found that the incidence of HTS in the group who healed spontaneously within 14 days was lower than children with scalds who had been operated on with split skin grafts and healed within 14 days after injury [52]. These findings were supported by Hassan et al in 2014, who suggested that burns up to $5 \%$ might be left to heal spontaneously beyond 21 days without increasing the risk of hypertrophic scarring [48]. It is also worth mentioning in this context that both Cubison and Hassan used a retrospective design, which might have influenced the validity of the results. In our Study V, the incidence of HTS was $38 \%$ (15/39) which was similar to what Cubison reported [52].

Infection, in our regression analysis, was also found to be of relevance to the scar scores registered and hypertrophic scarring at the six months' follow up. The association between infection and scarring has been supported by most studies [48, 54, 135-137], but has also been questioned [131]. It has been argued that infection prolongs the inflammatory phase, thus resulting in the formation of HTS. Further, it has been claimed that infection also delays the onset and duration of epithelialisation, which is known to be associated with HTS, as has been described in earlier studies [58].

Potential ways to prevent or reduce scarring may be to harvest skin grafts from other locations, such as the back or buttocks (less visible scars). Using the scalp or harvest thinner grafts could potentially shorten healing times at the donor sites [138, 139] and save melanocytes in epidermal appendages, the latter to reduce the risk of hypopigmentation. Other surgical techniques such as dermis grafts can be advocated [140] or resurfacing the donor sites with thin grafts [141]; minced grafts [142] or by adding autologous skin cells [143]. 


\section{Strengths and Limitations}

\section{Strengths}

A methodological strength in this thesis is the use of the RCT design to reduce the risk of allocation bias. The patients' baseline characteristics were similar between groups at the start of the trials. To ensure equal-sized treatment groups we used blocked randomisation. This led also to favorable groups for comparisons. Applying wide inclusions criteria and thereby reducing exclusions also facilitated the clinical implementation as well as increased the generalisability of the study findings. As the wound healing and scarring prediction analyses on our scald study participants in Study IV-V confirmed previous results from studies mainly from Europe, we have reason to think that our "group" was representative of all children with burns in Western, developed countries.

Another strength is the attempt to report items according to the Consolidated Standards of Reporting Trials (CONSORT), which are claimed to improve the reporting standards of RCTs [144, 145].

As for the choice of outcome variables, we chose those most commonly used in previous publications to facilitate comparisons between studies. The number of articles on donor site scarring is, however, limited and Studies II and III can therefore contribute to the knowledge in this field, even though the number of observations were low.

The use of "more" objective markers for healing and scarring such as laser doppler flowmetry or imaging, narrow-band reflectance spectrophotometers measuring erythema and melanin, tissue biopsies or Cutometers would have been advantageous, but many of these still require a "subjective" interpretation, which could still introduce bias.

Another strength of the present studies is the relatively high return rate. Seventynine per cent of the surviving patients in Study I were included in Study II and of these $68 \%$ returned for Study III. In Study V, $79 \%$ of the children from Study IV were included, and $67 \%$ returned. Another strength is that the Observers of scar outcome were blinded.

\section{Limitations}

The limitations of these studies are issues that are often encountered in the evaluation of wound dressings in general, such as the lack of "solid" data, making reproducibility a challenge. Researchers in this field often use different nomencla- 
ture and varying evaluation methods, which makes homogenisation difficult, as has been pointed out by the Cochrane group [70,146] and shown in the discussion section. Research into wound healing is hampered by the relative lack of consensus regarding objective endpoints at which to assess healing and scarring. In the latter case there are two generally used outcome measures, the VSS and the POSAS.

In our RCT studies we have used two different techniques for the evaluation of healing, neither of which can be claimed to be totally objective. In Study I we used wound tracing and from this could calculate the percentage of the wound that had healed, because the donor sites were standardised in a particular form (a square) and located in an accessible area. In Study IV, we tried using the same method but realised early that this could not be done, because the burns were located in both convex and concave surfaces, and so were often less accessible for to measure. Therefore, the burn surgeon instead estimated the surface area burned by the rule of the palm ( $1 \%$ of the TBSA is roughly the size of the injured person's palm), and later the surface area healed using the same technique. The use of wound tracing on irregular surfaces has been reported to be associated with a significant risk of errors, which supports our choice of method [112].

Another limitation was the difficulty in blinding the observers for the evaluations of healing. The reason for this is that porcine xenografts adhere to the wound bed, and when finally rejected (with a healed wound surface underneath) a temporary mesh pattern can sometimes be seen. Hydrofibre dressings can also sometimes leave remnants, which is visible as white "threads" in the wound bed. It could be argued that the result has then become biased (assessment bias). To reduce such risks, it was decided that both surgeon and nurse had to agree on the healing status. The most accurate evaluation would, of course, be based on a strictly blinded procedure, but the nature of the dressings used made blinding difficult.

Most preferably we should have used intra-individual comparisons of dressings to reduce any patient-selection bias and effects of inter-individual variations. For Study I we concluded, as early as the planning phase, that the three different donor site dressings of choice would not be possible to apply side by side in the same donor site in a satisfactory way. As for the children in Study IV, their burns were irregular, of different depths and locations, making an intraindividual complete dressing evaluation difficult, not to say impossible. 
A general limitation in studying scars and scar maturation is the lack of consensus on what constitutes normal scar healing, maturation of a scar, and clearly pathological scarring. Modified scar scales, approaching a level of properly defining a non-pathological and pathological scars are being developed [147]. The most appropriate scar studies or use of scar scales is likely to be pairwise comparisons in the same scar, investigating the effects of potential treatments.

Use of the Cutometer has only recently been introduced at the department and was therefore not used in Study V. In the future, as our experience increases, the instrument is more likely to be used further in both adults and children, although suspected to be more difficult to use in small children, who are less compliant.

A significant limitation, which is out of our control, is loss to follow up in Studies II and III. As reported in Study II almost $50 \%$ of participants in Study I were deceased at the time of enrollment to Studies II and III. As described in Paper II this group was significantly older than the returning participants. Eight patients did not respond, or declined to participate in Study II and III for unknown reasons. A potential reason, we think, for declining to participate was the travelling distance. 


\section{CONCLUSIONS}

The results of the data presented and the ensuing prediction analyses made in this thesis are as follows:

- The choice of dressing does have an impact on the healing process of the split thickness skin graft donor site as well as in partial thickness burns. As hypothesised, the hydrofibre Aquacel ${ }^{\circledR}$ dressing was superior to the standard of care dressing. Donor sites treated with the hydrofibre Aquacel ${ }^{\circledR}$ covered with the Tegaderm $®$ - film or with the porcine xenograft Mediskin ${ }^{\circ}$ showed significantly shorter healing times compared with the standard of care dressing, the polyurethane foam Allevyn $®$. Partial thickness burns treated with the silver-foam Mepilex ${ }^{\circledR} A g$ showed shorter healing times than the standard of care dressing, the porcine xenograft EZderm®.

- The choice of dressing had an impact on the patient's opinion of the donor site scar quality, and those who had Aquacel $®$ together with Tegaderm $®$ were more satisfied. This finding could not be confirmed by a blinded observer or in the data gathered using the Cutometer® MPA 580.

- The choice of dressing for partial thickness burns did not have an effect on scar outcome.

- One specific and predictive factor associated with improved healing - and scar outcomes at donor sites - could be clearly identified. Females had longer healing times and also scored higher in their own scar evaluations as well as those done by the observer.

- Specific, and predictive factors associated with improved healing - and scar outcomes of partial thickness burns could also be identified. Previous known factors responsible for longer healing times in burns were: higher TBSA \%, the extent and presence of DDB, skin grafting, and infection. The same factors were identified to be important for higher scar scores with the special addition of longer healing times ( $>14$ days) that impacted negatively on the final scar outcome. 


\section{ACKNOWLEDGMENTS}

I am grateful to all who have supported me in becoming "Doctor Karlsson".

Special thanks to:

Folke Sjöberg, my main supervisor, for introducing me to the world of science, always supporting me in my work and teaching me new things.

Moustafa Elmasry, my supervisor, for all the effort you put in to this, and for helping me with everything.

Pia Olofsson, my supervisor and the Head of the Department of Hand Surgery, Plastic Surgery and Burns for supporting me and being honest.

Johan Thorfinn and Erkki Tarpila, previous supervisors, for all the support and efforts.

Ingrid Steinvall, co-author and mentor. You have taught me a lot, without asking for anything back.

Anita Sterling Halldin and Chamiran Saume, dear co-workers for all the laughs, support and efforts you have put into this.

Caroline Andersson, occupational therapist and co-worker, for all the work you have done with our scar studies. I look forward to future projects.

Benjamin Grossmann and Andreas Nilsson, friends and roommates for making things feel a little bit easier and advising me when I needed it.

Mats Fredriksson, statistician at Forum Östergötland for advice and support, and patience with us who are a bit slow to learn.

To Mary Evans and Andrea Smith, consultant technical editors, for revising the English text and adding comments and explanations - teaching me to become a better writer.

Forum Östergötland for advice and support with our studies. 
Annelie Munther and Annelie Lindström at Linkoping University for saving me, every time.

Göran Nylander and Thomas Hansson, former Heads of the Department of Hand Surgery, Plastic Surgery and Burns and Åsa Johansson for giving me the confidence and time to do this.

Selma and Matheo, my children, Johan, my love and Carro, Stina and Elin, my oldest friends, for reminding me that work is not that important.

My deepest gratitude to Ingmarie Jarnhed Andersson, my companion, I would have never even thought of doing this without you.

Sorry, to those I did forget. 


\section{REFERENCES}

1. Kujath P and Michelsen A. Wounds - from physiology to wound dressing. Dtsch Arztebl Int, 2008. 105(13): p. 239-48.

2. Feldman RP and Goodrich JT. The Edwin Smith Surgical Papyrus. Childs Nerv Syst, 1999. 15(6-7): p. 281-4.

3. Forrest RD. Early history of wound treatment. J R Soc Med, 1982. 75(3): p. 198-205.

4. Shah JB. The history of wound care. J Am Col Certif Wound Spec, 2011. 3(3): p. 65-6.

5. Moues CM, Heule F, Legerstee R, et al. Five millennia of wound care products--what is new? A literature review. Ostomy Wound Manage, 2009. 55(3): p. 16-8, 20, 22 passim.

6. Porter JR. Antony van Leeuwenhoek: tercentenary of his discovery of bacteria. Bacteriol Rev, 1976. 40(2): p. 260-9.

7. Mohr KI. History of Antibiotics Research. Curr Top Microbiol Immunol, 2016. 398: p. 237-272.

8. Filius PM and Gyssens IC. Impact of increasing antimicrobial resistance on wound management. Am J Clin Dermatol, 2002. 3(1): p. 1-7.

9. Gottrup F, Apelqvist J, Bjarnsholt T, et al. EWMA document: Antimicrobials and non-healing wounds. Evidence, controversies and suggestions. J Wound Care, 2013. 22(5 Suppl): p. S1-89.

10. Jull AB, Cullum N, Dumville JC, et al. Honey as a topical treatment for wounds. Cochrane Database Syst Rev, 2015(3): p. Cd005083.

11. Norman G, Christie J, Liu Z, et al. Antiseptics for burns. Cochrane Database Syst Rev, 2017. 7: p. Cd011821.

12. Norman G, Dumville JC, Mohapatra DP, et al. Antibiotics and antiseptics for surgical wounds healing by secondary intention. Cochrane Database Syst Rev, 2016. 3: p. Cd011712.

13. Ehrenfried A. Reverdin and Other Methods of Skin-Grafting. The Boston Medical and Surgical Journal, 1909. 161(26): p. 911-917. 
14. Davis JS. Address of the president: The story of plastic surgery. Ann Surg, 1941. 113(5): p. 641-56.

15. Singh M, Nuutila K, Collins KC, et al. Evolution of skin grafting for treatment of burns: Reverdin pinch grafting to Tanner mesh grafting and beyond. Burns, 2017. 43(6): p. 1149-1154.

16. Spear M. Acute or chronic? What's the difference? Plast Surg Nurs, 2013. 33(2): p. 98-100.

17. Kanitakis J. Anatomy, histology and immunohistochemistry of normal human skin. Eur J Dermatol, 2002. 12(4): p. 390-9; quiz 400-1.

18. Agarwal S and Krishnamurthy K, Histology, Skin, in StatPearls. 2019, StatPearls Publishing LLC.: Treasure Island (FL).

19. Murphrey MB and Zito PM, Histology, Stratum Corneum, in StatPearls. 2019, StatPearls Publishing LLC.: Treasure Island (FL).

20. Dick MK and Limaiem F, Histology, Fibroblast, in StatPearls. 2019, StatPearls Publishing LLC.: Treasure Island (FL).

21. Hashmi S and Marinkovich MP. Molecular organization of the basement membrane zone. Clin Dermatol, 2011. 29(4): p. 398-411.

22. Brown TM and Krishnamurthy K, Histology, Dermis, in StatPearls. 2019, StatPearls Publishing LLC.: Treasure Island (FL).

23. Yousef H, Alhajj M and Sharma S, Anatomy, Skin (Integument), Epidermis, in StatPearls. 2019, StatPearls Publishing LLC.: Treasure Island (FL).

24. Oranges T, Dini V and Romanelli M. Skin Physiology of the Neonate and Infant: Clinical Implications. Adv Wound Care (New Rochelle), 2015. 4(10): p. 587-595.

25. Rodrigues M, Kosaric N, Bonham CA, et al. Wound Healing: A Cellular Perspective. Physiol Rev, 2019. 99(1): p. 665-706.

26. Singer AJ and Clark RA. Cutaneous wound healing. N Engl J Med, 1999. 341(10): p. 738-46.

27. Tardaguila-Garcia A, Garcia-Morales E, Garcia-Alamino JM, et al. Metalloproteinases in chronic and acute wounds: A systematic review and meta-analysis. Wound Repair Regen, 2019. 27(4): p. 415-420.

28. Marshall CD, Hu MS, Leavitt T, et al. Cutaneous Scarring: Basic Science, Current Treatments, and Future Directions. Adv Wound Care (New Rochelle), 2018. 7(2): p. 29-45. 
29. Malpass KG, Snelling CF and Tron V. Comparison of donor-site healing under Xeroform and Jelonet dressings: unexpected findings. Plast Reconstr Surg, 2003. 112(2): p. 430-9.

30. Serebrakian AT, Pickrell BB, Varon DE, et al. Meta-analysis and Systematic Review of Skin Graft Donor-site Dressings with Future Guidelines. Plast Reconstr Surg Glob Open, 2018. 6(9): p. e1928.

31. Shupp JW, Nasabzadeh TJ, Rosenthal DS, et al. A review of the local pathophysiologic bases of burn wound progression. J Burn Care Res, 2010. 31(6): p. 849-73.

32. Oryan A, Alemzadeh E and Moshiri A. Burn wound healing: present concepts, treatment strategies and future directions. J Wound Care, 2017. 26(1): p. 5-19.

33. Jackson DM. [The diagnosis of the depth of burning]. Br J Surg, 1953. 40(164): p. 588-96.

34. Moore RA, Waheed A and Burns B, Rule of Nines, in StatPearls. 2019, StatPearls Publishing LLC.: Treasure Island (FL).

35. Amirsheybani HR, Crecelius GM, Timothy NH, et al. The natural history of the growth of the hand: I. Hand area as a percentage of body surface area. Plast Reconstr Surg, 2001. 107(3): p. 726-33.

36. Lund C BN. The estimation of areas of burns. Surg Gynaecol Obstet 1944(79): p. 352-8.

37. Thom D. Appraising current methods for preclinical calculation of burn size - A pre-hospital perspective. Burns, 2017. 43(1): p. 127-136.

38. Jabeen S, Clough ECS, Thomlinson AM, et al. Partial thickness wound: Does mechanism of injury influence healing? Burns, 2019. 45(3): p. 531-542.

39. Rose LF and Chan RK. The Burn Wound Microenvironment. Adv Wound Care (New Rochelle), 2016. 5(3): p. 106-118.

40. Tiwari VK. Burn wound: How it differs from other wounds? Indian J Plast Surg, 2012. 45(2): p. 364-73.

41. Wehrens KM, Arnoldussen CW, Booi DI, et al. Clinical Evaluation of Wound Healing in Split-Skin Graft Donor Sites Using Microscopic Quantification of Reepithelialization. Adv Skin Wound Care, 2016. 29(6): p. 254-60. 
42. Ubbink DT, Lindeboom R, Eskes AM, et al. Predicting complex acute wound healing in patients from a wound expertise centre registry: a prognostic study. Int Wound J, 2015. 12(5): p. 531-6.

43. Wong SL, Demers M, Martinod K, et al. Diabetes primes neutrophils to undergo NETosis, which impairs wound healing. Nat Med, 2015. 21(7): p. 815-9.

44. Stojadinovic O, Lee B, Vouthounis C, et al. Novel genomic effects of glucocorticoids in epidermal keratinocytes: inhibition of apoptosis, interferon-gamma pathway, and wound healing along with promotion of terminal differentiation. J Biol Chem, 2007. 282(6): p. 4021-34.

45. Sorensen LT. Wound healing and infection in surgery. The clinical impact of smoking and smoking cessation: a systematic review and meta-analysis. Arch Surg, 2012. 147(4): p. 373-83.

46. Khalil H, Cullen M, Chambers H, et al. Elements affecting wound healing time: An evidence based analysis. Wound Repair Regen, 2015. 23(4): p. 550-6.

47. Horng HC, Chang WH, Yeh CC, et al. Estrogen Effects on Wound Healing. Int J Mol Sci, 2017. 18(11).

48. Hassan S, Reynolds G, Clarkson J, et al. Challenging the dogma: relationship between time to healing and formation of hypertrophic scars after burn injuries. J Burn Care Res, 2014. 35(2): p. e118-24.

49. Brown NJ, Kimble RM, Gramotnev G, et al. Predictors of reepithelialization in pediatric burn. Burns, 2014. 40(4): p. 751-8.

50. Eller MS, Ostrom K and Gilchrest BA. DNA damage enhances melanogenesis. Proc Natl Acad Sci U S A, 1996. 93(3): p. 1087-92.

51. Wallace HJ, Fear MW, Crowe MM, et al. Identification of factors predicting scar outcome after burn injury in children: a prospective casecontrol study. Burns Trauma, 2017. 5: p. 19.

52. Cubison TC, Pape SA and Parkhouse N. Evidence for the link between healing time and the development of hypertrophic scars (HTS) in paediatric burns due to scald injury. Burns, 2006. 32(8): p. 992-9.

53. Wallace HJ, Fear MW, Crowe MM, et al. Identification of factors predicting scar outcome after burn in adults: A prospective case-control study. Burns, 2017. 43(6): p. 1271-1283.

54. Baker RH, Townley WA, McKeon S, et al. Retrospective study of the association between hypertrophic burn scarring and bacterial colonization. J Burn Care Res, 2007. 28(1): p. 152-6. 
55. Gangemi EN, Gregori D, Berchialla P, et al. Epidemiology and risk factors for pathologic scarring after burn wounds. Arch Facial Plast Surg, 2008. 10(2): p. 93-102.

56. Sood RF, Hocking AM, Muffley LA, et al. Race and Melanocortin 1 Receptor Polymorphism R163Q Are Associated with Post-Burn Hypertrophic Scarring: A Prospective Cohort Study. J Invest Dermatol, 2015. 135(10): p. 2394-2401.

57. Lonie S, Baker $P$ and Teixeira RP. Healing time and incidence of hypertrophic scarring in paediatric scalds. Burns, 2017. 43(3): p. 509-513.

58. Butzelaar L, Soykan EA, Galindo Garre F, et al. Going into surgery: Risk factors for hypertrophic scarring. Wound Repair Regen, 2015. 23(4): p. $531-7$.

59. Jones CM, Rothermel AT and Mackay DR. Evidence-Based Medicine: Wound Management. Plast Reconstr Surg, 2017. 140(1): p. 201e-216e.

60. Nicks BA, Ayello EA, Woo K, et al. Acute wound management: revisiting the approach to assessment, irrigation, and closure considerations. Int J Emerg Med, 2010. 3(4): p. 399-407.

61. Ubbink DT, Brolmann FE, Go PM, et al. Evidence-Based Care of Acute Wounds: A Perspective. Adv Wound Care (New Rochelle), 2015. 4(5): p. 286-294.

62. Hinman CD and Maibach H. Effect of air exposure and occlusion on experimental human skin wounds. Nature, 1963. 200: p. 377-8.

63. Bolton LL, Monte K and Pirone LA. Moisture and healing: beyond the jargon. Ostomy Wound Manage, 2000. 46(1A Suppl): p. 51S-62S; quiz 63S-64S.

64. Rakel BA, Bermel MA, Abbott LI, et al. Split-thickness skin graft donor site care: a quantitative synthesis of the research. Appl Nurs Res, 1998. 11(4): p. 174-82.

65. Wiechula R. The use of moist wound-healing dressings in the management of split-thickness skin graft donor sites: a systematic review. Int J Nurs Pract, 2003. 9(2): p. S9-17.

66. Voineskos SH, Ayeni OA, McKnight L, et al. Systematic review of skin graft donor-site dressings. Plast Reconstr Surg, 2009. 124(1): p. 298-306.

67. Brown JE and Holloway SL. An evidence-based review of split-thickness skin graft donor site dressings. Int Wound J, 2018. 15(6): p. 1000-1009. 
68. Pham C, Greenwood J, Cleland H, et al. Bioengineered skin substitutes for the management of burns: a systematic review. Burns, 2007. 33(8): p. 946-57.

69. Aziz Z, Abu SF and Chong NJ. A systematic review of silver-containing dressings and topical silver agents (used with dressings) for burn wounds. Burns, 2012. 38(3): p. 307-18.

70. Wasiak J, Cleland H, Campbell F, et al. Dressings for superficial and partial thickness burns. Cochrane Database Syst Rev, 2013(3): p. Cd002106.

71. Vloemans AF, Hermans MH, van der Wal MB, et al. Optimal treatment of partial thickness burns in children: a systematic review. Burns, 2014. 40(2): p. 177-90.

72. Rashaan ZM, Krijnen P, Klamer RR, et al. Nonsilver treatment vs. silver sulfadiazine in treatment of partial-thickness burn wounds in children: a systematic review and meta-analysis. Wound Repair Regen, 2014. 22(4): p. 473-82.

73. Heyneman A, Hoeksema H, Vandekerckhove D, et al. The role of silver sulphadiazine in the conservative treatment of partial thickness burn wounds: A systematic review. Burns, 2016. 42(7): p. 1377-1386.

74. Nherera LM, Trueman P, Roberts CD, et al. A systematic review and meta-analysis of clinical outcomes associated with nanocrystalline silver use compared to alternative silver delivery systems in the management of superficial and deep partial thickness burns. Burns, 2017. 43(5): p. 939-948.

75. Soltan Dallal MM, Safdari R, Emadi Koochak H, et al. A comparison between occlusive and exposure dressing in the management of burn wound. Burns, 2016. 42(3): p. 578-82.

76. Selig HF, Lumenta DB, Giretzlehner M, et al. The properties of an "ideal" burn wound dressing--what do we need in daily clinical practice? Results of a worldwide online survey among burn care specialists. Burns, 2012. 38(7): p. 960-6.

77. Lars PK, Giretzlehner M, Trop M, et al. The properties of the "ideal" donor site dressing: results of a worldwide online survey. Ann Burns Fire Disasters, 2013. 26(3): p. 136-41.

78. Liu Z, Saldanha IJ, Margolis D, et al. Outcomes in Cochrane systematic reviews related to wound care: An investigation into prespecification. Wound Repair Regen, 2017. 25(2): p. 292-308. 
79. Bell-Syer S, Brady M, Bruce J, et al. Letter: evidence-based wound care in the UK: a response to David Leaper's editorial in International Wound Journal April 20096 (2). Int Wound J, 2009. 6(4): p. 306-9; author reply 309-10.

80. Karcioglu O, Topacoglu H, Dikme O, et al. A systematic review of the pain scales in adults: Which to use? Am J Emerg Med, 2018. 36(4): p. 707-714.

81. Principles of best practice: Minimising pain at wound dressing-related procedures. A consensus document. London: MEP Ltd, 2004.

82. Merkel SI, Voepel-Lewis T, Shayevitz JR, et al. The FLACC: a behavioral scale for scoring postoperative pain in young children. Pediatr Nurs, 1997. 23(3): p. 293-7.

83. Kokki A, Kankkunen P, Pietila AM, et al. Validation of the Parents' Postoperative Pain Measure in Finnish children aged 1-6 years. Scand J Caring Sci, 2003. 17(1): p. 12-8.

84. Nilsson S, Finnstrom B and Kokinsky E. The FLACC behavioral scale for procedural pain assessment in children aged 5-16 years. Paediatr Anaesth, 2008. 18(8): p. 767-74.

85. Sjoberg F, Danielsson P, Andersson L, et al. Utility of an intervention scoring system in documenting effects of changes in burn treatment. Burns, 2000. 26(6): p. 553-9.

86. van der Wal MB, Verhaegen PD, Middelkoop E, et al. A clinimetric overview of scar assessment scales. J Burn Care Res, 2012. 33(2): p. e79-87.

87. Sullivan T, Smith J, Kermode J, et al. Rating the burn scar. J Burn Care Rehabil, 1990. 11(3): p. 256-60.

88. Sachdeva S. Fitzpatrick skin typing: applications in dermatology. Indian J Dermatol Venereol Leprol, 2009. 75(1): p. 93-6.

89. Fulton JA, Blasiole KN, Cottingham T, et al. Wound dressing absorption: a comparative study. Adv Skin Wound Care, 2012. 25(7): p. 315-20.

90. Argirova M, Hadjiski $\mathrm{O}$ and Victorova A. Acticoat versus Allevyn as a split-thickness skin graft donor-site dressing: a prospective comparative study. Ann Plast Surg, 2007. 59(4): p. 415-22.

91. Higgins L, Wasiak J, Spinks A, et al. Split-thickness skin graft donor site management: a randomized controlled trial comparing polyurethane with calcium alginate dressings. Int Wound J, 2012. 9(2): p. 126-31. 
92. Brenner M, Hilliard C, Peel G, et al. Management of pediatric skin-graft donor sites: a randomized controlled trial of three wound care products. $\mathrm{J}$ Burn Care Res, 2015. 36(1): p. 159-66.

93. Barnea Y, Amir A, Leshem D, et al. Clinical comparative study of aquacel and paraffin gauze dressing for split-skin donor site treatment. Ann Plast Surg, 2004. 53(2): p. 132-6.

94. Dornseifer U, Lonic D, Gerstung TI, et al. The ideal split-thickness skin graft donor-site dressing: a clinical comparative trial of a modified polyurethane dressing and aquacel. Plast Reconstr Surg, 2011. 128(4): p. 918-24.

95. Brolmann FE, Eskes AM, Goslings JC, et al. Randomized clinical trial of donor-site wound dressings after split-skin grafting. Br J Surg, 2013. 100(5): p. 619-27.

96. Salisbury RE, Wilmore DW, Silverstein P, et al. Biological dressings for skin graft donor sites. Arch Surg, 1973. 106(5): p. 705-6.

97. Breach NM, Davies DM and Yiacoumettis A. Study of effects of porcine skin and bovine dermis on the healing of split-skin graft donor sites in humans. Plast Reconstr Surg, 1979. 63(4): p. 546-9.

98. Vanstraelen P. Comparison of calcium sodium alginate (KALTOSTAT) and porcine xenograft (E-Z DERM) in the healing of split-thickness skin graft donor sites. Burns, 1992. 18(2): p. 145-8.

99. Troy J, Karlnoski R, Downes K, et al. The Use of EZ Derm(R) in PartialThickness Burns: An Institutional Review of 157 Patients. Eplasty, 2013. 13: p. e14.

100. Burkey B, Davis W, 3rd and Glat PM. Porcine xenograft treatment of superficial partial-thickness burns in paediatric patients. J Wound Care, 2016. 25(2): p. S10-5.

101. Davies P, McCarty S and Hamberg K. Silver-containing foam dressings with Safetac: a review of the scientific and clinical data. J Wound Care, 2017. 26(Sup6a): p. S1-s32.

102. Lachenbruch $\mathrm{C}$ and VanGilder C. Estimates of evaporation rates from wounds for various dressing/support surface combinations. Adv Skin Wound Care, 2012. 25(1): p. 29-36.

103. Blome-Eberwein S, Johnson RM, Miller SF, et al. Hydrofiber dressing with silver for the management of split-thickness donor sites: a randomized evaluation of two protocols of care. Burns, 2010. 36(5): $\mathrm{p}$.

$665-72$. 
104. Salisbury RE, Carnes RW and Enterline D. Biological dressings and evaporative water loss from burn wounds. Ann Plast Surg, 1980. 5(4): p. $270-2$.

105. Chang WH, Gomez NH and Edelstein LM. Use of lyophilised pig skin for donor site cover. Br J Plast Surg, 1973. 26(2): p. 147-9.

106. Gao ZR, Hao ZQ, Li Y, et al. Porcine dermal collagen as a wound dressing for skin donor sites and deep partial skin thickness burns. Burns, 1992. 18(6): p. 492-6.

107. Paddle-Ledinek JE, Nasa Z and Cleland HJ. Effect of different wound dressings on cell viability and proliferation. Plast Reconstr Surg, 2006. 117(7 Suppl): p. 110S-118S; discussion 119S-120S.

108. Rosdy M and Clauss LC. Cytotoxicity testing of wound dressings using normal human keratinocytes in culture. J Biomed Mater Res, 1990. 24(3): p. 363-77.

109. van Luyn MJ, van Wachem PB, Nieuwenhuis P, et al. Cytotoxicity testing of wound dressings using methylcellulose cell culture. Biomaterials, 1992. 13(5): p. 267-75.

110. Gilliver SC, Ashworth JJ and Ashcroft GS. The hormonal regulation of cutaneous wound healing. Clin Dermatol, 2007. 25(1): p. 56-62.

111. Silverstein P, Heimbach D, Meites H, et al. An open, parallel, randomized, comparative, multicenter study to evaluate the cost-effectiveness, performance, tolerance, and safety of a silver-containing soft silicone foam dressing (intervention) vs silver sulfadiazine cream. J Burn Care Res, 2011. 32(6): p. 617-26.

112. Gee Kee EL, Kimble RM, Cuttle L, et al. Randomized controlled trial of three burns dressings for partial thickness burns in children. Burns, 2015. 41(5): p. 946-55.

113. Hundeshagen G, Collins VN, Wurzer P, et al. A Prospective, Randomized, Controlled Trial Comparing the Outpatient Treatment of Pediatric and Adult Partial-Thickness Burns with Suprathel or Mepilex Ag. J Burn Care Res, 2018. 39(2): p. 261-267.

114. Gee Kee E, Kimble RM, Cuttle L, et al. Comparison of three different dressings for partial thickness burns in children: study protocol for a randomised controlled trial. Trials, 2013. 14: p. 403.

115. Jung JA, Han SK, Jeong SH, et al. In Vitro Evaluation of Betafoam, a New Polyurethane Foam Dressing. Adv Skin Wound Care, 2017. 30(6): p. 262-271. 
116. Szweda P, Gorczyca G and Tylingo R. Comparison of antimicrobial activity of selected, commercially available wound dressing materials. J Wound Care, 2018. 27(5): p. 320-326.

117. Halstead FD, Rauf M, Bamford A, et al. Antimicrobial dressings: Comparison of the ability of a panel of dressings to prevent biofilm formation by key burn wound pathogens. Burns, 2015. 41(8): p. 1683-1694.

118. Yunoki S, Kohta M, Ohyabu Y, et al. In Vitro Parallel Evaluation of Antibacterial Activity and Cytotoxicity of Commercially Available SilverContaining Wound Dressings. Plast Surg Nurs, 2015. 35(4): p. 203-11.

119. Innes ME, Umraw N, Fish JS, et al. The use of silver coated dressings on donor site wounds: a prospective, controlled matched pair study. Burns, 2001. 27(6): p. 621-7.

120. Weitemeyer MB, Bramsen P, Klausen TW, et al. Patient-and observerreported long-term scar quality of wide local excision scars in melanoma patients. J Plast Surg Hand Surg, 2018: p. 1-6.

121. Schulz A, Rothermund I, Lefering R, et al. Long-term Scar Quality after Treatment of Standardized Partial-Thickness Skin Graft Donor Sites. Adv Skin Wound Care, 2018. 31(3): p. 109-117.

122. McBride CA, Kempf M, Kimble RM, et al. Variability in split-thickness skin graft depth when using an air-powered dermatome: A paediatric cohort study. Burns, 2017. 43(7): p. 1552-1560.

123. McBride CA, Kimble RM and Stockton KA. Prospective randomised controlled trial of Algisite M, Cuticerin, and Sorbact(R) as donor site dressings in paediatric split-thickness skin grafts. Burns Trauma, 2018. 6: p. 33.

124. Chadwick SL, Yip C, Ferguson MW, et al. Repigmentation of cutaneous scars depends on original wound type. J Anat, 2013. 223(1): p. 74-82.

125. Velangi SS and Rees JL. Why are scars pale? An immunohistochemical study indicating preservation of melanocyte number and function in surgical scars. Acta Derm Venereol, 2001. 81(5): p. 326-8.

126. Spronk I, Polinder S, Haagsma JA, et al. Patient-reported scar quality of adults after burn injuries: A five-year multicenter follow-up study. Wound Repair Regen, 2019. 27(4): p. 406-414.

127. Garcia E, Stone E, Chan LS, et al. Donor-site preferences in women during autologous skin grafting. Plast Reconstr Surg, 2014. 133(3): p. 378e-382e. 
128. Werdin F, Tenenhaus M, Becker M, et al. Healing Time Correlates With the Quality of Scaring: Results From a Prospective Randomized Control Donor Site Trial. Dermatol Surg, 2018. 44(4): p. 521-527.

129. Gee Kee EL, Kimble RM, Cuttle L, et al. Scar outcome of children with partial thickness burns: A 3 and 6 month follow up. Burns, 2016. 42(1): p. 97-103.

130. Cockington RA. Ambulatory management of burns in children. Burns, 1989. 15(4): p. 271-3.

131. Chipp E, Charles L, Thomas C, et al. A prospective study of time to healing and hypertrophic scarring in paediatric burns: every day counts. Burns Trauma, 2017. 5: p. 3.

132. Finlay V, Burrows S, Burmaz M, et al. Increased burn healing time is associated with higher Vancouver Scar Scale score. Scars Burn Heal, 2017. 3: p. 2059513117696324.

133. Deitch EA, Wheelahan TM, Rose MP, et al. Hypertrophic burn scars: analysis of variables. J Trauma, 1983. 23(10): p. 895-8.

134. Chan QE, Harvey JG, Graf NS, et al. The correlation between time to skin grafting and hypertrophic scarring following an acute contact burn in a porcine model. J Burn Care Res, 2012. 33(2): p. e43-8.

135. Ogawa R. The most current algorithms for the treatment and prevention of hypertrophic scars and keloids. Plast Reconstr Surg, 2010. 125(2): p. 557-68.

136. Butzelaar L, Ulrich MM, Mink van der Molen AB, et al. Currently known risk factors for hypertrophic skin scarring: A review. J Plast Reconstr Aesthet Surg, 2016. 69(2): p. 163-9.

137. Singer AJ and McClain SA. Persistent wound infection delays epidermal maturation and increases scarring in thermal burns. Wound Repair Regen, 2002. 10(6): p. 372-7.

138. Guogiene I, Kievisas M, Grigaite A, et al. Split-thickness skin grafting: early outcomes of a clinical trial using different graft thickness. J Wound Care, 2018. 27(1): p. 5-13.

139. Buehrer G, Arkudas A and Horch RE. Treatment of standardised wounds with pure epidermal micrografts generated with an automated device. Int Wound J, 2017. 14(5): p. 856-863.

140. Han S-K, Yoon T-H, Kim J-B, et al. Dermis Graft for Wound Coverage. Plastic and Reconstructive Surgery, 2007. 120(1): p. 166-172. 
141. Bian Y, Sun C, Zhang X, et al. Wound-healing improvement by resurfacing split-thickness skin donor sites with thin split-thickness grafting. Burns, 2016. 42(1): p. 123-30.

142. Miyanaga T, Kishibe M, Yamashita M, et al. Minced Skin Grafting for Promoting Wound Healing and Improving Donor-Site Appearance after Split-Thickness Skin Grafting: A Prospective Half-Side Comparative Trial. Plast Reconstr Surg, 2019. 144(2): p. 475-483.

143. $\mathrm{Hu} \mathrm{Z}$, Guo D, Liu P, et al. Randomized clinical trial of autologous skin cell suspension for accelerating re-epithelialization of split-thickness donor sites. Br J Surg, 2017. 104(7): p. 836-842.

144. Moher D, Hopewell S, Schulz KF, et al. CONSORT 2010 Explanation and Elaboration: updated guidelines for reporting parallel group randomised trials. BMJ, 2010. 340: p. c869.

145. Brolmann FE, Eskes AM, Sumpio BE, et al. Fundamentals of randomized clinical trials in wound care: reporting standards. Wound Repair Regen, 2013. 21(5): p. 641-7.

146. Page MJ, McKenzie JE, Kirkham J, et al. Bias due to selective inclusion and reporting of outcomes and analyses in systematic reviews of randomised trials of healthcare interventions. Cochrane Database Syst Rev, 2014(10): p. Mr000035.

147. Fearmonti RM, Bond JE, Erdmann D, et al. The modified Patient and Observer Scar Assessment Scale: a novel approach to defining pathologic and nonpathologic scarring. Plast Reconstr Surg, 2011. 127(1): p. 242-7. 


\section{APPENDIX}

\begin{tabular}{|c|c|c|c|c|}
\hline \multicolumn{5}{|c|}{$\begin{array}{l}\text { Appendix 1. Predictors for longer healing times in Study IV in Children not skin- } \\
\text { grafted }(n=40)\end{array}$} \\
\hline & & Coefficient & $95 \%$ CI & p value \\
\hline \multicolumn{5}{|l|}{ Independently related } \\
\hline \multirow[t]{2}{*}{ Days to $97 \%$ healing } & TBSA $\%$ & 0.50 & 0.02 to 0.98 & 0.026 \\
\hline & DDB & 5.86 & 2.29 to 9.43 & 0.002 \\
\hline \multicolumn{5}{|l|}{ In a model } \\
\hline & TBSA $\%$ & 0.23 & $-0,27$ to 0,72 & 0,368 \\
\hline & DDB & 5.11 & 1.16 to 9.06 & 0.012* \\
\hline Model & & & & 0.005 \\
\hline Adjusted $R$ square & & & & 0.162 \\
\hline \multicolumn{5}{|l|}{ Independently related } \\
\hline \multirow[t]{2}{*}{ Days to complete (100\%)healing } & TBSA $\%$ & 1.01 & 0.40 to 1.63 & $<0.001$ \\
\hline & DDB & 10.75 & 6.42 to 15.08 & $<0.001$ \\
\hline \multicolumn{5}{|l|}{ In a model } \\
\hline & TBSA $\%$ & 0.54 & -0.05 to 1.14 & 0.071 \\
\hline & DDB & 9.03 & 4.40 to 13.66 & $<0.001 *$ \\
\hline Model & & & & $<0.001$ \\
\hline Adjusted R square & & & & 0.351 \\
\hline
\end{tabular}

* Factor significant in the model 


\section{Appendix 2. Predictors for longer healing times in Study IV without outliers}

\begin{tabular}{|c|c|c|c|c|}
\hline & & Coefficient & $95 \% \mathrm{CI}$ & p value \\
\hline \multicolumn{5}{|l|}{ Independently related } \\
\hline \multirow[t]{2}{*}{ Days to $97 \%$ healing } & TBSA $\%$ & 0.58 & 0.21 to 0.97 & 0.003 \\
\hline & DDB & 6.34 & 2.90 to 9.78 & 0.001 \\
\hline \multicolumn{5}{|l|}{ In a model } \\
\hline & TBSA $\%$ & 0.21 & -0.29 to 0.70 & 0.408 \\
\hline & DDB & 2.19 & 0.27 to 4.10 & $0.026 *$ \\
\hline Model & & & & 0.001 \\
\hline Adjusted R square & & & & 0.202 \\
\hline \multicolumn{5}{|l|}{ Independently related } \\
\hline \multirow[t]{2}{*}{ Days to complete healing } & TBSA $\%$ & 1.01 & 0.40 to 1.63 & $<0.001$ \\
\hline & DDB & 10.75 & 6.42 to 15.08 & $<0.001$ \\
\hline \multicolumn{5}{|l|}{ In a model } \\
\hline & TBSA $\%$ & 0.49 & -0.11 to 1.10 & 0.109 \\
\hline & DDB & 3.25 & 0.90 to 5.59 & $0.008 *$ \\
\hline Model & & & & $<0.001$ \\
\hline Adjusted $R$ square & & & & 0.335 \\
\hline
\end{tabular}

* Factor significant in the model

$\begin{aligned} & \text { Appendix 3. Predictor models of scarring at } 6 \text { months in Study V not skin-grafted (n=33) } \\
& \text { using POSAS Observer scores }\end{aligned}$
\begin{tabular}{llccr}
\hline & Coefficient & $\mathbf{9 5} \%$ CI & p value \\
\hline Independently related & & & & \\
& Healing time (days) & 0.38 & 0.17 to 0.60 & 0.001 \\
& Infection & 6.86 & 1.98 to 11.74 & 0.007 \\
& DDB & 6.44 & 2.15 to 10.72 & 0.004
\end{tabular}

In a model

\begin{tabular}{lccr} 
Healing time (days) & 0.19 & -0.48 to 0.44 & 0.112 \\
Infection & $\mathbf{5 . 0 5}$ & $\mathbf{0 . 5 7}$ to 9.53 & $\mathbf{0 . 0 2 8}^{*}$ \\
DDB & 4.10 & -0.31 to 8.50 & 0.067 \\
& & & $<0.001$ \\
& & & 0.443 \\
\hline
\end{tabular}

Model

Adjusted R Square

* Factor significant in the model 


\begin{tabular}{|c|c|c|c|}
\hline \multicolumn{4}{|c|}{$\begin{array}{l}\text { Appendix 4. Predictor models of scarring at } 12 \text { months in Study V not skin-grafted ( } n=28) \\
\text { using POSAS Observer scores }\end{array}$} \\
\hline & Coefficient & $95 \% \mathrm{CI}$ & p value \\
\hline \multicolumn{4}{|l|}{ Independently related } \\
\hline Healing time (days) & 0.33 & 0.11 to 0.54 & 0.005 \\
\hline Model & & & 0.005 \\
\hline Model $R$ square (only one variable included) & & & 0.269 \\
\hline
\end{tabular}

* Factor significant in the model

\begin{tabular}{|c|c|c|c|c|c|c|}
\hline \multicolumn{7}{|c|}{$\begin{array}{l}\text { Appendix } 5 \text {. Predictors for scarring at } 6 \text { and } 12 \text { months for children not skin-grafted using } \\
\text { VSS scores }\end{array}$} \\
\hline & \multicolumn{3}{|c|}{$\underline{6 \text { months }(\mathrm{n}=33)}$} & \multicolumn{3}{|c|}{12 months $(\mathrm{n}=28)$} \\
\hline & Coefficient & $95 \% \mathrm{CI}$ & p value & Coefficient & $95 \%$ CI & p value \\
\hline \multicolumn{7}{|c|}{ Independently related } \\
\hline Healing time(days) & 0.16 & 0.07 to 0.25 & 0.001 & 0.18 & 0.10 to 0.28 & $<0.001$ \\
\hline DDB & 2.57 & 0.72 to 4.43 & 0.008 & \multicolumn{3}{|c|}{ Non-significant } \\
\hline Sex $($ male $=1)$ & \multicolumn{2}{|c|}{ Non-significant } & & 1.93 & 0.01 to 3.90 & 0.049 \\
\hline \multicolumn{7}{|l|}{ In a model } \\
\hline Healing time(days) & 0.12 & 0.01 to 0.23 & $0.028 *$ & 0.17 & 0.07 to 0.26 & $0.001 *$ \\
\hline DDB & 1.37 & -0.67 to 3.40 & 0.181 & \multicolumn{2}{|c|}{ Non-significant } & \\
\hline Sex $($ male $=1)$ & Non-sigr & ìcant & & 1.29 & -0.34 to 2.91 & 0.116 \\
\hline $\begin{array}{l}\text { Model, } \\
\text { Adjusted R Square }\end{array}$ & & & $\begin{array}{l}0.003 \\
0.281\end{array}$ & & & $\begin{array}{l}0.001 \\
0.400\end{array}$ \\
\hline
\end{tabular}

* Factor significant in the model 


\begin{tabular}{|c|c|c|c|c|c|c|}
\hline \multicolumn{7}{|c|}{ Appendix 6. Predictors for HTS at 6 and 12 months for non-grafted children } \\
\hline & \multicolumn{3}{|c|}{$\underline{6 \text { months }}(\mathrm{n}=33)$} & \multicolumn{3}{|c|}{12 months $(\mathrm{n}=28)$} \\
\hline & OR & $95 \% \mathrm{CI}$ & p value & OR & $95 \% \mathbf{C I}$ & p value \\
\hline \multicolumn{7}{|c|}{ Independently associated } \\
\hline Healing time(days) & 1.13 & 1.03 to 1.25 & 0.013 & 1.17 & 1.04 to 1.32 & 0.012 \\
\hline Not healed at day 14 & \multicolumn{6}{|c|}{ Perfect prediction of HTS (not possible to analyse } \\
\hline Infection & 6.25 & 1.15 to 34.12 & 0.034 & \multicolumn{3}{|c|}{ Non-significant } \\
\hline \multicolumn{7}{|l|}{ In a model } \\
\hline Healing time(days) & 1.12 & 1.01 to 1.24 & $0.034 *$ & 1.17 & 1.04 to 1.32 & $0.012 *$ \\
\hline Infection & 4.09 & 0.62 to 26.84 & 0.143 & \multicolumn{3}{|c|}{ Non-significant } \\
\hline Model. & & & 0.006 & & & 0.003 \\
\hline Model prediction \% & & & 75.8 & & & 75.0 \\
\hline (Nagelkerke R Square) & & & 0.381 & & & 0.372 \\
\hline Hosmer-Lemenshow go & s of fit & & 0.819 & & & 0.210 \\
\hline
\end{tabular}

* Factor significant in the model 


\section{Papers}

The papers associated with this thesis have been removed for copyright reasons. For more details about these see:

http://urn.kb.se/resolve?urn=urn:nbn:se:liu:diva-161746 


\section{FACULTY OF MEDICINE AND HEALTH SCIENCES}

Linköping University Medical Dissertation No. 1704, 2019 Department of Hand Surgery, Plastic Surgery and Burns and Department of Clinical and Experimental Medicine

Linköping University

SE-581 83 Linköping, Sweden

www.liu.se 